\title{
Project Plan for the Background Soils Project for the Paducah Gaseous Diffusion Plant, Paducah, Kentucky
}

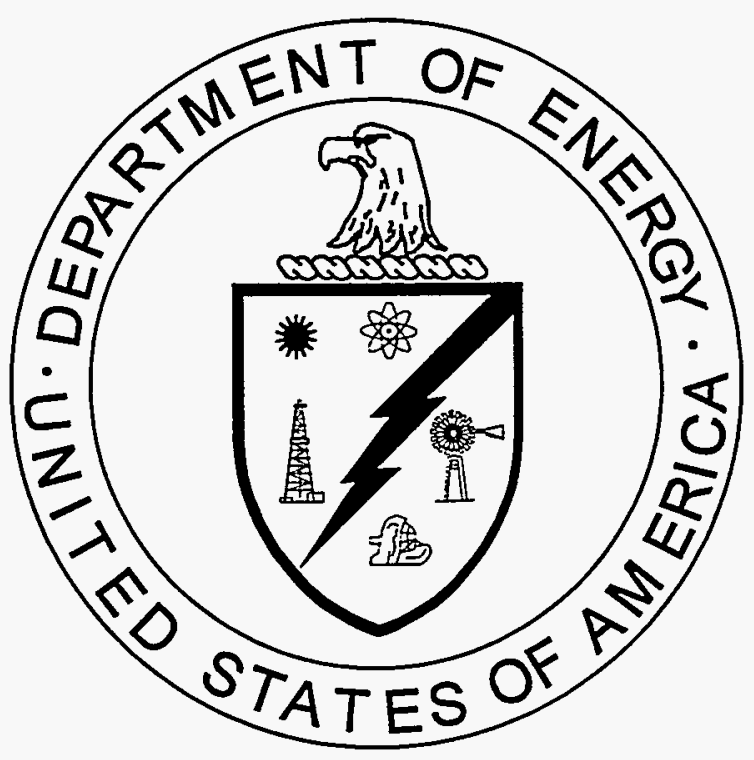

RECEIVED

MAR 131996

Q S.T I

\section{DISCLAIMER}

This report was prepared as an account of work sponsored by an agency of the United States Government. Neither the United States Government nor any agency thereof, nor any of their employees, makes any warranty, express or implied, or assumes any legal liability or responsibility for the accuracy, completeness, or usefulness of any information, apparatus, product, or process disclosed, or represents that its use would not infringe privately owned rights. Reference herein to any specific commercial product, process, or service by trade name, trademark, manufacturer, or otherwise does not necessarily constitute or imply its endorsement, recommendation, or favoring by the United States Government or any agency thereof. The views and opinions of authors expressed herein do not necessarily state or reflect those of the United States Government or any agency thereof.

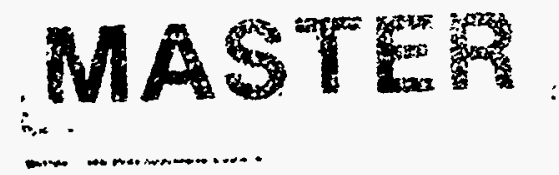


Jaycor, Inc.

contributed to the preparation of this document and should not be considered an eligible contractor for its review. 


\title{
Project Plan for the Background Soils Project for the Paducah Gaseous Diffusion Plant, Paducah, Kentucky
}

\author{
Environmental Restoration Program \\ Paducah Gaseous Diffusion Plant \\ Paducah, Kentucky
}

Date Issued-September 1995

\author{
Prepared by \\ Environmental Sciences Division \\ Oak Ridge National Laboratory \\ ESD Publication 4419
}

Prepared for the

U.S. Department of Energy

Office of Environmental Management

under budget and reporting code EU-2010302

\section{LOCKHEED MARTIN ENERGY SYSTEMS, INC.}

managing the

Environmental Restoration and Waste Management Programs at

Oak Ridge K-25 Site Paducah Gaseous Diffusion Plant

Oak Ridge Y-12 Plant Portsmouth Gaseous Diffusion Plant

Oak Ridge National Laboratory

under contract DE-AC05-84OR21400

for the

U.S. DEPARTMENT OF ENERGY

DISTRIBUTION OF THS DOCUMENT IS UNLLATTED 


\section{Contributors}

D. R. Watkins

R. R. Bonczek

J. L. Carpenter

M. P. Elless

T. L. Hatmaker

V. L. Holt

B. L. Jackson

T. M. Koepp

S. Y. Lee

D. A. Lietzke

R. L. Schmoyer

J. Switek

K. M. Turnage

\section{Contributors Affiliations}

R. R. Bonczek and T. L. Hatmaker are members of the Health Sciences Research Division; B. L. Jackson is a member of the Computing Applications Division; S. Y. Lee, J. Switek, and D. R. Watkins (Project Manager) are members of the Environmental Sciences Division; T. M. Koepp is with the Environmental Restoration Quality Organization; and R. L. Schmoyer is a member of the Computer Science and Mathematics Division; all part of the Oak Ridge National Laboratory. All of the aforementioned organizations are managed by Lockheed Martin Energy Systems, Inc. M. P. Elless and K. M. Turnage are associated with the Oak Ridge Institute for Science and Education; J. L. Carpenter is associated with Midwest Technical Inc.; and V. L. Holt is affiliated with Jaycor, Inc. D. A. Lietzke is a consultant.

\section{Acknowledgements}

The contributions of A. L. Harkey and her staff are gratefully acknowledged in the technical editing of this plan, along with the efforts of $\mathrm{K} . \mathrm{M}$. Turnage in assembling inputs to this document. 


\section{APPROVALS}

Project Plan for the Background Soils Project for the Paducah Gaseous Diffusion Plant,

Paducah, Kentucky

(DOE/OR/07-1414\&D1)

Approved by:

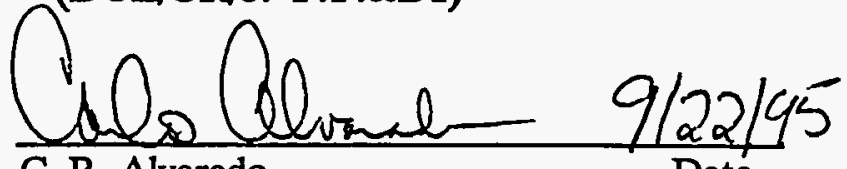

C. R. Alvarado

Date

Program Manager

DOE-Paducah Site Office

Approved by:

Aavid m. Carden

$9 / 27 / 95$

D. M. Carden

Date

QA/QC Program Manager

Environmental Restoration Division

DOE-Oak Ridge Operations

Approved by: $\frac{\text { ClMarshall September 22,1995 }}{\text { C. J. Marshall }}$

Manager of Remedial Actions

Paducah Environmental Restoration Program

Lockheed Martin Energy Systems, Inc.

Approved by $\angle$

J. R. Blewett

Quality Assurance Specialist

Paducah Environmental Restoration Program

Lockheed Martin Energy Systems, Inc.

Approved by/

Submitted by:

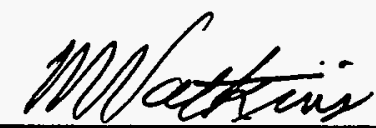

D. R. Watkins, Project Manager

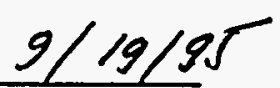

Environmental Sciences Division

Oak Ridge National Laboratory

Lockheed Martin Energy Systems, Inc.

Approved by:

T. M. Koepp

Quality Assurance Specialist

Date

Oak Ridge Environmental Restoration Program

Lockheed Martin Energy Systems, Inc. 



\section{CONTENTS}

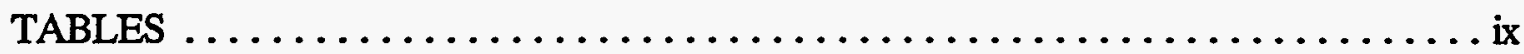

FIGURES $\ldots \ldots \ldots \ldots \ldots \ldots \ldots \ldots \ldots \ldots \ldots \ldots \ldots \ldots \ldots \ldots \ldots \ldots \ldots \ldots \ldots$

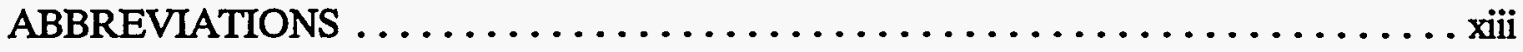

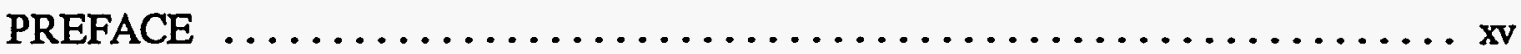

EXECUTIVE SUMMARY $\ldots \ldots \ldots \ldots \ldots \ldots \ldots \ldots \ldots \ldots \ldots \ldots \ldots$ xvii

1. INTRODUCTION AND ORGANIZATION $\ldots \ldots \ldots \ldots \ldots \ldots \ldots \ldots \ldots \ldots, \ldots$

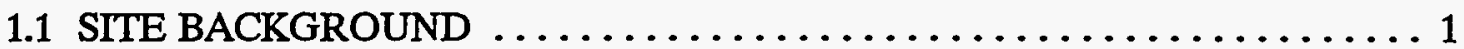

1.1.1 History of the Paducah Gaseous Diffusion Plant Facilities .......... 1

1.1.2 General Description of the Plant Facilities $\ldots \ldots \ldots \ldots \ldots \ldots \ldots \ldots$

1.2 REGULATORY BACKGROUND ....................... 3

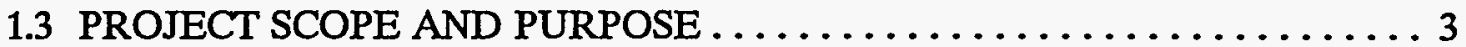

1.4 PROJECT ORGANIZATION AND MANAGEMENT $\ldots \ldots \ldots \ldots \ldots \ldots 4$

1.4.1 Organization and Responsibilities $\ldots \ldots \ldots \ldots \ldots \ldots \ldots \ldots \ldots \ldots \ldots$

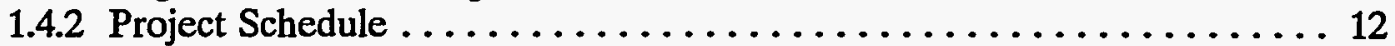

2. DATA QUALITY, PROJECT OBJECTIVES, AND APPROACH $\ldots \ldots \ldots \ldots 16$

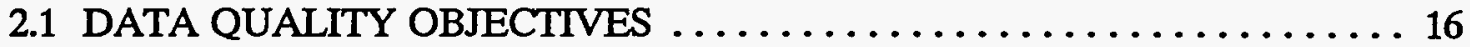

2.2 PROJECT OBJECTIVES $\ldots \ldots \ldots \ldots \ldots \ldots \ldots \ldots \ldots \ldots \ldots \ldots \ldots \ldots \ldots \ldots \ldots \ldots \ldots \ldots$

2.3 GENERAL APPROACH $\ldots \ldots \ldots \ldots \ldots \ldots \ldots \ldots \ldots \ldots \ldots \ldots \ldots \ldots \ldots \ldots \ldots \ldots$

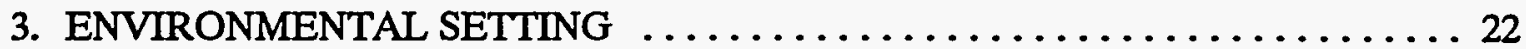

3.1 GEOGRAPHY AND TOPOGRAPHY $\ldots \ldots \ldots \ldots \ldots \ldots \ldots \ldots \ldots \ldots \ldots \ldots \ldots \ldots \ldots, 22$

3.2 GEOLOGY $\ldots \ldots \ldots \ldots \ldots \ldots \ldots \ldots \ldots \ldots \ldots \ldots \ldots \ldots \ldots \ldots \ldots \ldots \ldots \ldots \ldots \ldots, 22$

3.3 SOILS $\ldots \ldots \ldots \ldots \ldots \ldots \ldots \ldots \ldots \ldots \ldots \ldots \ldots \ldots \ldots \ldots \ldots \ldots \ldots \ldots \ldots \ldots \ldots, 25$

3.4 HYDROGEOLOGY AND CLIMATE $\ldots \ldots \ldots \ldots \ldots \ldots \ldots \ldots \ldots$

4. SAMPLING SITE SELECTION $\ldots \ldots \ldots \ldots \ldots \ldots \ldots \ldots \ldots \ldots \ldots \ldots \ldots \ldots \ldots$

4.1 SAMPLING SITE SELECTION APPROACH $\ldots \ldots \ldots \ldots \ldots \ldots \ldots \ldots 27$

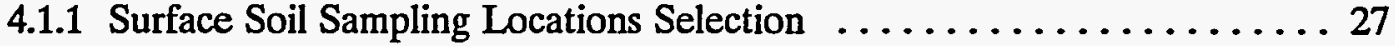

4.1.2 Deep Strata Sampling Locations Selection ................ 29

4.2 SURFACE SOIL SAMPLING LOCATION, DETERMINATION, AND

IDENTIFICATION/DESIGNATIONS $\ldots \ldots \ldots \ldots \ldots \ldots \ldots \ldots \ldots, 31$

4.2.1 Conceptual Framework and Rationale ................. 31

4.2.2 Preparation for Potential Site Selection and a Randomizing

Procedure for Potential Site Selection $\ldots \ldots \ldots \ldots \ldots \ldots \ldots \ldots, \ldots \ldots \ldots$

4.2.3 Field Site Selection Conditions $\ldots \ldots \ldots \ldots \ldots \ldots \ldots \ldots \ldots \ldots \ldots \ldots$

5. SAMPLING AND ANALYSIS PLAN $\ldots \ldots \ldots \ldots \ldots \ldots \ldots \ldots \ldots \ldots \ldots \ldots \ldots \ldots \ldots$

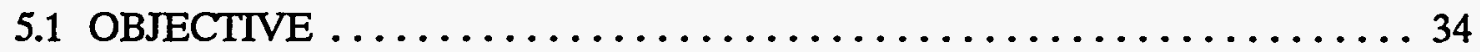

5.2 QUALITY ASSURANCE OBJECTIVES $\ldots \ldots \ldots \ldots \ldots \ldots \ldots \ldots \ldots \ldots$ 
5.2.1 Quality Assurance Objectives for Field Measurement Data . . . . . . . 37

5.2 .2 Data Quality Levels for Field Data ................... 37

5.2.3 Quality Assurance Objectives for Laboratory Measurement Data . . . . . 37

5.2 .4 Data Quality Level of Analyses ... . . . . . . . . . . . . . . 37

5.2 .5 Calibration Procedure and Frequency ................. 38

5.3 SAMPLE COLLECTION PROCEDURES $\ldots \ldots \ldots \ldots \ldots \ldots \ldots \ldots \ldots \ldots$

5.3 .1 Collection of Surface Soil Samples $\ldots \ldots \ldots \ldots \ldots \ldots \ldots \ldots \ldots \ldots \ldots \ldots$

5.3 .2 Collection of Deep Strata Samples .................... 40

5.3 .3 Compositing Deep Strata Samples $\ldots \ldots \ldots \ldots \ldots \ldots \ldots \ldots \ldots . \ldots . \ldots . \ldots$

5.3 .4 Handling of Soil Samples ........................ 43

5.4 SAMPLE IDENTIFICATION, HANDLING, AND TRANSPORT $\ldots \ldots \ldots . .44$

5.4 .1 Sample Identification $\ldots \ldots \ldots \ldots \ldots \ldots \ldots \ldots \ldots \ldots \ldots \ldots$

5.4 .2 Soil Sample Numbering System . . . . . . . . . . . . . . . 45

5.4 .3 Prevention of Cross Contamination .................. 45

5.4.4 Shipping, Handling, and Storage of Samples and Data ......... 45

5.4 .5 Field Data Management . . . . . . . . . . . . . . . . 45

5.4 .6 Sample Custody ......................... 45

5.4 .7 Sample Turnaround Time $\ldots \ldots \ldots \ldots \ldots \ldots \ldots \ldots \ldots \ldots \ldots$

5.5 SAMPLE ANALYSIS $\ldots \ldots \ldots \ldots \ldots \ldots \ldots \ldots \ldots \ldots \ldots \ldots \ldots \ldots \ldots$

5.5 .1 Analytical Procedures $\ldots \ldots \ldots \ldots \ldots \ldots \ldots \ldots \ldots \ldots \ldots . \ldots \ldots$

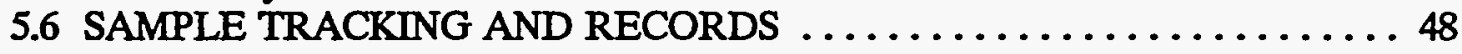

5.6 .1 Logbooks .............................. 48

5.6 .2 Sample Custody Documentation .................... 49

5.7 DATA REDUCTION, VALIDATION, AND REPORTING . . . . . . . . 49

5.7.1 Field Data Reduction and Reporting ................ 49

5.7.2 Laboratory Data Reduction and Reporting .............. 51

5.7 .3 Data Validation ............................ 51

5.8 INTERNAL QUALITY CONTROL CHECKS . . . . . . . . . . . 53

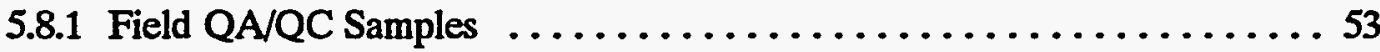

5.8 .2 Laboratory QA/QC Samples .................... 53

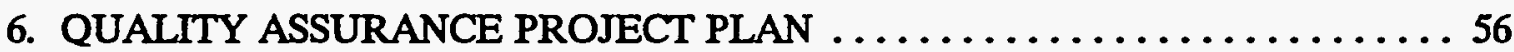

6.1 QA TRAINING AND AWARENESS $\ldots \ldots \ldots \ldots \ldots \ldots \ldots \ldots \ldots \ldots$

6.2 PERFORMANCE AND SYSTEM AUDITS $\ldots \ldots \ldots \ldots \ldots \ldots \ldots \ldots \ldots$

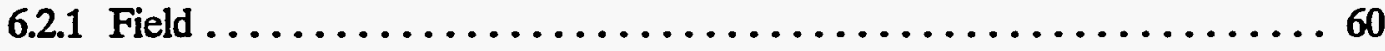

6.2 .2 Laboratory ........................... 61

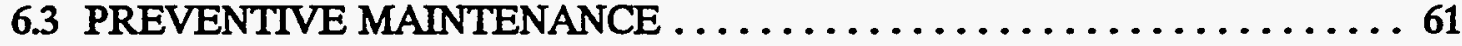

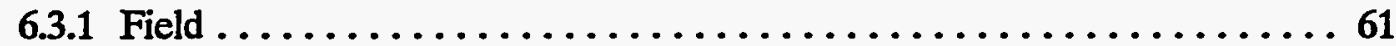

6.3 .2 Laboratory $\ldots \ldots \ldots \ldots \ldots \ldots \ldots \ldots \ldots \ldots \ldots \ldots \ldots \ldots \ldots \ldots$

6.4 QUALITY IMPROVEMENT ..................... 62

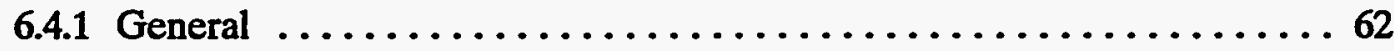

6.4 .2 Control of Nonconforming Items $\ldots \ldots \ldots \ldots \ldots \ldots \ldots \ldots \ldots \ldots \ldots$

6.4 .3 Corrective Actions $\ldots \ldots \ldots \ldots \ldots \ldots \ldots \ldots \ldots \ldots \ldots \ldots \ldots \ldots \ldots$

6.4 .4 Variance System .......................... 63

6.5 QUALITY ASSURANCE REPORTS TO MANAGEMENT . . . . . . . 65

6.5.1 Formal Written Reports ..................... 65

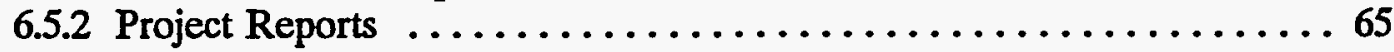

6.6 PURCHASED ITEMS AND SERVICES CONTROL $\ldots \ldots \ldots \ldots \ldots \ldots \ldots 6$ 
7. DATA AND RECORDS MANAGEMENT PLAN $\ldots \ldots \ldots \ldots \ldots \ldots \ldots$

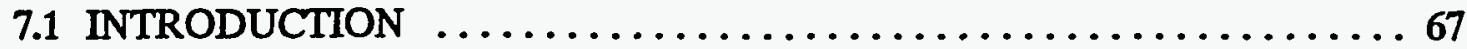

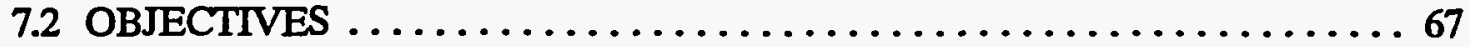

7.3 DATA MANAGEMENT $\ldots \ldots \ldots \ldots \ldots \ldots \ldots \ldots \ldots \ldots \ldots \ldots \ldots \ldots \ldots \ldots \ldots \ldots$

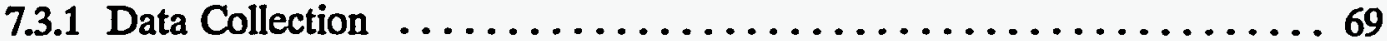

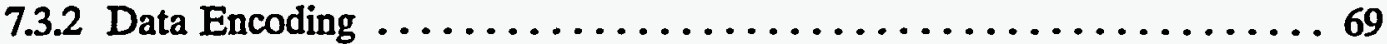

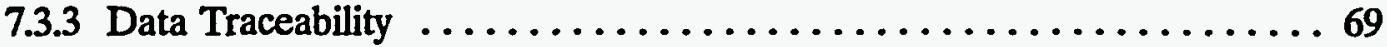

7.3.4 Data Security and Availability $\ldots \ldots \ldots \ldots \ldots \ldots \ldots \ldots \ldots \ldots, 70$

7.4 DOCUMENT CONTROL . . . . . . . . . . . . . . . . . . . . . 70

7.5 RECORDS MANAGEMENT SYSTEM $\ldots \ldots \ldots \ldots \ldots \ldots \ldots \ldots \ldots, 70$

7.5.1 Records Control Process ........................ 70

7.5.2 Document Archive and Index $\ldots \ldots \ldots \ldots \ldots \ldots \ldots \ldots \ldots \ldots, 73$

7.5.3 Document Accessibility . . . . . . . . . . . . . . . . . . . . . 73

7.6 ADMINISTRATIVE RECORD $\ldots \ldots \ldots \ldots \ldots \ldots \ldots \ldots \ldots \ldots \ldots \ldots \ldots$

8. STATISTICAL SAMPLING DESIGN AND ANALYSIS $\ldots \ldots \ldots \ldots \ldots \ldots, 74$

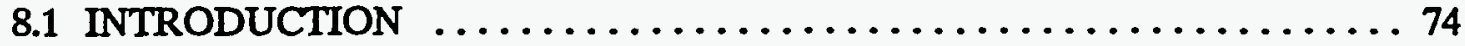

8.2 SAMPLING PLAN DESIGN $\ldots \ldots \ldots \ldots \ldots \ldots \ldots \ldots \ldots \ldots \ldots \ldots \ldots \ldots \ldots$

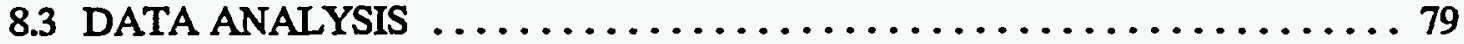

9. DATA INTERPRETATION PLAN $\ldots \ldots \ldots \ldots \ldots \ldots \ldots \ldots \ldots \ldots \ldots \ldots$

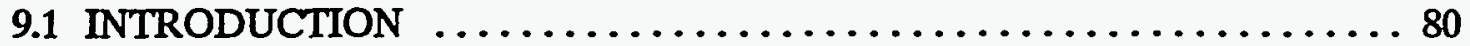

9.2 APPROACH FOR DATA EVALUATION $\ldots \ldots \ldots \ldots \ldots \ldots \ldots \ldots \ldots 80$

9.3 DATA INTERPRETATION AND COMPARISONS $\ldots \ldots \ldots \ldots \ldots \ldots . \ldots 0$

10. RISK ANALYSIS PLAN $\ldots \ldots \ldots \ldots \ldots \ldots \ldots \ldots \ldots \ldots \ldots \ldots \ldots, \ldots 2$

10.1 INTRODUCTION $\ldots \ldots \ldots \ldots \ldots \ldots \ldots \ldots \ldots \ldots \ldots \ldots \ldots, \ldots 2$

10.2 IMPORTANCE $\ldots \ldots \ldots \ldots \ldots \ldots \ldots \ldots \ldots \ldots \ldots \ldots \ldots \ldots, \ldots 2$

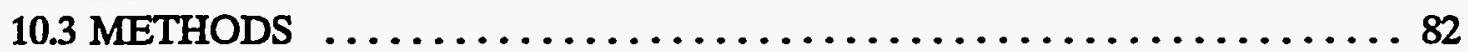

10.3.1 Comparison to Human Health Risk-Based Screening Criteria and Ecological Benchmarks ..................... 82

10.3.2 Uncertainties in Using Background Concentrations and Activities to Select Contaminants of Potential Concern .............. 83

11. HEALTH AND SAFETY PROGRAM $\ldots \ldots \ldots \ldots \ldots \ldots \ldots \ldots \ldots \ldots \ldots$

11.1 INTRODUCTION $\ldots \ldots \ldots \ldots \ldots \ldots \ldots \ldots \ldots \ldots \ldots \ldots \ldots, 84$

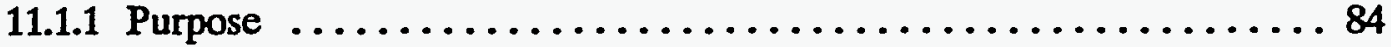

11.1.2 Applicability .................................... 84

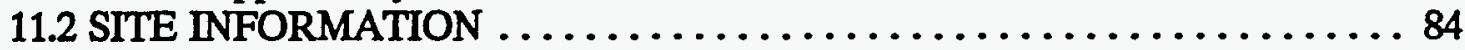

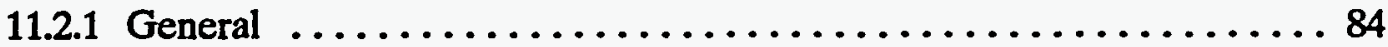

11.2.2 Physical Hazards $\ldots \ldots \ldots \ldots \ldots \ldots \ldots \ldots \ldots \ldots \ldots \ldots, \ldots, \ldots \ldots \ldots$

11.3 SITE TASK HAZARD ANALYSIS $\ldots \ldots \ldots \ldots \ldots \ldots \ldots \ldots \ldots \ldots . \ldots 6$

11.3.1 Site Requirements $\ldots \ldots \ldots \ldots \ldots \ldots \ldots \ldots \ldots \ldots \ldots \ldots, 86$

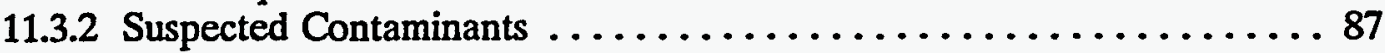

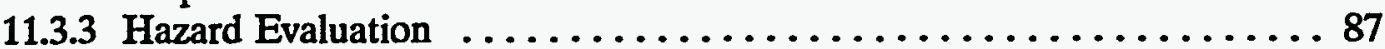

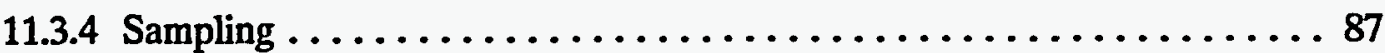

11.3.5 Equipment Cleaning $\ldots \ldots \ldots \ldots \ldots \ldots \ldots \ldots \ldots \ldots \ldots \ldots, 87$

11.4 SPECIAL HAZARDS $\ldots \ldots \ldots \ldots \ldots \ldots \ldots \ldots \ldots \ldots \ldots \ldots \ldots \ldots$

11.4.1 Temperature Extremes $\ldots \ldots \ldots \ldots \ldots \ldots \ldots \ldots \ldots \ldots \ldots, 88$ 
11.4.2 Biological Stress $\ldots \ldots \ldots \ldots \ldots \ldots \ldots \ldots \ldots \ldots \ldots \ldots \ldots \ldots . . .69$

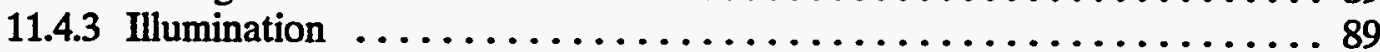

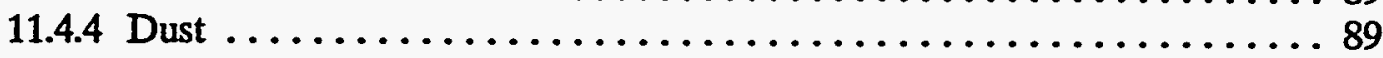

11.4.5 Ergonomics ............................. 89

11.4.6 Physical Sampling Location Hazards $\ldots \ldots \ldots \ldots \ldots \ldots \ldots \ldots . . \ldots$

11.5 EMERGENCY PROCEDURES $\ldots \ldots \ldots \ldots \ldots \ldots \ldots \ldots \ldots \ldots \ldots, 90$

11.5.1 Plant Shift Superintendent $\ldots \ldots \ldots \ldots \ldots \ldots \ldots \ldots \ldots \ldots \ldots . \ldots \ldots$

11.5.2 Reporting an Emergency $\ldots \ldots \ldots \ldots \ldots \ldots \ldots \ldots \ldots \ldots \ldots, \ldots 1$

11.6 SITE MONITORING $\ldots \ldots \ldots \ldots \ldots \ldots \ldots \ldots \ldots \ldots \ldots \ldots \ldots, 92$

11.6.1 Instrument Calibration and Response Checks $\ldots \ldots \ldots \ldots \ldots \ldots \ldots 92$

11.6.2 Monitoring Equipment Action Limits $\ldots \ldots \ldots \ldots \ldots \ldots \ldots \ldots . .93$

11.7 SITE CONTROL MEASURES-SAMPLING AREA $\ldots \ldots \ldots \ldots \ldots \ldots 93$

11.8 HEALTH AND SAFETY TRAINING REQUIREMENTS $\ldots \ldots \ldots \ldots \ldots 93$

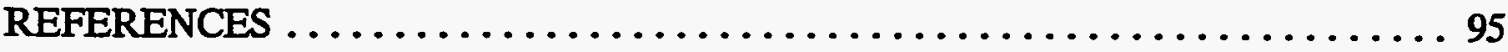

Appendix A. STATUS OF EXISTING BACKGROUND SOIL INFORMATION

AT THE PADUCAH GASEOUS DIFFUSION PLANT $\ldots \ldots \ldots \ldots \ldots \ldots$ A-1

Appendix B. REFERENCE SOIL PROFILE DESCRIPTIONS $\ldots \ldots \ldots \ldots \ldots$ B-1

Appendix C. SOIL SURVEY MAP OF BALLARD COUNTY ........... C-1 


\section{TABLES}

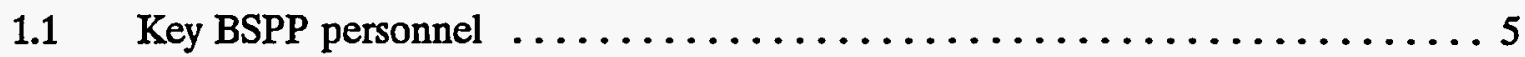

1.2 Functional responsibility matrix for the BSPP $\ldots \ldots \ldots \ldots \ldots \ldots \ldots \ldots$

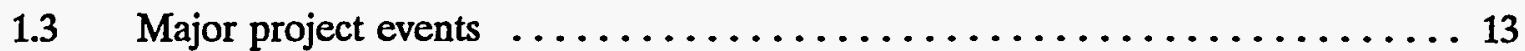

$5.1 \quad$ Analyte list for atomic absorption metals $\ldots \ldots \ldots \ldots \ldots \ldots \ldots \ldots \ldots$

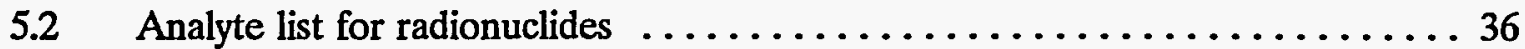

$5.3 \quad$ Number of soil and QC samples for analysis $\ldots \ldots \ldots \ldots \ldots \ldots \ldots$

5.4 Recommended sample containers, sample preservation, sample size, and sample holding time requirements for analytical samples $\ldots \ldots \ldots \ldots \ldots 46$

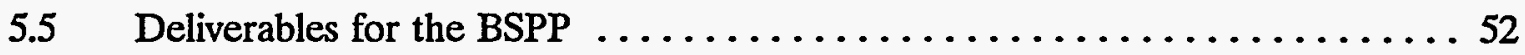

6.1 Modular profile and cross-reference of ER Division QA Program Plan, EPA QAMS-005/80 and DOE Order 5700.6C ............... 57

6.2 Background soil characterization project-1995 schedule of

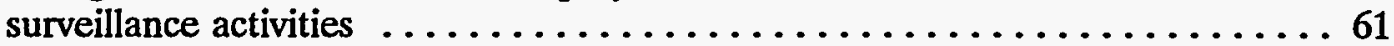

7.1 Records to be included in the Paducah DMC and BSPP files ......... 71

8.1 Variance estimates for uranium (base-ten $\log$ of $\mathrm{pCi} / \mathrm{g}) \ldots \ldots \ldots \ldots \ldots$

8.2 Estimates of power (Eq. 2) for PGDP uranium $(\sigma=0.17) \ldots \ldots \ldots \ldots \ldots$

11.1 Protective equipment for on-site activities $\ldots \ldots \ldots \ldots \ldots \ldots \ldots$

11.2 Safe working distances from electrical transmission lines for drill rigs $\ldots \ldots \ldots 8$ 



\section{FIGURES}

1.1 Regional map showing location of the Paducah Gaseous Diffusion Plant $\ldots \ldots 2$

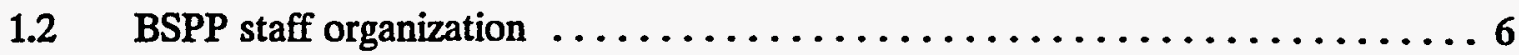

$1.3 \quad$ Project schedule $\ldots \ldots \ldots \ldots \ldots \ldots \ldots \ldots \ldots \ldots \ldots \ldots \ldots \ldots \ldots \ldots$

2.1 Step 5: Development of a decision rule, deep strata sampling . . . . . . . 19

2.2 Step 5: Development of a decision rule, surface soil sampling $\ldots \ldots \ldots \ldots \ldots 20$

3.1 Columnar section of the Jackson Purchase Region $\ldots \ldots \ldots \ldots \ldots \ldots$

3.2 Schematic of the north-south section showing regional stratigraphic relationships and Hydrogeologic Units 1 through $4 \ldots \ldots \ldots \ldots \ldots \ldots$

3.3 Typical pattern of soils and underlying material in Calloway-Henry

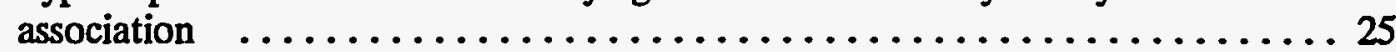

4.1 Vicinity map around the PGDP showing soil sampling area and drill sites .... 28

5.1 Soil sampling and compositing approach $\ldots \ldots \ldots \ldots \ldots \ldots \ldots \ldots \ldots \ldots$

$5.2 \quad$ Number of samples to be collected by hydrogeologic unit $\ldots \ldots \ldots \ldots \ldots \ldots$

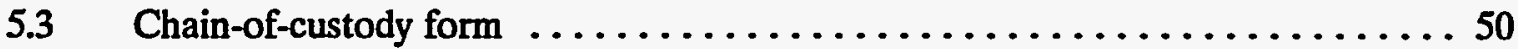

6.1 Change request/variance form $\ldots \ldots \ldots \ldots \ldots \ldots \ldots \ldots \ldots \ldots \ldots \ldots \ldots \ldots \ldots$

7.1 Responsibility matrix and process flow of BSPP samples, data and documents $\ldots \ldots \ldots \ldots \ldots \ldots \ldots \ldots \ldots \ldots \ldots \ldots \ldots \ldots \ldots \ldots$

8.1 Parameters and statistics for a hypothetical background distribution and sample $\ldots \ldots \ldots \ldots \ldots \ldots \ldots \ldots \ldots \ldots \ldots \ldots \ldots \ldots \ldots$

8.2 Probability plot for the PGDP ${ }^{234} \mathrm{U}$ data $\ldots \ldots \ldots \ldots \ldots \ldots \ldots \ldots$ 


\section{ABBREVIATIONS}

\begin{tabular}{|c|c|}
\hline AFIRO & available for infiltration or runoff \\
\hline BSCP & Background Soil Characterization Project (on the Oak Ridge Reservation) \\
\hline BSPP & Background Soils Project for the Paducah Gaseous Diffusion Plant \\
\hline CERCLA & Comprehensive Environmental Response, Compensation, and Liability Act \\
\hline $\mathbf{C L P}$ & Contract Laboratory Program \\
\hline DBGS & disturbed background site \\
\hline DMC & Document Management Center \\
\hline DOE & U.S. Department of Energy \\
\hline DQ & data quality \\
\hline DQO & data quality objective \\
\hline EIMS & Paducah Environmental Information Management System \\
\hline EPA & U.S. Environmental Protection Agency \\
\hline ER & Environmental Restoration \\
\hline ERWM & Environmental Restoration and Waste Management \\
\hline ESD & Environmental Sciences Division (of Oak Ridge National Laboratory) \\
\hline ESP & Environmental Sciences Procedure (of ESD) \\
\hline FOP & field operation procedure \\
\hline HSA & hollow stem auger \\
\hline HU & hydrogeologic unit \\
\hline ICP-MS & inductively coupled plasma-mass spectroscopy \\
\hline KDEP & Kentucky Department of Environmental Protection \\
\hline KDHS & Kentucky Department for Health Services \\
\hline KOW & Kentucky Ordinance Works \\
\hline LMES & Lockheed Martin Energy Systems, Inc. \\
\hline MSL & mean sea level \\
\hline NAA & neutron activation analysis \\
\hline NIST & National Institute of Standards and Technology \\
\hline OREIS & Oak Ridge Environmental Information System \\
\hline PGDP & Paducah Gaseous Diffusion Plant \\
\hline PSS & plant shift superintendent \\
\hline QA & quality assurance \\
\hline QAPP & quality assurance project plan \\
\hline QAS & quality assurance specialist \\
\hline QC & quality control \\
\hline RASCAL & Radiation Standards Calibration Laboratory \\
\hline RCRA & Resource Conservation and Recovery Act \\
\hline RI/FS & Remedial Investigation and Feasibility Study \\
\hline SAS & Statistical Analysis System \\
\hline SCS & Soil Conservation Service \\
\hline SOP & standard operating procedure \\
\hline SOW & statement of work \\
\hline SPL & Soil Preparation Laboratory \\
\hline SVOC & semivolatile organic compound \\
\hline TQM & Total Quality Management \\
\hline TVA & Tennessee Valley Authority \\
\hline
\end{tabular}


UBGS undisturbed background site

USEC United States Enrichment Corporation

VOC volatile organic compound

WKWMA Western Kentucky Wildlife Management Area 


\section{PREFACE}

The Project Plan for the Background Soils Project for the Paducah Gaseous Diffusion Plant (PGDP), Paducah, Kentucky (DOE/OR/07-1414\&D1, ES/ER/TM-155\&D1) was prepared in accordance with requirements under the Comprehensive Environmental Response, Compensation, and Liability Act (CERCLA) to plan, organize, and implement a project to extend significantly the site background soils characterization database for PGDP. This work is performed under Work Breakdown Structure 1.4.12.7.1.02.19.03.03 ("PGDP Radiological Background Levels in Soils"). Publication of this document meets a DOE deliverable milestone of September 29, 1995. This document provides the Paducah Environmental Restoration Program with essential information on the structure and execution of a project to provide background soils data critical to planning and implementation of future remedial actions on the PGDP reservation. Data from this project will be used to (1) differentiate between naturally occurring soil constituents and site-related contamination, (2) form the basis for determining estimates of baseline human health risk, and (3) establish cleanup levels and develop remedial design criteria from feasibility studies to be developed in other documents to follow for specific future remedial actions. 
 


\section{EXECUTIVE SUMMARY}

The Background Soils Project for the Paducah Gaseous Diffusion Plant (BSPP) will determine the background concentration levels of selected naturally occurring metals, other inorganics, and radionuclides in soils from uncontaminated areas in proximity to the Paducah Gaseous Diffusion Plant (PGDP) in Paducah, Kentucky. The data will be used for comparison with characterization and compliance data for soils, with significant differences being indicative of contamination. All data collected as part of this project will be in addition to other background databases established for the PGDP.

The BSPP will address the variability of surface and near-surface concentration levels with respect to (1) soil taxonomical types (series) and (2) soil sampling depths within a specific soil profile. The BSPP will also address the variability of concentration levels in deeper geologic formations by collecting samples of geologic materials. The BSPP will establish a database, with recommendations on how to use the data for contaminated site assessment, and provide data to estimate the potential human health and ecological risk associated with background level concentrations of potentially hazardous constituents.

BSPP data will be used or applied as follows. The first application will be in differentiating between naturally occurring constituents and site-related contamination. This is a very important step in risk assessment because if sufficient background data are not available, then no known contaminant can be eliminated from the assessment on the basis of comparison to background, even if the sample concentration is minimal. The second use of the BSPP data will be in evaluating risks from background concentrations against those from site-specific contamination risks can be compared. The third application will be the establishment of cleanup levels using the background soils characterization data as reference parameters for use by regulators and stakeholders.

This project plan provides a detailed map for establishing the Paducah site-specific background soils database. Project scope and data requirements were established through the Data Quality Objective process. The plan calls for transfer of data to the Paducah Environmental Restoration Program database after analysis and interpretation of analytical data and delivery of the BSPP data report to the Department of Energy Paducah Site Office at project completion. 


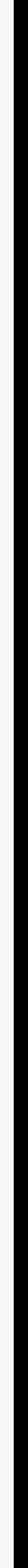




\section{INTRODUCTION AND ORGANIZATION}

\subsection{SITE BACKGROUND}

\subsubsection{History of the Paducah Gaseous Diffusion Plant Facilities}

The Paducah Gaseous Diffusion Plant (PGDP) has been operational since 1951 and performs the first step in the uranium enrichment process. PGDP enriches the ${ }^{235} \mathrm{U}$ radionuclide in a physical separation process. This separation is based on the faster rate at which ${ }^{235} \mathrm{U}$ diffuses through a barrier in comparison to the heavier ${ }^{238} \mathrm{U}$. Extensive support facilities are required for maintaining the diffusion process. Some of the major support facilities include a steam plant, four major electrical switchyards, four sets of cooling towers, a building for chemical cleaning and decontamination, a water treatment plant, maintenance facilities, laboratory facilities, and an active landfill. Several inactive facilities are also located at PGDP (Energy Systems 1990a).

\subsubsection{General Description of the Plant Facilities}

The U.S. Department of Energy (DOE) owns PGDP. In July 1993, DOE leased the plant production facilities to the United States Enrichment Corporation (USEC) which, in turn, contracted with Lockheed Martin Utility Services, Inc., to provide operations and maintenance services. Lockheed Martin Energy Systems, Inc., (LMES) manages the Environmental Restoration and Waste Management activities for DOE.

PGDP is located on the DOE Reservation of 1484 ha (3667 acres) in western McCracken County, about $16 \mathrm{~km}$ (10 miles) west of Paducah, Kentucky, and about $4.8 \mathrm{~km}$ (3 miles) south of the Ohio River (Fig. 1.1). The plant is situated between Bayou Creek (also called Big Bayou Creek) to the west and Little Bayou Creek to the east. These creeks join north (downgradient) of PGDP before entering the Ohio River. Some of the flow in the creeks is from process effluents from PGDP. The surrounding area is predominantly rural, and homes and farms are located in all directions around the plant (Energy Systems 1990).

Approximately 303 ha (748 acres) of PGDP are within the fenced security area. The rawwater treatment plant, the residential landfill, and the inert landfill are the only operating areas outside the security area to date. The C-612 NW Plume Pilot Pump and Treat Facility will be operational outside the security fence in August 1995. A considerable number of hunters and fishermen use the Western Kentucky Wildlife Management Area (WKWMA) consisting of 1682 ha (4157 acres). Approximately 20 of the 35 ponds in the WKWMA support fishing, and about 200 deer are taken from the area each year through hunting (CH2M Hill 1991).

Southwest of the plant (in an area that is now part of the WKWMA) is the production area of the former Kentucky Ordinance Works (KOW), a trinitrotoluene (TNT) production facility that operated during and immediately after World War II. While in operation, the KOW included the area currently occupied by PGDP and by the Tennessee Valley Authority 


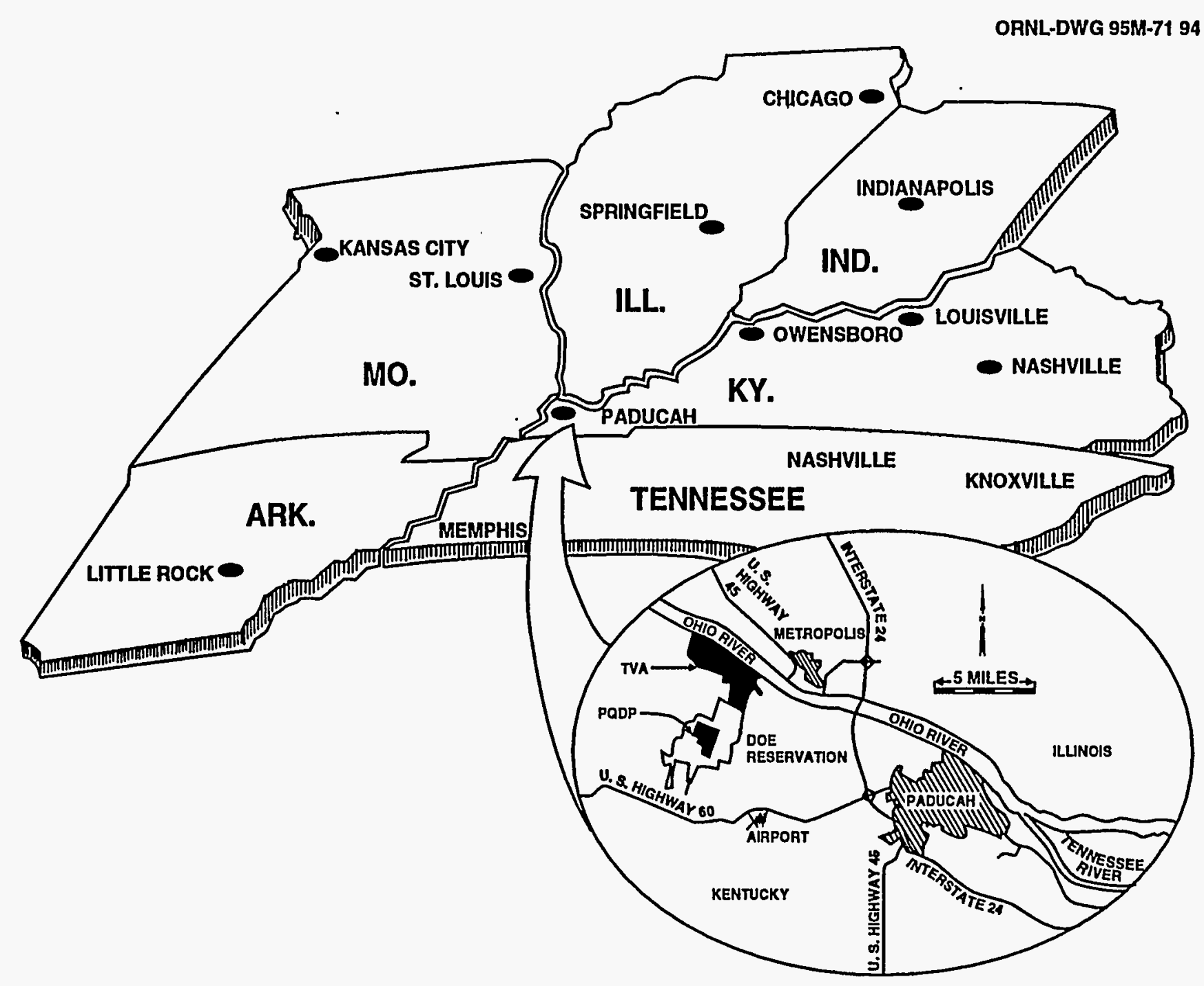

Fig. 1.1. Regional map showing location of the Paducah Gaseous Diffusion Plant. 
(TVA) Shawnee Steam Plant. Currently, DOE owns 1484 ha (3667 acres) of the former KOW. Of this area, 302 ha (748 acres) are part of the fenced security area of PGDP, and 945 ha (2323 acres) are under use permit to the Commonwealth of Kentucky Department of Fish and Wildlife Resources. In addition, the Department of Fish and Wildlife Resources owns approximately another 1684 ha (4157 acres) of the former KOW property. As noted earlier, TVA owns 552 ha (1362 acres) of the former KOW, which is the location of the Shawnee Steam Plant. Portions of the former KOW [2811 ha (6940 acres)] are privately owned (CH2M Hill 1991).

\subsection{REGULATORY BACKGROUND}

PGDP was added to the National Priorities List in May 1994, which indicates that PGDP warrants further investigation to assess the nature and extent of the public health and environmental risks associated with PGDP and to determine the extent that Comprehensive Environmental Response, Compensation, and Liability Act (CERCLA) remedial actions may be appropriate. PGDP also has a Resource Conservation and Recovery Act (RCRA) permit that requires corrective actions at solid waste management units. CERCLA, RCRA, and DOE Order 5400.1 (effective November 9,1989 ) address the necessity of establishing background values for chemical and radiological constituents in conjunction with the Remedial Investigation and Feasibility Study (RI/FS) process. Existing data pertinent to the determination of background values at PGDP are presented in Appendix A. To establish the presence and distribution of chemical and radiological constituents associated with a potentially contaminated site, a determination of the presence or absence of those contaminants in the natural environment is required. The term background soil is defined here as a natural soil that is not contaminated by constituents generated by operations at PGDP. Therefore, background soils contain only constituents originating from parent material, global fallout, and non-DOE-related anthropogenic activities. The concentration levels of the constituents in background soils are herein referred to as background values or background concentration levels.

\subsection{PROJECT SCOPE AND PURPOSE}

The BSPP will determine background concentration levels of selected metals, other inorganics, and radionuclides in soils from areas in proximity to PGDP. The scope of the project includes determination of background concentration levels and ranges for naturally occurring inorganic and radiological parameters. These data and existing data (Appendix A) will be utilized for comparison with characterization and compliance data for soils and sediments, with significant differences being indicative of contamination. The specific objectives of the BSPP are stated in Sect. 2.2.

The BSPP will address the variability of surface and near-surface concentration levels in terms of (1) soil taxonomical types (series) and (2) soil sampling depths within a specific soil profile. The BSPP will also address the variability of concentration levels in deeper geologic formations by collecting samples of geologic materials. Consistent with project objectives stated in Sect. 2.2, the BSPP will establish a database, with recommendations on how to use the data for contaminated site assessment, and provide data to estimate the potential human 
health risk associated with background level concentrations of potentially hazardous constituents.

BSPP data will be used and applied as follows consistent with the specific project objectives stated in Sect. 2.2. The first application will be the establishment of cleanup levels using the background soils characterization data as reference parameters. The second use of background data will be in differentiating between naturally occurring constituents and site-related contamination for contaminated site assessments. This differentiation is very important in identifying the presence of contamination, because if sufficient background data are not available, then no known contaminant can be eliminated from consideration in the $\mathrm{RI} / \mathrm{FS}$, even if the sampled concentration is minimal. The third application will be in evaluating risks from background concentrations against those from site-specific contamination.

\subsection{PROJECT ORGANIZATION AND MANAGEMENT}

The project plan is organized as follows: Sections 1 through 3 include an introduction and summaries of historical, geographical, and environmental data for PGDP, followed by project scope, organization, and management. Sections 4 and 5 present the heart of the project plan. These sections address site selection, soil sampling and analysis, sample tracking, and field record management and project support activities. The general approach and methods to be followed during sample analysis are presented in these sections. Sections 6 through 11 discuss the quality assurance/quality control plan, the data management plan, the statistical analysis plan, the data interpretation and data quality assessment plan, the risk analysis plan, and the health and safety program, respectively. Supporting data, information, and exhibits are presented in the Appendixes A, B, and C.

The management of the BSPP is under the DOE and LMES management structure for the Environmental Restoration (ER) Program at PGDP.

\subsubsection{Organization and Responsibilities}

The BSPP staff organization is summarized in Table 1.1 and Fig. 1.2. Functional responsibilities for project activities are listed in this section. Also included are specific responsibilities for quality assurance, and health and safety. Table 1.2 is the functional responsibility matrix for the BSPP. Its purpose is to provide a cross-reference from specific quality-affecting activities to those project staff positions responsible for their accomplishment. General responsibilities for ER Program management, BSPP management, and QA staff are described in the ER Quality Assurance Program Plan (Energy Systems 1994) and are not restated here.

\section{Program Manager}

The program manager is the principal contact between the ER programs of DOE and LMES. Specific duties include the following:

- Provides the upper-level interface with counterparts in the ER Program and DOE. 
- Reviews and approves the project plan.

- Ensures that programmatic resources required to accomplish the project are available.

- Ensures that the philosophy of Total Quality Management (TQM) is applied to the BSPP.

\section{Project Manager}

The project manager is the principal project contact between the BSPP coordinators and the LMES ER Program. The project manager has overall responsibility for technical, financial, and scheduling matters. Specific duties of the BSPP manager include the following:

- Ensures excellence in meeting the goals and objectives of the BSPP in a timely and costeffective manner.

- Provides project planning, organization, coordination, and supervision.

- Assigns duties to the project staff and orients the staff to the needs and requirements of the project.

- Reviews and approves analytical laboratory statements of work for accuracy and completeness to ensure that results are consistent with BSPP objectives.

- Allocates resources to facilitate achievement of project objectives and requirements.

- Provides budget and schedule control and coordinates/manages preparation of the project plan.

- Obtains DOE approval for the proposed variances to any of the support plans, if required.

- Coordinates corrective actions and nonconformance reports.

- Reviews subcontract work and approves subcontract invoices.

- Establishes and maintains project files and the records management system.

- Ensures that field records and all data submitted by BSPP investigators are safeguarded in secure files.

- Ensures that project reports and submissions are reviewed for technical accuracy and completeness.

- Ensures that project milestones and deliverables are achieved and submitted according to the project schedule.

Table 1.1. Key BSPP personnel

\begin{tabular}{lll}
\hline \multicolumn{1}{c}{ Responsibility } & \multicolumn{1}{c}{ Name } & \multicolumn{1}{c}{ Telephone } \\
\hline Project Manager & D. R. Watkins & (423) $576-9931$ \\
Technical Coordinator & S. Y. Lee & (423) $574-6316$ \\
Project QA Representative (field) & J. R. Blewett & (502) $441-5167$ \\
Project QC Representative (laboratory) & T.L. Hatmaker & (423) $241-5064$ \\
Paducah Program Manager & C.J. Marshall & (502) $441-5083$ \\
PGDP Industrial Hygiene/HAZWOPER & E. J. Fisher & (502) $441-5047$ \\
PGDP Health Physics & S. E. Meiners & (502) $441-5043$ \\
PGDP Safety & D. J. Pea & (502) $441-5045$ \\
\hline
\end{tabular}




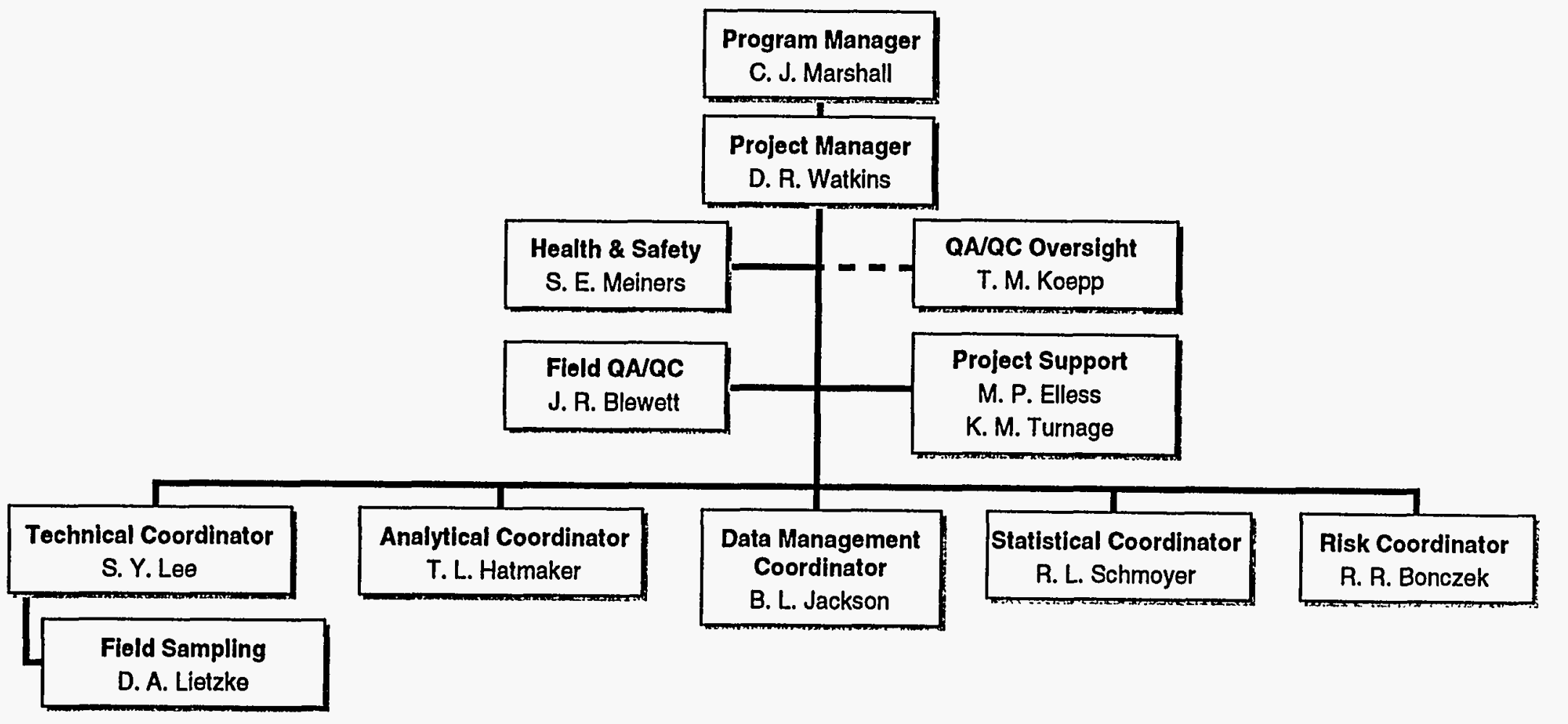

Fig. 1.2. BSPP staff organization. 
Table 1.2. Functional responsibility matrix for the BSPP

\begin{tabular}{|c|c|c|c|c|c|c|c|c|}
\hline Documents/actions ${ }^{a}$ & $\begin{array}{l}\text { Program } \\
\text { manager }\end{array}$ & $\begin{array}{l}\text { Project } \\
\text { manager }\end{array}$ & $\begin{array}{l}\text { Technical } \\
\text { coordinator }\end{array}$ & $\begin{array}{l}\text { Analytical } \\
\text { coordinator }\end{array}$ & $\begin{array}{l}\text { Field QA } \\
\text { coordinator }\end{array}$ & $\begin{array}{c}\text { Technical } \\
\text { and scientific } \\
\text { staff }\end{array}$ & $\begin{array}{c}\text { ER } \\
\text { Program } \\
\text { QAS }\end{array}$ & $\begin{array}{c}\text { Contract } \\
\text { laboratory }\end{array}$ \\
\hline Data quality objectives & $\mathbf{R} / \mathbf{A}$ & $\mathbf{R} / \mathbf{A}$ & $\mathbf{P}$ & $\mathbf{P}$ & & $\mathrm{P} / \mathrm{I}$ & $\mathbf{R}$ & \\
\hline Project scoping & $\mathbf{R} / \mathbf{A}$ & $\mathbf{P} / \mathbf{R} / \mathbf{A}$ & $\mathbf{P} / \mathbf{I}$ & I & $I$ & I & & \\
\hline $\begin{array}{l}\text { Project plan } \\
\text { development }\end{array}$ & $\mathbf{R} / \mathbf{A}$ & P/R/A & $\mathbf{P} / \mathbf{I} / \mathbf{R}$ & $\mathbf{P} / \mathbf{I} \mathbf{R}$ & $\mathbf{P} / \mathbf{I}$ & I & I/R/A & \\
\hline Procurement & & $\mathbf{R} / \mathbf{A}$ & $\mathrm{P} / \mathrm{A} / \mathrm{I}$ & $\mathrm{P} / \mathrm{A} / \mathrm{I}$ & & I & $\mathbf{R}$ & \\
\hline Project procedures & & $\mathbf{A}$ & $\mathbf{P} / \mathbf{I} / \mathbf{R}$ & & $\mathbf{I} / \mathbf{R}$ & I/R & $\mathbf{s}$ & \\
\hline Readiness review & P/R/A & $\mathbf{R} / \mathbf{A}$ & $\mathrm{P} / \mathrm{I}$ & $\mathbf{P} / \mathbf{I}$ & $\mathbf{I}$ & I & $\mathbf{R}$ & \\
\hline Soil sampling & & $\mathbf{R}$ & $\mathbf{P} / \mathbf{I} / \mathbf{R} / \mathbf{A}$ & & $\mathrm{R} / \mathrm{S}$ & $\mathbf{P}$ & $\mathbf{S}$ & \\
\hline Laboratory analysis & & $\mathbf{R}$ & $\mathbf{R}$ & $\mathbf{P} / \mathbf{I} / \mathbf{A}$ & & $\mathbf{I} / \mathbf{R}$ & $\mathbf{S}$ & $\mathbf{P}$ \\
\hline Data validation & & $\mathbf{R}$ & $\mathbf{R}$ & P/R/S/A & & I/R & $\mathbf{S}$ & \\
\hline Surveillance and audit & $\mathbf{R}$ & $\mathbf{R} / \mathbf{A}$ & $\mathbf{R}$ & $\mathbf{P} / \mathbf{1}$ & $\mathrm{P} / \mathrm{I}$ & $\mathbf{P}$ & $\mathrm{P} / \mathrm{I} / \mathrm{R}$ & \\
\hline $\begin{array}{l}\text { Nonconformance } \\
\text { reports }\end{array}$ & & $\mathrm{R} / \mathrm{A}$ & I/R/A & $\mathbf{P}$ & $\mathbf{P}$ & & I/R/S/A & \\
\hline Stop work actions & & $\mathrm{P} / \mathrm{R} / \mathrm{A}$ & $\mathrm{P} / \mathrm{I} / \mathrm{R}$ & $\mathrm{P} / \mathrm{I} / \mathrm{R}$ & & & $\mathrm{P} / \mathrm{R} / \mathrm{S}$ & \\
\hline QA records & & $\mathbf{R} / \mathbf{A}$ & $\mathbf{P} / \mathbf{I}$ & $\mathrm{P} / \mathbf{I}$ & $\mathrm{P} / \mathrm{I} / \mathrm{S}$ & & $R / S$ & \\
\hline $\begin{array}{l}\text { Data report } \\
\text { development }\end{array}$ & $\mathbf{R}$ & $\mathrm{P} / \mathrm{I} / \mathrm{R} / \mathrm{A}$ & $\mathrm{P} / \mathrm{I}$ & $\mathrm{P} / \mathrm{I}$ & & $\mathbf{P} / \mathbf{I}$ & $\mathbf{s}$ & \\
\hline
\end{tabular}

Key: A, approve; I, input; P, prepare/perform; R, review; S, surveillance.

- ESD will make available ER documents for the BSPP; BSPP will distribute BSPP procedures. 
- Ensures that work is done in accordance with the project plan.

- Initiates a stop work order, if required.

- Is responsible for application of the philosophy of TQM to all aspects of the BSPP.

- Ensures that variances, field changes, and corrective actions are communicated and discussed with all project staff concerned with data quality.

- Ensures that all general records and project QA records and files are transferred to the ER Document Management Center (DMC) for permanent storage and retrieval.

- Ensures that all personnel are qualified for their assigned tasks.

- Provides oversight for field sampling activities and laboratory analyses.

- Ensures adherence to the Project Plan throughout field activities.

\section{Technical Coordinator}

The technical coordinator is responsible for coordinating efforts of field work planning, site selection, providing field equipment, soil sampling, sample preparation, and sample characterization. The technical coordinator facilitates interactions and information flow among the analytical coordinator, the statistical analysis coordinator, and the risk analysis coordinator. Specific responsibilities of the technical coordinator include the following:

- Assists the project manager in achieving the goals and objectives of the BSPP.

- Oversees all technical aspects of the project and provides assistance to other task coordinators, as required.

- Provides input for the project plan and project progress reports.

- Supervises and reviews site selection, soil sampling, data collection, and subcontractor activities, as appropriate and as outlined in the project plan.

- Reviews the analytical laboratory statement of work.

- Is responsible for tracking custody of samples from the field, through the process of sample preparation, and shipment of samples to the analytical laboratory.

- Maintains field/sample records in accordance with the Data Management Plan.

- Provides final data assessment of field and analytical laboratory data, review of data for completeness, documentation, procedures, and consistency with sound physical-chemical principles.

- Resolves any technical questions concerning the data and interpretations.

- Implements appropriate staff training and ensures that all project staff comply with project quality assurance/quality control (QA/QC), health and safety, data management requirements, and project-generated waste management requirements, if needed.

- Ensures coordination between all organizations involved in the data gathering and data transfer activities in the project.

- Ensures that all organizations involved in project data collection activities are aware of their responsibilities and data quality requirements, as outlined in the project plan.

- Establishes a file for project QA records and ensures their deposition into the records management system.

- Arranges for peer and editorial review of technical reports prepared by the project team.

- Ensures that project technical reports satisfy the technical requirements of the ER Program.

- Initiates a stop work order, if required, and contacts Industrial Hygiene and Health Physics to determine if sampling may continue at the site.

- Notifies the appropriate Shift Superintendent or support personnel of plans and scheduled field activities. 
- Obtains required permits and documentation.

- Coordinates provision of field equipment.

- Ensures adherence to the work plan throughout the field investigation.

- Determines in-field procedural variances necessary to respond to site-specific conditions.

- Documents and reports unforeseen site-specific changes and corrective actions.

- Establishes and makes available at the site an emergency action plan, with telephone numbers and appropriate radio communication information.

- Identifies key plant personnel (and alternates) who are responsible for specific safety-related areas, such as health, plant safety, health physics, industrial hygiene, and the Shift Superintendent's organization to facilitate emergency response.

- Ensures that penetration/excavation permits have been obtained and that a signed copy is available on-site, prior to commencing the field work.

- Ensures that all project personnel who report an injury go to the appropriate Health Center for evaluation and treatment.

- Ensures that personnel stand clear of overhead work and temporarily suspended equipment.

The technical coordinator designates the field team leader to ensure that field QA requirements are met, reviews the field entries for completeness and accuracy, suspends site work and requires personnel to evacuate a potentially hazardous area, and verifies that the drill rig will not be located so that any part of it is within $10 \mathrm{ft}$ of any electrical transmission line.

\section{Analytical Coordinator}

The analytical coordinator is responsible for identifying analytical requirements, determining viable analytical methods, identifying data recording and documentation requirements, contracting analytical service laboratories, selecting target inorganics/metals and radionuclides for analysis, specifying analytical methods and detection limits, and coordinating with other tasks. Specific responsibilities of the analytical coordinator include the following:

- Assists the project manager in achieving the goals and objectives of the BSPP.

- Prepares the detailed analytical laboratory statement of work for approval of project manager and the QA oversight representative.

- Provides assistance to other task coordinators, as required.

- Provides input for the project plan and project progress reports.

- Selects target metal and radionuclide lists for analysis in consultation with project team members and coordinates extraction and analytical methods with analytical service laboratories for the BSPP.

- Establishes QA/QC procedures with laboratory contractors and establishes analytical laboratory data documentation procedures.

- Resolves any technical questions concerning the data with the responsible laboratory.

- Maintains data records and data packages in accordance with the Data Management Plan.

- Provides validation of analytical laboratory data, review of data packages for completeness, documentation level, procedures, and consistency with accepted physicalchemical principles.

- Is responsible for receipt of data from the analytical laboratory and availability of data to the data management coordinator following data validation. 


\section{Data Management Coordinator}

The data management coordinator establishes required procedures and coordinates all database management activities. Additional responsibilities include the following:

- Interfaces with technical coordinator and analytical coordinator to receive sample and analytical data, verify database entry, and receive and report validated data.

- Designs, creates, and maintains hardcopy and electronic database.

- Provides data to risk analysis coordinator.

- Provides data tables for project reports.

- Provides electronic database to Paducah ER database, the Paducah Environmental Information Management System (EIMS), for archival and dissemination.

\section{Statistical Analysis Coordinator}

The statistical analysis coordinator provides appropriate statistical design (test design) for sample collection to ensure adequate representation of the background soils for the BSPP. The statistical analysis coordinator assists in determining data collection requirements for statistical analysis, assists in the preparation of the project plan, and provides statistical analysis for technical interpretation of data. The statistical analysis coordinator summarizes the statistical findings in draft form and in the final report. The statistical analysis coordinator interacts with the site selection team to achieve statistically valid sampling sites and with the risk analysis coordinator to guide data collection towards reducing uncertainty in risk analysis.

\section{Risk Assessment Coordinator}

The risk assessment coordinator has responsibility for ensuring the collection of quantifiable data and for conducting analyses to assess any risks to human health resulting from background levels of inorganics/metals and radionuclides in soils. The risk assessment coordinator interacts with the analytical coordinator for listing target elements and compounds for analysis, establishing analytical detection limits, and ensuring that data are of suitable quantity and quality for use in baseline risk assessments. The risk assessment coordinator provides input and review for the project plan and a summary of risk-related information for the project data report.

\section{Field QA/QC Coordinator}

The field QA/QC coordinator is responsible for developing field QA/QC procedures related to BSPP sampling, analysis, and chain-of-custody requirements. Responsibilities of the field QA/QC coordinator include the following:

- Prepares the field sampling portions of the QA plan.

- Verifies that specified methods are appropriate for obtaining data of known quality, integrity, and validity and in accordance with standard operating procedures (SOPs).

- Conducts field surveillances of sampling methods to ensure that procedures adhere to chain-of-custody requirements.

- Reports quality-related issues to project management and maintains stop work authority.

- Prepares corrective action documentation and nonconformance reports and ensures that variance activities are initiated, completed, and documented appropriately. 
- Ensures that the data requirements specified in the field project plan activities are provided to trained samplers and other project staff.

- Provides QA liaison and oversight of the sampling crew, ensuring that the data generated satisfy the requirements of the field activities and SOW for laboratory services.

- Reports any variances and nonconformances in the field activities to the project manager and technical coordinator as soon as possible to allow for quick corrective action.

\section{QA Oversight Representative}

The $Q A$ oversight representative ensures the overall validity of $Q A$ aspects of the project and approves the analytical laboratory SOW. Specific duties include the following:

- Conducts initial oversight review.

- Reviews all nonconformance reports generated by project activities.

- Reviews the results of all surveillances and audits.

- Initiates a stop work order, if required, and approves stop work actions initiated by others.

- Reviews and approves the analytical laboratory SOW.

r

Vendors, Consultants, and Subcontractors

- Vendors, consultants, and subcontractors conduct assigned project activities in accordance with the requirements of the project plan.

\section{Project Personnel}

- Conduct assigned project activities in accordance with the requirements of the project plan.

- Take all reasonable precautions to prevent injury to themselves and their fellow employees; are alert to potentially harmful situations.

- Conduct radiation monitoring according to accepted procedures (BSPP-SOP-01, Rev. 1).

- Perform only those tasks that they believe they can do safely and immediately report any accidents and/or unsafe conditions to the technical coordinator.

- Notify the technical coordinator of any medical conditions (e.g., allergies, diabetes, and pregnancy) that require special consideration. Approval from the Health Division and/or a physician's recommendation may be required before an individual with a medical condition can be assigned a specific field task.

- Prevent spillage to the extent possible. In the event that a spill occurs, contain the liquid, if possible, and notify the technical coordinator.

- Use all of their senses to stay alert to potentially harmful situations.

- Practice good housekeeping by maintaining order, thereby reducing the likelihood of potentially harmful situations.

- Be familiar with the physical characteristics of sampling and the site.

- Report all injuries to the technical coordinator, no matter how minor.

It is anticipated that no hazardous wastes or environmental contaminants will be generated as a result of operations in this project. All refuse and conventional wastes will be disposed of according to approved PGDP practices. 


\section{PGDP Industrial Hygiene (HAZWOPER)}

The PGDP Industrial Hygiene Section is responsible for the oversight and approval of field investigative efforts related to industrial hygiene. In addition, the Industrial Hygiene representative has stop work authority and may be consulted regarding personal protective equipment, as well as industrial hygiene monitoring and sampling. The Industrial Hygiene representative also may be consulted to authorize a return to work after any site hazard has been resolved.

\section{PGDP Health Physics}

PGDP Health Physics is responsible for the oversight of field investigative efforts related to health physics. PGDP Health Physics approves all plans prior to mobilization and the commencement of field activities. In addition, Health Physics has stop work authority and may be consulted regarding personal protective equipment and health physics monitoring and sampling. Health Physics also may be consulted to authorize a return to work after any hazardous situation on site has been resolved.

\section{PGDP Industrial Safety}

The PGDP Industrial Safety Section is responsible for oversight of field investigative efforts relating to safety. The technical coordinator approves all plans prior to the mobilization and commencement of field activities, and Industrial Safety then reviews them and provides necessary input. Industrial Safety has stop work and continuation authority and may be consulted regarding safety-related issues relevant to personnel and equipment.

\subsubsection{Project Schedule}

Major project events and milestones for submission to DOE are presented in Table 1.3. The project schedule, organized by major project elements, is provided in Fig. 1.3.

Note that the schedule presented in Fig. 1.3 and the major events presented in Table 1.3 are generic, based on the most likely project funding scenario for FY 1996 available at the time of schedule preparation. The schedule is presented in this manner for purposes of individual task/element scoping. The actual project schedule will be developed and issued separate from this plan when project funding is approved and becomes available and the project is ready to move forward into the field. Note also that individual task/element durations in the schedule presented in Fig. 1.3 will remain valid and will be reflected in the actual project schedule to be issued later. 
Table 1.3. Major project events

\begin{tabular}{lc}
\hline \multicolumn{1}{c}{ Major Event } & Completion Date \\
\hline Complete BSPP draft project plan & $7 / 6 / 95$ \\
Deliver BSPP project plan for review & $9 / 29 / 95$ \\
Deliver revised project plan to DOE-PAD & $1 / 10 / 96$ \\
Project readiness review & $1 / 12 / 96$ \\
Initiate field activities & $1 / 15 / 96$ \\
Initiate analytical laboratory work & $1 / 29 / 96$ \\
Project status review & $2 / 21 / 96$ \\
Complete field activities & $3 / 29 / 96$ \\
Complete analytical laboratory work & $4 / 26 / 96$ \\
Project status review & $5 / 15 / 96$ \\
Transfer data to Paducah ER database & $8 / 14 / 96$ \\
Present data to Paducah ER, DOE, and regulators & $10 / 16 / 96$ \\
Complete draft data report & $10 / 31 / 96$ \\
Deliver BSPP data report to DOE-PAD & $2 / 12 / 97$ \\
\hline
\end{tabular}




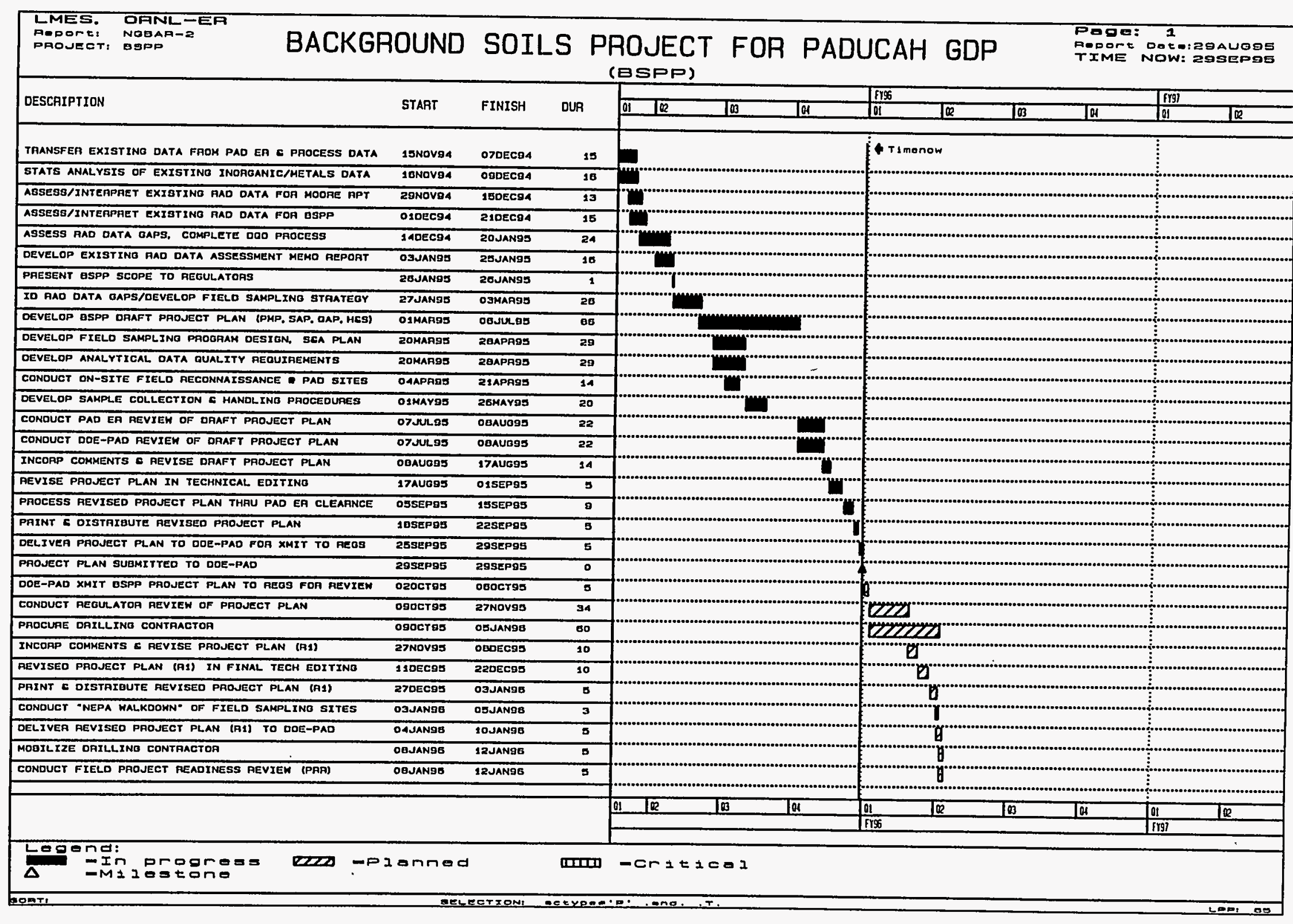

Fig. 1.3. Project schedule. Beginning October 2, 1995, the start of actual field work will be delayed one day for each day's delay of the release of FY 1996 funding. Similar delays will occur as a consequence of late receipt of reviewer comments. 


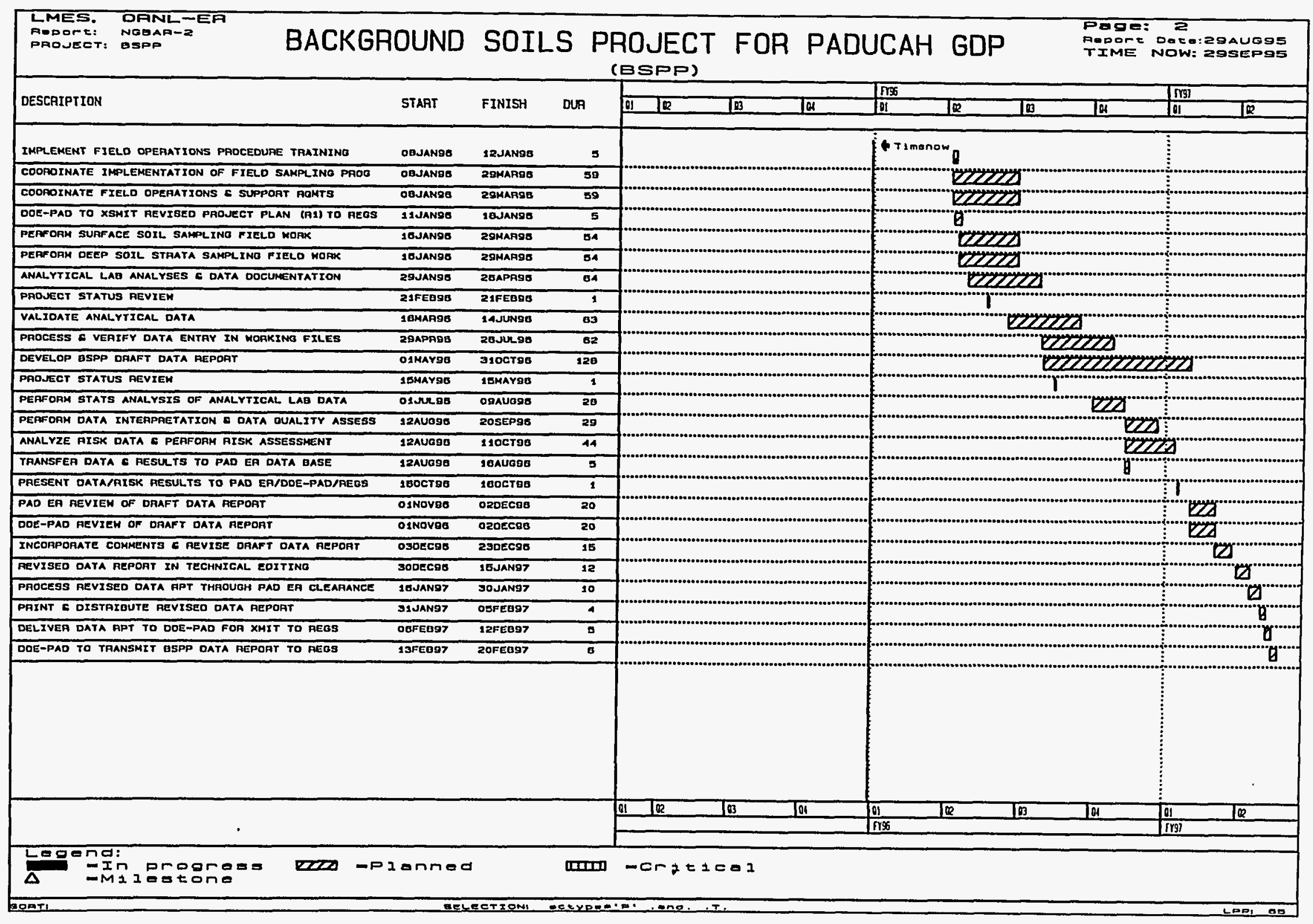

Fig. 1.3 (continued) 


\section{DATA QUALITY, PROJECT OBJECTIVES, AND APPROACH}

\subsection{DATA QUALITY OBJECTIVES}

In recent CERCLA-driven investigations, great emphasis has been placed on clearly identifying project objectives during project planning to collect the most useful data for decision making. The U.S. Environmental Protection Agency's (EPA's) Data Quality Objective (DQO) Process for Superfund (EPA 1993) places strong emphasis on identifying those conditions at a site that greatly affect the ability to make cost-effective remediation decisions. To provide a rigorous framework within which proposed sampling would fill critical data gaps, the EPA DQO method was used to develop the BSPP Sampling and Analysis Plan.

The following paragraphs present Steps 1 through 7 in the DQO process for the BSPP.

Step 1: Define the Problem

A sufficient, defensible, and verifiable database on background soil characteristics, particularly radionuclides, that are representative of the PGDP site does not exist to meet regulatory requirements. Some radionuclide data were obtained in past remedial investigation activities, but they were later found to be insufficient. Overall, possible contaminants of concern at PGDP include volatile organic compounds (VOCs) (e.g., trichloroethylene and derivatives), semivolatile organic compounds (SVOCs) (e.g., PCBs and derivatives), inorganics (arsenic, in particular, and other metals), and, especially, process-derived radionuclides (uranium and technetium) (CH2M Hill 1991). (Contaminants of interest to this investigation are described in Tables 5.1 and 5.2.)

Step 1.1 Purpose of the Project. The purpose of the BSPP is to obtain the necessary background data on the constituents in soils at Paducah to develop a sound, defensible background data set for PGDP. Background for purposes of this investigation is defined as the natural components in soils, as well as the components derived from sources not associated with PGDP activities.

\section{Step 2: Identify the Decision}

The decision to be made is whether the legally defensible and technically valid project database can distinguish between background and nonbackground. Background is defined by natural/geologic components that include certain metals and radionuclides and man-made components characterized by site conditions in existence prior to activities at PGDP or sources not associated with PGDP (e.g., atmospheric fallout and agricultural sources). Nonbackground includes man-made components and potential contaminants of concern attributable to activities at PGDP since the initial start of operations, such as technetium-99 $\left({ }^{99} \mathrm{Tc}\right)$ and uranium.

The decision will be based on the estimates of means and percentiles of the analyte background distributions. Focus will be placed particularly on upper percentiles of background distributions, which delineate the gray area where background ends and possible 
contamination begins. The estimates may take the form of confidence bounds (in addition to point estimates), which ensure that overestimation or underestimation is unlikely.

\section{Step 3: Identify Inputs to the Decision}

Inputs to the decision consist of background soil data (obtained under EPA analytical definition data) that have been sufficiently validated and verified as being representative of background soils on the Paducah Reservation and surrounding off-site areas as to meet regulatory requirements for a background soils database. Inputs to the decision include the following:

- location, depth, and areal extent of contamination;

- soil type;

- contaminant concentration;

- detection limits;

- analytes;

- historical data (and its defensibility).

Step 4: Define the Boundaries of the Study

If any radioactivity is above the natural background level during the site screening process, then that site will be rejected for actual sampling purposes.

Step 4.1 Analyte Selection and Detection Limits. Selection of appropriate analytes, analytical procedures, and detection limits will proceed according to specifics identified in the quality assurance project plan of the RCRA Field Investigation Work Plan for Waste Area Groupings 1 and 7 at PGDP (DOE 1995). The Work Plan for Waste Area Groupings 1 and 7 was selected because this is the work plan first approved by the regulators and the one that serves as the model to follow in developing subsequent RI work plans at Paducah.

Technical constraints of the project include the following:

- presence of radiological contamination above background or presence of VOCs in sampling areas;

- possible lack of continuity of soil series and soil horizons/strata;

- local property access limitations;

- evidence of previous local land use or disturbance;

- existence of suitable deep strata core material and adequate data obtained from existing deep soil cores;

- $\quad$ existence of previous background values (see Appendix A);

- difficulties in identifying threshold levels to distinguish between contaminated and uncontaminated sampling sites;

- low detection limits required for background data; and

- chemical analyses of background samples, which must conform to PGDP RCRA Field Investigation requirements in order to be comparable to existing data and meet project DQO requirements. 
Time constraints consist of the following:

- Sampling needs to be conducted under low flow or semidry conditions and in topographically high groundwater recharge areas.

Funding constraints dictate that it is important to obtain the maximum amount of useful data for the minimum cost.

\section{Step 5: Develop a Decision Rule}

A decision rule is needed to distinguish with statistical confidence between background and site contamination in performing assessments of contaminated field sites. Stated in an if/then form, the Decision Rule is as follows: If the legally defensible and technically valid project database can distinguish with confidence between the two categories of soil components identified in Step 2, then background has indeed been estimated, and the data are representative of the PGDP Reservation. The specific steps to be traced in conducting this process are represented in the flow diagrams in Figs. 2.1 and 2.2.

Applying the decision rule will rely on standard statistical estimators and confidence bounds for means and percentiles of background data. This includes tolerance bounds, which are confidence bounds for distribution percentiles (see Sect. 8). It would not be possible at project outset to anticipate all possible soil environments and sampling conditions to be encountered in assessing contaminated sites. What has been attempted in scoping this project is to anticipate the most likely data needs and potential applications in developing the project DQOs and the sampling and analysis plan for this project.

\section{Step 6: Specify Acceptable Limits on Decision Errors}

Among the many estimates and confidence bounds that will make up the decision will be $90 \%$ lower confidence bounds (i.e., tolerance bounds) for 90th percentiles (Fig. 8.1). Each of these confidence bounds should exceed one-half of the corresponding (true) 90th percentile with probability 0.90 or more (see Sect. 8 for rationale).

\section{Step 7: Optimize the Design}

Composited simple random samples will be collected within areas defined by soil types and political boundaries. The level of compositing (i.e., the number of composites per sample sent to the laboratory) will be based on prior experience with background sampling in Oak Ridge (DOE 1993). Because there are few preliminary PGDP background data for the analytes of interest in this study, it is not feasible to reckon necessary sample sizes for most analytes. Therefore, attention will be focused on uranium to ensure that a necessary sample size is met, at least for uranium. Sample size determination is discussed further in Sect. 8 and in the sampling site selection plan in Sect. 4. 


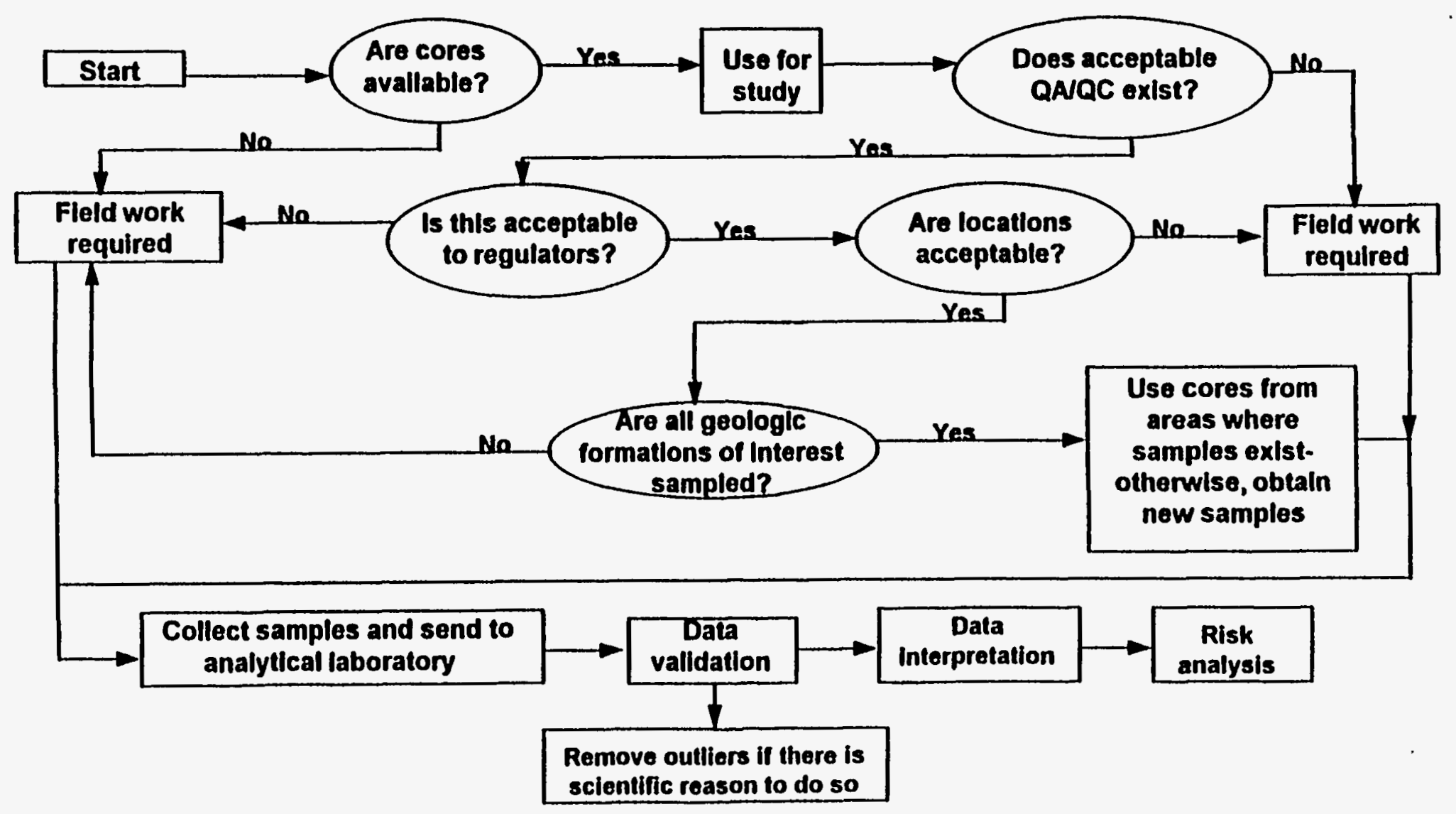

Fig. 21. Step 5: Development of a decision rule, deep strata sampling. 


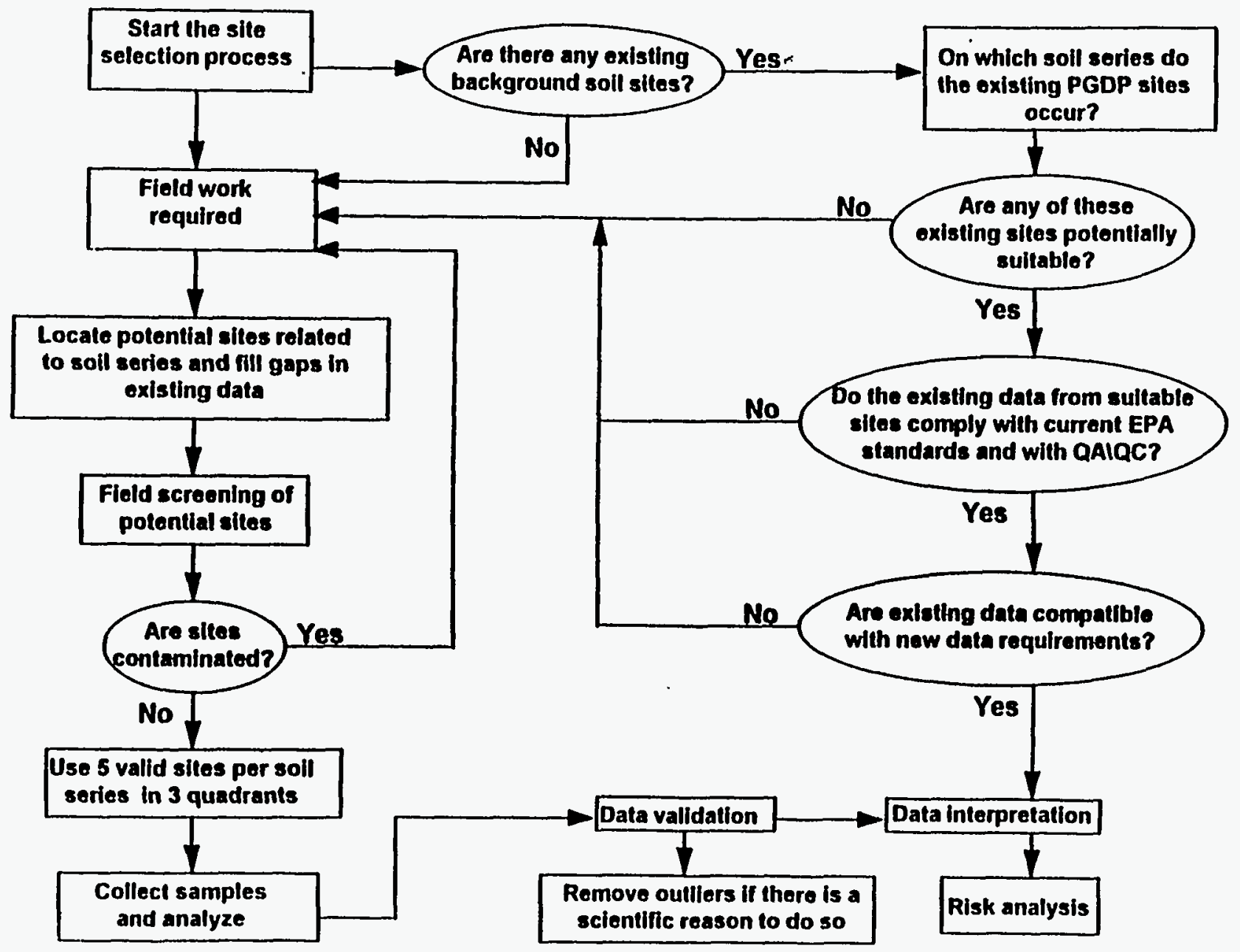

Fig. 2.2. Step 5: Development of a decision rule, surface soil sampling- 


\section{PROJECT OBJECTIVES}

The objectives of the BSPP are to

- determine the background concentration levels of selected inorganics/metals and radionuclides in undisturbed soils and provide the database for determining cleanup levels of contaminants,

- provide validated and defensible baseline data for contaminated site assessment, and

- provide the data needed to evaluate risk from constituents in background soils for comparison with risks from contaminated sites.

\subsection{GENERAL APPROACH}

The following technical approach will be taken to achieve these objectives:

- Identification and selection of the most important Quaternary deposits underlying potentially contaminated sites at PGDP.

- Identification and selection of a residuum soil corresponding to each Quaternary deposit and selected formation.

- Statistically random selection of uncontaminated surface soil sampling sites in the northeastern part of Ballard County from the uppermost Quaternary loess deposits.

- Sampling from two deep drilling boreholes representing deep Quaternary strata, with subsequent analysis by gamma spectroscopy.

- Chemical and radiological analyses by designated contract laboratories. Gamma spectroscopy will be performed at the Low-Level Radionuclide Analysis Laboratory of the Environmental Sciences Division (ESD) at Oak Ridge National Laboratory (ORNL), and neutron activation analysis will be performed by the analytical laboratory.

- Data processing and validation.

- Statistical analysis.

- Risk analysis.

- Data transfer to EIMS, the Paducah Environmental Information Management System database.

- Data report preparation, review, and production.

The BSPP will be coordinated with environmental monitoring and remedial action programs now being conducted at PGDP in compliance with the provisions of CERCLA, RCRA, the National Environmental Policy Act (as mandated by DOE), and regulations and requirements of the Commonwealth of Kentucky Department of Environmental Protection.

The general approach proposed in this plan was developed from the approach successfully implemented on the Oak Ridge Reservation Background Soil Characterization Project (BSCP) (DOE 1993a). 


\section{ENVIRONMENTAL SETTING}

The following sections are taken from the Management Strategy for Surface Water Integrator Units at PGDP (DOE 1993b) and are presented here to give an overview of characteristics found near PGDP.

\subsection{GEOGRAPHY AND TOPOGRAPHY}

PGDP lies in the Jackson Purchase Region of western Kentucky, an area characterized by low relief. Elevation ranges from about $90 \mathrm{~m}(300 \mathrm{ft})$ above mean sea level (MSL) along the Ohio River north of the plant to more than $135 \mathrm{~m}(450 \mathrm{ft})$ above MSL south of the plant. Topography at the plant site is relatively flat, with elevations ranging from 105 to $114 \mathrm{~m}$ (350 to $380 \mathrm{ft})$ MSL. The topography slopes approximately $5.0 \mathrm{~m} / \mathrm{km}(27 \mathrm{ft} / \mathrm{mile})$ toward the Ohio River (CH2M Hill 1991).

\subsection{GEOLOGY}

PGDP lies within the northern tip of the Mississippi Embayment portion of the Gulf Coastal Plain Province. The Mississippi Embayment was a large sedimentary trough oriented nearly north-south, which existed during Cretaceous and Tertiary time. This trough received sediments that were transported from the central part of the North American Continent. The stratigraphic sequence in the region and at the site consists of Cretaceous, Tertiary, and Quaternary sediments unconformably overlying Paleozoic bedrock (Fig. 3.1). The sedimentary sequence in the vicinity of PGDP consists mainly of fine- to medium-grained clastic materials, including (from oldest to youngest) a basal gravel (Tuscaloosa Formation), the McNairy Formation, the Porters Creek Clay, and the undifferentiated, discontinuous Eocene sands. These strata dip gently to the southwest toward the axis of the Embayment (Fig. 3.2). Following deposition, uplift occurred and an erosional surface developed that truncated the Embayment sediments. Subsequently, during the late Tertiary and the Quaternary, continental deposits were laid down in the region, and an angular unconformity resulted from the deposition of upper continental deposits on the underlying sediments. Immediately overlying the continental deposits, late Quaternary Pleistocene loess was deposited in a layer of variable thickness (Energy Systems 1989). This late Quaternary land surface has been altered by headway cutting and widening of the stream floodplain. Reworked loess occupies the narrow to quite wide terraces and floodplains. In places, gravel from the underlying continental deposits are mixed in with the reworked loess (alluvium).

The continental deposits can be subdivided into two components: a lower gravel or sandy gravel unit (gravel facies) that is reported to vary in thickness from 0 to $32 \mathrm{~m}(0$ to $105 \mathrm{ft}$ ) and an upper clay-sand unit (clay facies) with a comparable range in thickness (Fig. 3.1). The top of the gravel facies unit occurs at a depth of approximately 13 to $20 \mathrm{~m}$ (43 to $66 \mathrm{ft}$ ) in the vicinity of PGDP. The clay facies of the continental deposits are believed to consist of discontinuous, fine sand lenses enclosed by the dominant clay. Although this interpretation is based on limited data, the lack of continuity of the interbedded sands supports this conclusion (Energy Systems 1989). 


\begin{tabular}{|c|c|c|c|c|}
\hline SYSTEM & SERIES & FORMATION & $\begin{array}{c}\text { THICKNESS } \\
\text { (UNEEET }\end{array}$ & DESCRIPTION \\
\hline \multirow{3}{*}{$\sum_{\frac{1}{\alpha}}^{2}$} & $\begin{array}{l}\text { PLEISTOCENE } \\
\text { AND RECENT }\end{array}$ & ALLUVIUM & $0-40$ & $\begin{array}{l}\text { Brown or gray and and } \\
\text { silty clay or chayoy silt with } \\
\text { strakks of and. }\end{array}$ \\
\hline & PLEISTOCENE & LOE & $0-43$ & $\begin{array}{l}\text { Brown or yollowtahbrown to } \\
\text { tan to gray unstratfied silty ciay. }\end{array}$ \\
\hline & PLEISTOCENE & \multirow{2}{*}{$\begin{array}{l}\text { CONTINENTAL } \\
\text { DEPOSITS }\end{array}$} & \multirow{2}{*}{$3-121$} & $\begin{array}{l}\text { Clay Faeles - orange to yollowish } \\
\text { brown to brown clayoy all, some } \\
\text { very fine sand, trace of fino sand } \\
\text { to grewel. Otten micaceous. }\end{array}$ \\
\hline \multirow{4}{*}{$\underset{⿱ 亠 䒑}{\alpha}$} & $\begin{array}{l}\text { PLIOCENE- } \\
\text { MIOCNE (?) }\end{array}$ & & & $\begin{array}{l}\text { Gravel Facies - reddlsh-brown } \\
\text { sllty and sandy chart gravel and } \\
\text { beds of gray sandy gravel, allt, } \\
\text { and clay. }\end{array}$ \\
\hline & \multirow[b]{2}{*}{ EOCENE } & \multirow{2}{*}{$\begin{array}{l}\text { JACKSON, } \\
\text { CLAIBORNE, } \\
\text { AND } \\
\text { WILCOX } \\
\text { FORMATIONS }\end{array}$} & $0-200+$ & $\begin{array}{l}\text { Red, brown, or while fine to coares } \\
\text { grained eand. Beds of whito to } \\
\text { dark gray clay are distributed } \\
\text { at random. }\end{array}$ \\
\hline & & & $0-100+$ & $\begin{array}{l}\text { White to gray sandy clay, elay } \\
\text { conglomerated and bouldere, } \\
\text { scattered clay leneas and lenses of } \\
\text { coarse red sand. Black to dark } \\
\text { gray lignitle clay, ellt or fine } \\
\text { gralned sand. }\end{array}$ \\
\hline & PALEOCENE & $\begin{array}{l}\text { PORTERS } \\
\text { CREEK } \\
\text { CLAY } \\
\end{array}$ & $?$ & $\begin{array}{l}\text { Dark gray, sllghtly to very } \\
\text { micaceous clay. Fine grained clayoy } \\
\text { sand, commonily glauconilte in the } \\
\text { upper part, Glauconitle sand and } \\
\text { clay at the baso. }\end{array}$ \\
\hline \multirow{2}{*}{\multicolumn{2}{|c|}{ CRETACEOUS }} & $\begin{array}{l}\text { CLAYTON } \\
\text { FORMATION } \\
\text { MENAIRY } \\
\text { FORMATION }\end{array}$ & $200-300$ & $\begin{array}{l}\text { Wthologleally similar to underiyling } \\
\text { MeNalry formation. } \\
\text { Graylsh-white to dark gray } \\
\text { mleaceous clay, often } \\
\text { silty, Interbedded with llght gray to } \\
\text { yollowish-brown very tino to } \\
\text { medlum gralned sand. The upper } \\
\text { part is mostly clay; the lower part } \\
\text { is predominantly micaceous fine eand. }\end{array}$ \\
\hline & & $\begin{array}{c}\text { TUSCALOOSA } \\
\text { FORMATION }\end{array}$ & $?$ & $\begin{array}{l}\text { Whith, well rounded or broken } \\
\text { chart gravel with elay. }\end{array}$ \\
\hline \multicolumn{2}{|c|}{ MISSISSIPPIAN } & $\begin{array}{l}\text { MISSISSIPPIAN } \\
\text { CARBONATES }\end{array}$ & $500+$ & $\begin{array}{l}\text { Dark gray limestone and } \\
\text { interbodded chart, some ahale. }\end{array}$ \\
\hline
\end{tabular}

Fig. 3.1. Columnar section of the Jackson Purchase Region. Source: Taken from Clausen et al. (1992). 


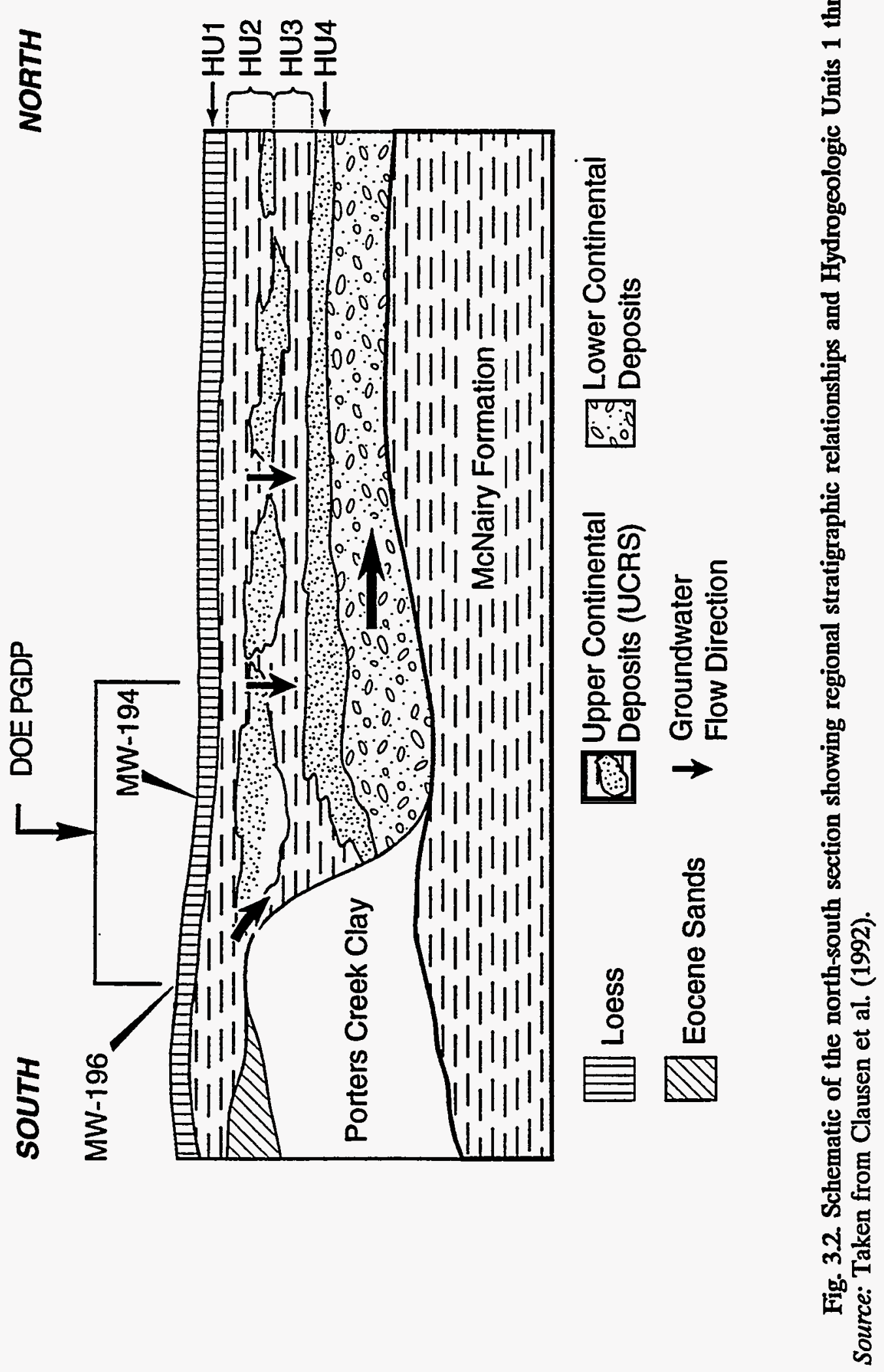




\subsection{SOILS}

The characteristics of the soil at any given point depend largely on landscape position (relief), physical and chemical composition of parent material, and time. Other soil forming factors such as climate and vegetation were fairly uniform and unimportant in accounting for differences among soils in McCracken and Ballard counties (SCS 1976). The plant and surrounding areas are a plain that slopes gently to the north. The plain is modified by a dendritic drainage system into three relief subdivisions: fairly smooth uplands, fairly rough uplands, and valleys. The uplands of the area are covered with a moderately thick mantle of loess. Underlaying the loess are unconsolidated Coastal Plain deposits left by a northern extension of the Gulf of Mexico in Quaternary, Tertiary, and Cretaceous times.

Dominant soils at the PGDP area, a northwestern part of McCracken County, belong to the Calloway-Henry association. This association consists of nearly level, somewhat poorly drained, and medium-textured soils on uplands (SCS 1976). Elevation ranges mainly from 360 to $380 \mathrm{ft}$, and a few natural drainageways dissect the association (Fig. 3.3). The association extends through a large, continuous area in the northeastern part of Ballard County.

In this soil association, the Calloway and Henry series are on uplands and make up about $67 \%$ of the association. Minor soils of this association are Grenada, Falaya, Collins, Waverly, Vicksburg, Loring, and Brandon soil series. The Grenada, Loring and Brandon soils are on uplands near branches and creeks. The Vicksburg, Falaya, Collins, and Waverly soils are on the floodplains that consist of alluvium and colluvium parent material derived from upland loess soils. The difference in the basic process of soil genesis greatly affects the appearance and properties of soil profiles depending on whether a soil formed under oxidizing conditions or under reducing conditions or in an environment with fluctuating redox conditions. Some specific properties that change with time as soil genesis proceeds, even beginning with the same parent material, are base saturation, metal accumulation, and fragipan development.

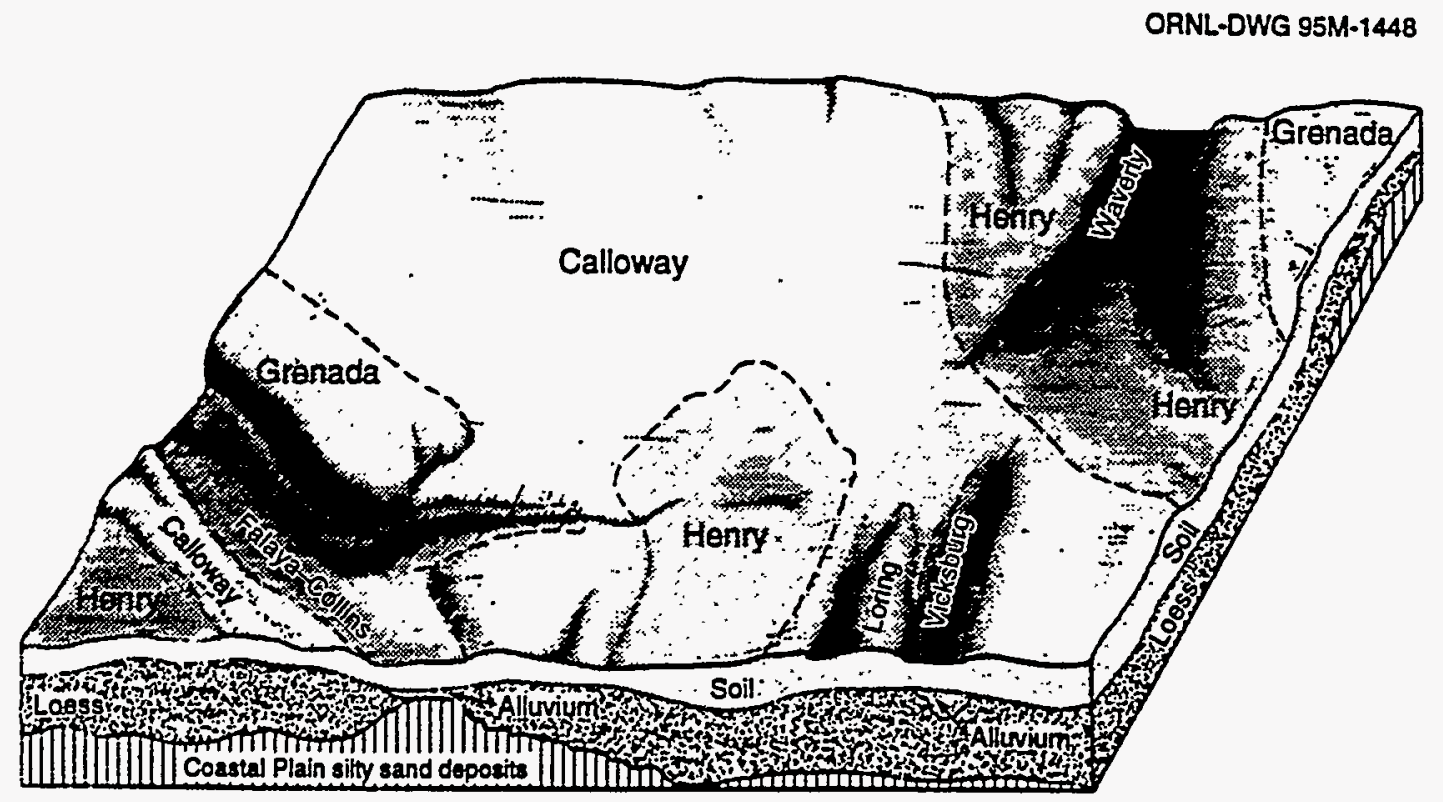

Fig. 3.3. Typical pattern of soils and underlying material in Calloway-Henry association. Source: SCS (1976). 


\subsection{HYDROGEOLOGY AND CLIMATE}

The climate of the region is humid-continental and characterized by wide extremes of both temperature and precipitation. Summers are generally dry; precipitation occurs mainly during the spring and fall. Winters are characterized by moderately cold days; the average temperature during the coldest month, January, is about $1.7^{\circ} \mathrm{C}\left(35^{\circ} \mathrm{F}\right)$. Summers are warm and humid; the average temperature during the warmest month, July, is about $29^{\circ} \mathrm{C}\left(79^{\circ} \mathrm{F}\right)$. The average monthly precipitation is $10.6 \mathrm{~cm}$ (4.2 in.) and ranges from an average of $7.6 \mathrm{~cm}$ (3.0 in.) in January to an average of $13.1 \mathrm{~cm}$ (5.2 in.) in April (CH2M Hill 1991). From March to July and during November and December, the weather is somewhat drier than average. Less than $2 \%$ of the annual precipitation is snow. Yearly precipitation averages about $112 \mathrm{~cm}$ (44 in.).

The prevailing wind direction is from the south to southwest, and the average wind speed is $15.8 \mathrm{~km} / \mathrm{h}(9.8 \mathrm{mph})$. Stronger winds are generally observed from the southwest or northwest (Energy Systems 1990a). The prevailing wind direction dictated the selection of the surface soil sampling area-that is, the west side of the potential sources (PGDP and TVA). From June through October, precipitation either dissipates through evapotranspiration or replenishes the depleted soil moisture. During this time, excess water probably does not occur. From November to May, there is excess water available for surface runoff to streams or infiltration to the water table; average AFIRO (available for infiltration and runoff) is $53.4 \mathrm{~cm}$ (21.0 in.) (CH2M Hill 1991). 


\section{SAMPLING SITE SELECTION}

\subsection{SAMPLING SITE SELECTION APPROACH}

The complexity of the geological and hydrological setting of PGDP and surrounding areas requires that care be taken in establishing locations for the background soil sampling sites. Therefore, the location and number of reference soils and deep drill soil core samples have been determined by considering soil classification, parent material, bedrock formation, geomorphology, hydrology, sediment stratigraphy, and land use history of the sites. The following describes the approaches to be taken in a stepwise manner after consultation with site RI/FS investigators and statisticians to avoid contaminated areas and to collect representative samples. Furthermore, candidate sampling sites, to be discussed below, will be screened according to criteria in Sect. 5.2.1 to eliminate potentially contaminated sites from the background database.

\subsubsection{Surface Soil Sampling Locations Selection}

The approach for the selection of background soil sampling sites is to use sites outside PGDP. The selection of off-site sampling locations in northeastern Ballard County is discussed in this section (Fig. 4.1). The area has the same soil series developed from the same Quaternary deposits as found at PGDP. Subsequent analyses are expected to confirm that such distances are sufficient to avoid any contamination caused by plant operations.

Candidate surface soil sampling sites within each soil association series will be selected using statistical methods to minimize sampling bias. Each candidate site will then be field checked by the technical coordinator and the sampling personnel to ensure that the site is suitable and accessible. Sampling sites will be subjected to a field check for man-made radionuclide contaminants and organics using protocols outlined in the Soil Sampling and Analysis Plan before sampling begins. After reviewing soil survey information at and around the PGDP area (SCS 1976), the characterization team selected two sets of upland soils (Calloway/Grenada and Henry series) and one set of stream terrace soils (Falaya-WaverlyVicksburg association). The two landscape positions were selected based on differences in soil chemistry and clay sorting processes that will yield different elemental concentrations. The offsite location for surface soils is located in Ballard County (Fig. 4.1). Surface soil sample sites are within this geographic area. General soil descriptions of the selected soils follow.

\section{Calloway and Grenada Series (Upper Quaternary Loess Deposits)}

Grenada soils are quite widespread around the PGDP. These soils are moderately welldrained to somewhat poorly drained and occupy narrow interfluves. Grenada soils have a restrictive layer (fragipan) at a depth generally less than $60 \mathrm{~cm}$, unless erosion has stripped off some of the surface material. Calloway soils are closely associated to Grenada soils but are more poorly drained (i.e., somewhat poorly to poorly drained). Calloway soils occur on broader interfluves and are usually less eroded than Grenada soils. Calloway soils also have a fragipan, beginning at a depth of 60 to $75 \mathrm{~cm}$. The fragipan in both soils perches water and causes a redistribution of iron and manganese. Both soils contain abundant manganese, usually enough to rapidly degrade $30 \%$ hydrogen peroxide. Manganese is finely disseminated 


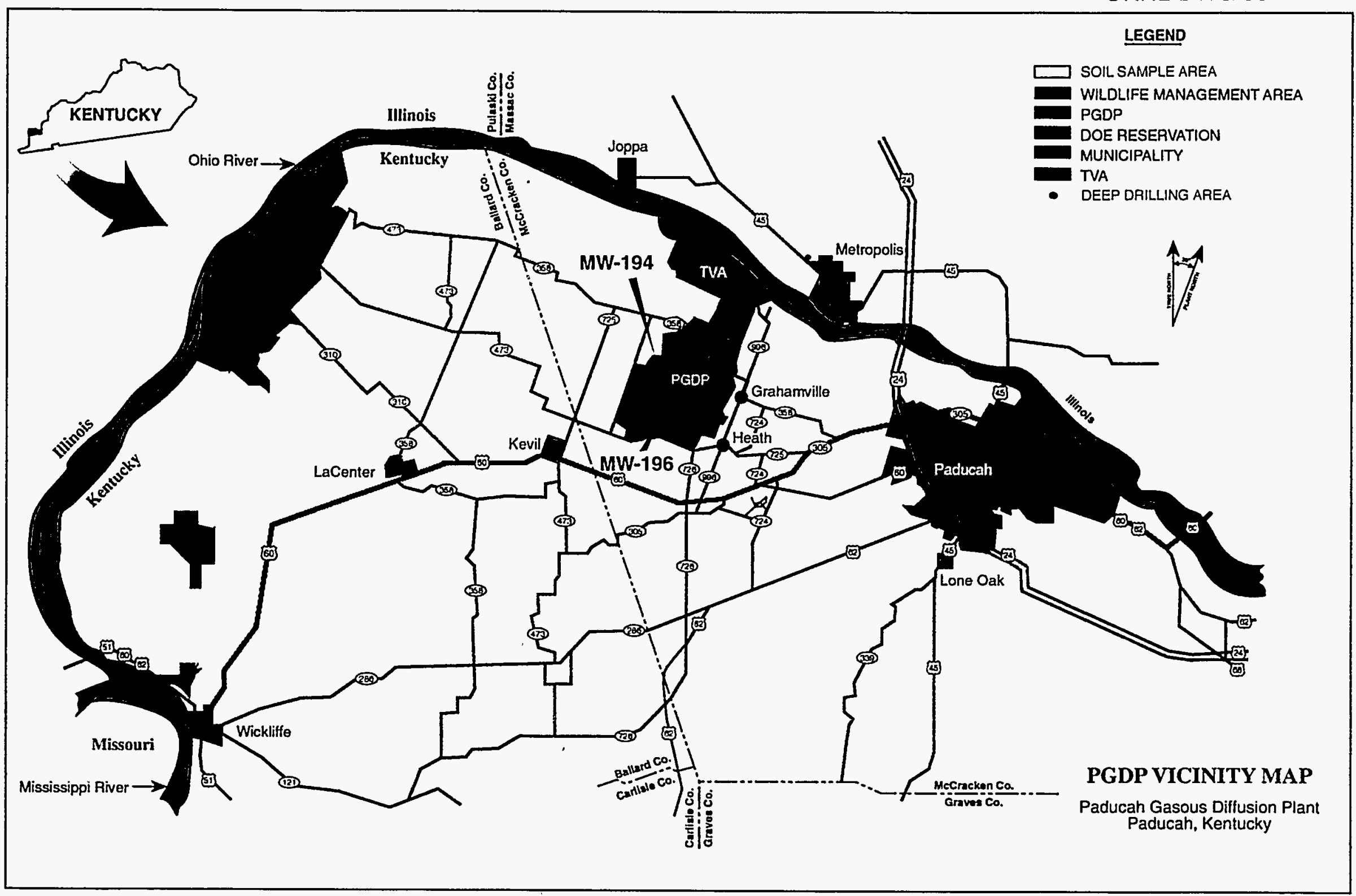

Fig. 4.1. Vicinity map around the PGDP showing soil sampling area and drill sites. 
throughout the layers above the fragipan. Within the fragipan, differential water flow plus variable redox potential have resulted in the formation of usually soft manganese nodules. Below the fragipan, water flow pathways are easily seen by the near vertical gray zones along the faces of cracks or peds. Soil chemistry is driven more by manganese than by iron in these soils.

\section{Henry Soil Series (Upper Quaternary Loess Deposits)}

Soils classified as Henry soils are widespread in and immediately adjacent to PGDP. Henry soils are poorly to very poorly drained; in fact, some areas of Henry soils will meet the Corps of Engineers requirements for wetlands. Henry soils, if there is a net downward flow of rain, are usually highly depleted in manganese, except for hard nodules. When the water table rises during wet periods, these soils will have very abundant manganese stains or coatings near the surface and the gray subsoil below may have bright red iron coatings along root channels or on surfaces of cracks or peds. Henry soils should have a fragipan; however, it may have degraded to the extent that it is commonly no longer recognized as a fragipan. A higher clay content subsoil horizon (Bt) may perch water in some Henry soils. The poorly drained conditions associated with Henry soils may occur by three mechanisms: (1) runoff from higher areas that keeps the soil saturated, (2) upwelling of ground water, and (3) perching of water above water-restrictive layers.

Henry soils will be sampled only in wooded areas and will represent undisturbed background. Twelve sites will be sampled, with samples from each site collected from the surface $A$ horizon and the subsoil $B$ horizon. The problem with the potential sampling area in Ballard County is the general lack of enough wooded Henry sites. It may be necessary to go east into McCracken County (sheet 8 of the Soil Survey Report) to obtain enough Henry soil sites.

\section{Falaya-Vicksburg-Waverly Association (Holocene-Modern Alluvium)}

Stream terrace soils classified in the Falaya, Vicksburg, and Waverly soil series have formed in water-reworked loess that has eroded from uplands and transported and deposited onto stream terraces. Because of water sorting, the loess is very silty and has a very low clay content. All of these soils are commonly finely stratified to the surface unless the surface has been disturbed by plowing. The upper 30 to $90 \mathrm{~cm}$ of these soils is considered to be modern sediments. These sediments are defined as being the same age or younger than the time of forest clearing for agriculture. Falaya soils are somewhat poorly drained, Vicksburg soils are well drained, and Waverly soils are poorly to very poorly drained. Most of these soils become saturated from an upwelling of groundwater. As a result, manganese commonly occurs in the topsoil and upper subsoil. In Falaya soils, it is not uncommon to have bright red iron root channel coatings in the subsoil that is otherwise mostly gray. Some of the areas associated with Waverly soils will meet the Corps of Engineers requirements for wetlands. Most areas of Waverly soils are wet and remain saturated from upwelling groundwater. Consequently, there is often a very high manganese content in the topsoil, while the gray subsoil beneath indicates that iron was reduced and leached from the soil profile. 


\subsubsection{Deep Strata Sampling Locations Selection}

Deep drill soil core samples will be obtained by drilling near two existing wells, MW 194 and 196, south and west of PGDP (Fig. 4.1). Considerations are given to surface and subsurface water flow systems and sediment stratigraphy.

1. Surface and subsurface water flow. Deep drilling will be done at surface elevations higher than PGDP to ensure that subsurface contaminant plumes have not migrated into any sampling site. In addition, drill sites will be located on interfluves between uncontaminated drainageways so that rainfall infiltrates into the soil and any overland flow are directed from the site. Both the Porters Creek Clay and the McNairy formations dip to the south, so there is a slight potential that subsurface water from beneath PGDP may flow southward. However, the basal gravels in the old river channel seem to direct subsurface water flow to the east and north away from potential drill locations. If sites are situated too far south, Eocene sands, which are not generally encountered in close proximity to PGDP, cover the Porters Creek Clay. However, paleo land surfaces were not uniform and it is likely that there are sporadic remnants of Eocene sands near the plant, probably as reworked gully fills. The Porters Creek Clay occurs on the terrace slope beneath the plant, and drill locations will be sited to reach this formation on or above the terrace slope.

2. Geologic considerations. Subsurface water flow dictates that areas south and west of PGDP will be the primary area for drill locations. Drill locations will most likely be within wildlife refuge areas that will allow better access. Potential drill locations will also be near existing wells because existing information from these wells can be used to (1) predict depths at which different strata should be encountered, and (2) provide additional data concerning shorter scale variability (i.e., 300 to $500 \mathrm{ft}$ ). If drill locations were farther from the plant, subsurface geology may change, and it may be more difficult to present a case that the data are representative.

Each drilling location is within the Big Bayou drainage basin. The south drill location is on the edge of the uplands just west of the main Big Bayou channel. The west drill location is between two drainageways that discharge into Big Bayou Creek. Potential drilling sites at each location will encompass access into an area that will have approximate dimensions of 100 by $100 \mathrm{ft}$. All potential drilling sites at each location are on slightly eroded narrow interfluves or on broader upland flat interfluves.

Each drilling location will have two sites. The potential drilling locations using the PGDP coordinate system are (1) south drill location (near MW 196) site S1 (A): $N-7500$, E -8000 and site S2 (B): N -7800, E -7800; and (2) west drill location (near MW 194) site W1 (A): N -1000, E -11000 and site W2 (B): N -1500, E -11500. Each site will be 300 to $500 \mathrm{ft}$ away from the other, and no drill site will be closer than $100 \mathrm{ft}$ to any road. Each drill site will be located on a landform that exhibits minimal erosion so that a complete loess thickness can be obtained.

Several hydrogeologic units (HUs) have been identified for PGDP (Clausen et al. 1992) (see Fig. 3.2). Some of these units will be sampled for this background project. 
HU1: This unit encompasses the Late Pleistocene loess that blankets the site. The soils in this loess unit contribute to the rapid development of mostly vertical water flow pathways close to the soil surface. Most of the upland soils have a fragipan or restrictive layer that has its upper boundary within 24 to 30 in. of the surface in minimally eroded areas and within 6 to 12 in. in eroded areas. This pan perches water resulting in lateral water flow during wet periods. The pan is composed of polygons ranging in cross-section width from about 3 in. to 12 in. These polygons may extend through the entire thickness of the loess section. Water flow is vertical along the edges of polygons. Water flow pathways are easily identified by the presence of gray, low-clay-content silt between polygons. Clay polygons result in another perched zone at the contact of the loess with the next lower HU. Deep drilling for background analysis will sample the lower part of Unit HU1.

HU2: This unit consists of discrete sand and gravel bodies within a fine-grained matrix identified as the upper continental alluvial deposit. Deep drilling will sample both the sand and gravel bodies and the fine-grained silt and clay materials of this HU.

HU3: Depending on the drill site location, this unit may be encountered. However, because of the drill site locations, this unit and the underlying units HU4 and HU5 should not be encountered as the drill sites are located on the terrace rise (west drill site) or above the terrace rise (south drill site). All four of the background drill sites should encounter the Porters Creek Clay after penetrating the Upper Continental Deposit.

Porters Creek Clay: The uppermost part of this unit will be sampled for background.

\subsection{SURFACE SOIL SAMPLING LOCATION, DETERMMNATION, AND IDENTIFICATION/DESIGNATIONS}

\subsubsection{Conceptual Framework and Rationale}

At meetings with PGDP and ORNL personnel, a thorough discussion of sampling requirements resulted in the following conceptual sampling plan rationale:

1. Only the Ballard County area west of PGDP will be considered as the sampling area.

2. The Ballard County Soil Survey soil maps will serve as the basis for initially locating potential sites within a designated area.

3. Field identification of soils at each potential site will be made using current soil series concepts as defined by the Natural Resources Conservation Service. If the map unit delineation at a potential site does not have the named soils, that site will be rejected. The reason for sampling by soil series is that a considerable knowledge of soil properties already exists and better-drained soils have different soil chemistries than poorly drained soils. For example, the following elements are expected to deplete in Henry soils relative to Grenada soils: $\mathrm{As}, \mathrm{Be}, \mathrm{Co}, \mathrm{Pb}, \mathrm{Mn}, \mathrm{Ni}$, and $\mathrm{Zn}$. It is expected that the Calloway soils will have properties intermediate between Henry and Grenada. Similar differences for some elements should be expressed between the poorly drained Waverly and the better- 
drained stream terrace soils. We do not know at this time whether radionuclides will have a similar distribution due to uncertainties in the redox potential and where manganese dominates the soil chemistry.

4. A randomizing method will be used, as much as possible, for locating soil delineations on the soils map used to evaluate each site for potential suitability (Appendix B). Because soils do not occur in a random manner, it is not possible to locate all potential sampling sites through the random generation of grid cells. All Grenada/Calloway and Falaya and Vicksburg sites will be generated by the use of randomization. The Henry and Waverly sites, because of nonrandom distribution and small areas, will probably not be located by complete randomizing.

5. Because of differential land use in Ballard County, a subset of background sampling sites will be located for evaluating disturbed background sites (DBGS) versus undisturbed background sites (UBGS). DBGS will be confined to open fields, set aside fields, or Conservation Reserve acreage. UBGS will represent the regional background. These sites will have no evidence of any type of disturbance, including recent forest fire, no recent hardwood logging, and no evidence of any recent accelerated erosion or modern deposition that would affect surface soil background values.

6. No potential DBGS will be closer than $300 \mathrm{ft}$ from another site. Most potential sites will be more than $1000 \mathrm{ft}$ apart.

7. No potential DBGS will be located north or east of PGDP because of prevailing wind directions.

\subsubsection{Preparation for Potential Site Selection and a Randomizing Procedure for Potential Site Selection}

Ballard County soil survey sheets 3, 7, and 13 were taped together, and a 1000-ft grid was drawn. Each grid cell was given an $x$ and $y$ coordinate designation. Numbers corresponding to the north axis and numbers corresponding to the east axis were drawn at random. Each randomly identified grid cell was reviewed for its soil series composition. If that cell contained one or more desired soil series, small colored disks corresponding to a particular soil series were placed within the cell. This randomizing procedure was followed until it proved unable to randomly locate grid cells where certain soils of small extent were located. This nonrandom spatial distribution of soils eventually required that particular cells be checked for soil sites that were still needed. Additional potential sites, selected in this manner, were located to provide a more uniform coverage west of PGDP and to ensure that each major drainage basin had at least one potential site.

\subsection{Field Site Selection Conditions}

\section{Undisturbed Background Sites, Henry Soil Series}

Conditions required for field site selection follow.

1. The sites will have native hardwood forest vegetation with trees at least $\mathbf{3 0}$ to 50 years old. 
2. There will be no recent land-disturbing activity, including forest fire.

3. The site will be geomorphically stable, without evidence of any accelerated erosion or modern deposition.

4. The soil series within the previously identified delineation must be representative of the named soil series. If several soil observations at a potential site do not correspond to the named soil for that map unit delineation, then the site will be rejected.

5. If a potential site meets the vegetation, soil, and stability requirements, an area of approximately $100 \mathrm{ft}^{2}$ will be flagged at the four corners and a site-numbered wooden stake will be driven inside the plot. The route back to the closest point of road access will also be flagged. Trees will be spray painted at the site and also at the trail head. A suitable large tree at the trail head will be spray painted with the site number.

6. More than half of the UBGSs will be randomly generated.

\section{Disturbed Background Sites, All Other Soil Series}

Conditions required for field site selection follow.

1. Sites will be located within open fields. The soils must be representative of the named soil for that delineation, soil erosion must not be severe enough to remove all of the soil surface layer, and the fragipan cannot be located immediately beneath the plow layer.

2. If a potential local background site meets the soil and stability requirements, an area of approximately $100 \mathrm{ft}^{2}$ will be flagged and a site-numbered wooden stake driven into the ground. The route back to the closest point of road access will then be flagged.

If a larger number of suitable sites is selected than that required, then the exact number of suitable sampling sites for each soil series will be determined by a random number process. This will be done by the sampling team before soil sampling begins. 


\section{SAMPLING AND ANALYSIS PLAN}

\subsection{OBJECTIVE}

The objectives of the Soil Sampling and Analysis Plan are to (1) provide the framework or basis for developing the quality assurance objectives and (2) present comprehensive soil sampling requirements, procedures, and analytical methodology. After selecting the sampling sites, background soil sampling will begin. The samples will then be sent to the designated sample preparation and analytical laboratories for comprehensive analyses.

\subsection{QUALITY ASSURANCE OBJECTIVES}

Because the project plan emphasizes PGDP background soil characterization, data quality must be technically complete, comprehensive, and defensible. The intended uses of the data derived from the BSPP are very broad, as described in Sect. 2.2. Because this database will contain background concentrations of selected metals and radionuclides characteristic of the PGDP site, the data will be used by many ongoing and future remediation projects. Therefore, DQOs for the BSPP are derived from the intended uses of the data. The intended users and uses of the data are listed here.

1. The BSPP statistician will use the analytical data for estimating means, variances, confidence levels, etc.

2. Remedial actions project managers of the PGDP facilities will use the statistically treated data and risk analysis results to establish contamination levels relative to background concentrations and risks associated with their operable units and waste area groupings.

3. DOE managers and EPA and state regulators will use the data for establishing realistic cleanup levels and criteria (based on but not necessarily equal to background levels) for contaminated sites and for evaluating the performance of remedial technologies.

The number of field soil sampling sites, the sampling locations, and the sample compositing procedure were predetermined on a statistical and soil characteristics basis. The analytical data will be used to compute upper and lower tolerance limits as well as means and standard errors for background constituents. A tolerance limit is a confidence limit for a distribution interval or percentile. Preliminary information about the relative cost and uncertainty of field sampling and laboratory analysis indicates that soil samples should be composited to reduce the variability of survey estimates. The level of compositing was conservatively taken to be three field samples per laboratory sample. Also, tolerance limits will be premised on the underlying constituent distribution having a particular parametric form (such as normal or log-normal), the choice of which will be based solely on the data.

A group of risk assessment and soil specialists has identified the potential contaminants of concern by reviewing site RI/FS reports (Tables 5.1 and 5.2). Risk assessors can use the background soil concentrations to quantify risks to human health and the environment resulting from natural levels of contaminants. Background risks will be compared with the 
Table 5.1. Analyte list for atomic absorption metals

\begin{tabular}{|c|c|c|c|}
\hline Analyte & EPA method & $\begin{array}{c}\text { Estimated } \\
\text { detection limit } \\
(\mu \mathrm{g} / \mathrm{L})\end{array}$ & $\begin{array}{c}\text { Detection limit } \\
(\mu \mathrm{g} / \mathrm{kg})\end{array}$ \\
\hline
\end{tabular}

Inductively Coupled Plasma-Mass Spectroscopy

$\begin{array}{lccc}\text { Antimony } & 6020 \text { CLP-M } & 0.02 & 1.0 \\ \text { Beryllium } & 6020 \text { CLP-M } & 0.1 & 5 \\ \text { Thallium } & 6020 \text { CLP-M } & 0.05 & 2.5\end{array}$

Cold Vapor Atomic Absorption

$\begin{array}{llll}\text { Mercury } & 245.5 \text { CLP-M } & 0.2 & 100\end{array}$

Neutron Activation Analysis ${ }^{b}$

$\begin{array}{lccc}\text { Thorium-232 } & \begin{array}{c}\text { Multi-element } \\ \text { comparitive NAA }\end{array} & \text { N/A }^{c} & 0.1 \\ \text { Uranium-235 } & \begin{array}{c}\text { Multi-element } \\ \text { comparative NAA }\end{array} & \text { N/A } & 0.05 \\ \text { Uranium-238 } & \begin{array}{c}\text { Multi-element } \\ \text { comparative NAA }\end{array} & \text { N/A } & 0.1\end{array}$

- Soil detection limit calculated based on 1-gram sample adjusted to $100-\mathrm{mL}$ volume.

${ }^{b}$ Neutron activation analysis able to provide other metals such as $\mathrm{Al}, \mathrm{Sb}, \mathrm{As}, \mathrm{Ba}$, $\mathrm{Cr}, \mathrm{Co}, \mathrm{Fe}, \mathrm{Mg}, \mathrm{Mn}, \mathrm{Hg}, \mathrm{K}, \mathrm{Na}, \mathrm{V}$, and $\mathrm{Zn}$, depending on budget restraints.

${ }^{c} \mathrm{~N} / \mathrm{A}=$ not applicable.

risks associated with contaminated areas as part of the ongoing and future RI/FS projects at PGDP. To adequately determine background risks, appropriate data collection and useability criteria have been identified.

Background samples have been defined as critical reference samples for the site-specific $\mathrm{RI} / \mathrm{FS}$ projects. As such, the analytical data will meet the requirements of QC definitive data, as described in subsequent sections. Definitive data are sufficient for risk assessment purposes and all activities associated with the BSPP. To meet the data quality (DQ) requirement for use in RI/FS projects, QC definitive data (EPA 1993) will be applied for the project. EPA-approved methods (Contract Laboratory Program) will be the first choice for chemical 
analyses, if they are available. Commercial laboratories employing these methods will be used so that the metals and radionuclide analyses will be technically and legally defensible.

Three indicators can be utilized to judge the level of acceptance for data: precision, accuracy, and completeness.

Precision: A decision regarding the desired level of precision was made on the basis of exposure risk for selected elements and compounds. Precision will be measured by the standard deviation and range of the data set (see statistical analysis plan). Replicate quality control samples will be submitted from the field to provide the means of determining the precision of the measurement process (see Sect. 5.8).

Accuracy: Accuracy is controlled primarily by the laboratory and is reported as bias. Standards, spiked samples, and referee samples are all used to assess and control the accuracy of the results, as well as the comparability of the results (see Sect. 5.8).

Completeness: The BSPP sampling plan is designed to achieve the project objectives with the minimum number of samples needed to yield the desired level of precision for the final results. The probabilities of false positive and false negative answers are specified at the outset. Project coordinators have set a completeness objective at $90 \%$ for both field sampling and laboratory analyses.

Table 5.2 Analyte list for radionuclides

\begin{tabular}{lccc}
\hline \multicolumn{1}{c}{ Analyte } & Analysis method & $\begin{array}{c}\text { Estimated detection } \\
\text { limit } \\
(\mathrm{pCi} / \mathrm{g})\end{array}$ & Reference \\
\hline Technetium-99 & Scintillation $^{a}$ & 0.5 & Walker et al. (1980) \\
Cesium-137 & LLRAL-022 $^{b}$ & 0.1 & EPA 600/4-80-032 \\
Radium-226 & LLRAL-022 & 0.1 & EPA 600/4-80-032 \\
Thorium-228, 230, 232 & 907.0 & 0.1 & ORAU/ESSAP (1991) \\
Uranium-234, 238 & Se-01 & 0.1 & manual \\
Uranium-235 & Se-01 & 0.05 & HASL-300 \\
Neptunium-237 & Spectral & 0.05 & Cataldo et al. (1987) \\
Plutonium-238, 239, 240 & Pu-03 & 0.01 & HASL-300 \\
\hline
\end{tabular}

a This original method is used as modified by C. T. Garten, Jr. (personal communication, J. A. Volpe 1988; also Hoffman et al. 1986).

${ }^{b}$ LLRAL = Low-Level Radiation Analytical Laboratory. 


\subsubsection{Quality Assurance Objectives for Field Measurement Data}

The objectives for the BSPP field activities are to

1. select representative sampling sites,

2. provide representative samples to analytical laboratories, and

3. prevent cross contamination during sampling and maintain sample integrity.

The quality of the field soil sampling can be met only if the sites sampled are not disturbed by PGDP facility activities. Any presence of man-made radionuclides above global fallout levels ( $>1000$ beta-gamma dpm/100 $\mathrm{cm}^{2}$ ) will disqualify a site as a candidate site. If ${ }^{99} \mathrm{Tc}$ is present above global fallout levels after analyses, data will not be used. Below global fallout levels, data will still be evaluated for potential use in data interpretation. Furthermore, if ratios of uranium-234/235, 234/238, or $235 / 238$ vary significantly from theoretical ratios, data may not be used.

To meet field data use requirements, field measurement tasks will be assigned the appropriate data quality level. Detailed approaches to meet field quality are presented in the following sections.

\subsubsection{Data Quality Levels for Field Data}

Field data (including soil color, texture, depth, and approximate location) will consist primarily of descriptive materials and field notes. Descriptive field data will meet the requirements of DQ field screening as defined in Data Quality Objectives Process for Superfund (EPA 1993), because the data will not be quantitative and will be readily available in the field notebook.

\subsection{Quality Assurance Objectives for Laboratory Measurement Data}

The QA objectives for BSPP laboratory measurements and data are as follows:

- Laboratory data generated will withstand scientific scrutiny and be subject to data validation procedures.

- Data will be gathered using appropriate procedures for chain of custody, laboratory analyses, and data reporting.

- Data will be complete with precision ( $\leq 35 \%)$ and accuracy range (75-125\%) as well as being technically and legally defensible (Energy Systems 1992).

\subsection{Data Quality Level of Analyses}

Analytical laboratory data will meet the requirements of $\mathrm{DQ}$ definitive data. The contract laboratory will use standard EPA methods and those in the Contract Laboratory Program (CLP). Definitive data provide for a wide array of analytes with known accuracy and precision accompanied by rigorous QA/QC protocols and documentation which provides analytical data that are defensible.

To satisfy DQ definitive data $Q A / Q C$ requirements, $10 \%$ of the total number of samples taken will be splits for QA/QC purposes. One distilled water blank (ASTM Type II) will be 
submitted to verify the quality of the laboratory distilled water supply used for cleaning the sampling equipment. Eight equipment rinsate blanks will be submitted to verify the effectiveness of the equipment cleaning procedures.

\subsubsection{Calibration Procedure and Frequency}

For the BSPP, the measurement instrumentation requiring calibration will be almost exclusively laboratory analytical instrumentation. The exception will be beta-gamma radiation meters used at PGDP for site survey purposes only. Sampling crews will use ORNL survey meters that are calibrated in accordance with appropriate instrument-specific calibration procedures contained in the ORNL Radiation Standards Calibration Laboratory (RASCAL) Standard Operating Procedure Series 04-60. The PGDP Health Physics Department will conduct the radioactivity survey of samples to be shipped only if samples were brought onsite, within DOE Reservation property. Calibration procedures and frequencies for beta-gamma survey instruments are determined by the PGDP Health Physics Department and are executed by PGDP Health Physics representatives who keep calibration records for their instruments. The results of field calibrations of beta-gamma meters will be recorded in the field logbooks by field crew members.

Laboratory analytical instrumentation will be controlled through a calibration program that is in accordance with the following: Each instrument or analytical measurement system must be calibrated before use or, in some cases, the calibration checked after use. Records will be maintained by the responsible laboratory. Typically, a calibration procedure begins with requirements given in the analytical method and is expanded to cover instrument-specific needs and laboratory practices. For each method, the laboratory must have the detailed calibration procedure in an SOP and a summary in the laboratory QA plan. Standards used to calibrate an instrument must be traceable to the guidelines of the EPA or the National Institute of Standards and Technology (NIST), and the laboratory must maintain supporting documentation.

\subsection{SAMPLE COLLECTION PROCEDURES}

This section gives general guidance for the collection of soil samples during field operations. Guidance for preparing soil sampling protocols is included in the PGDP Environmental Restoration and Waste Management (ERWM) Field Operations Procedures Manual (Utility Services 1993). In this section, a general approach for the collection of soil samples is presented, and detailed requirements are presented in the soil sampling procedure. Table 5.3 shows the total number of samples to be collected, including QC samples.

\subsection{Collection of Surface Soil Samples}

- Equipment: The following equipment is available for field soil sampling in this project: stainless steel bowls, stainless steel spoons, stainless steel scoops, stainless steel hand augers, and stainless steel shovels. Equipment needs for deep drilling are not listed because the deep core sampling will be conducted by a subcontractor (to be selected). 
Table 5.3. Number of soil and QC samples for analysis

\begin{tabular}{llcc}
\hline Type & \multicolumn{1}{c}{ Source } & Horizon & Number of samples \\
\hline Surface & Calloway-Grenada & A & 4 \\
& & B & 4 \\
& Henry & A & 4 \\
& & B & 4 \\
& Vicksburg-Falaya-Waverly & A & 4 \\
& & B & 4 \\
\hline \multirow{2}{*}{ Deep strata } & Loess & & 4 \\
& Continental deposits & & 12 \\
& Eocene (or continental) & & 4 \\
& Porters Creek clay & & 4 \\
\hline \multirow{2}{*}{ QC } & Field split & & 5 \\
& Tool/equipment rinsate & & 62 \\
\hline & Source water blank & Total & 1 \\
\hline
\end{tabular}

- Confirmation of Soil Series: Taxonomical confirmation of the soil series at each selected site is made prior to soil sampling by comparing key soil properties with the reference soil profile descriptions (Appendix B).

- Preparation of Sampling Site Description: Site identification number, location, geomorphic position, slope and aspect, parent material, vegetation, and date are recorded in the field notebook. Site locations will be identified by specific coordinates, such as longitude and latitude, or by another accepted coordinate system.

- Topsoil (A Horizon) Sampling: Prior to sampling, leaves, grass, and surface debris are removed from the site to be sampled using a clean stainless steel spoon or shovel. Surface soil (entire depth of the A horizon) samples are then collected using a separate precleaned, stainless steel scoop or spoon.

- Subsoil (Bt Horizon) Sampling: Shallow subsurface soil samples are collected by digging a hole with a stainless steel shovel, then removing all of the loose soil and collecting a sample at the desired depth (entire thickness of Bt1 horizon) using a stainless steel spoon, a stainless steel hand auger, or by using an impact driver to obtain a core contained within a plastic sleeve. 
- Preparation of Composite Soil Samples: Soil samples for mercury analysis will be composited in the field (see Sect. 5.3.4), while soil samples for other analyses will be composited in the laboratory according to analysis procedures in Composite Sample Preparation, CP4-ER-SAM4204 (Utility Services 1993).

Samples from respective A and B horizons from three field sites/locations will be composited. The three samples for a given horizon will be passed through $4.75 \mathrm{~mm}$ stainless steel sieves in the soil preparation laboratory. An equal amount (about $1 \mathrm{~kg}$ ) of each sieved sample will be composited in a stainless steel container. One-fourth of each composite sample will be placed in a precleaned polypropylene bottle for metal and radionuclide analyses, one-fourth placed in a polypropylene bottle for the state (Kentucky) laboratory, and the remaining one-half used for gamma-emitting radionuclide analysis and neutron activation analysis. Only $5 \%$ of total samples will be shipped to the state laboratory for independent analyses. The composite samples will be shipped by the technical coordinator to the designated contract laboratories according to EPA guidelines. Details are discussed in Sect. 5.4. The time between field acquisition of a soil and completion of the sample compositing process for metals and radionuclide analysis will be less than $25 \%$ of EPA requirements.

Soil sampling will be done in accordance with Surface Soil Sampling, CP4-ER-SAM4201, and Subsurface Soil Sampling, CP4-ER-SAM4202 (Utility Services 1993). These procedures are also based on recommended techniques taken from appropriate sections of the following documents:

1. A Compendium of Superfund Field Operations Methods, EPA/540/P-87/001, U.S. Environmental Protection Agency, Washington, D.C. (EPA 1987).

2. Data Quality Objectives Process for Superfund, EPA/540/R-93/071, U.S. Environmental Protection Agency, Washington, D.C. (EPA 1993).

3. Samplers and Sampling Procedures for Hazardous Waste Streams, EPA/600/2-80/018, U.S. Environmental Protection Agency, Washington, D.C. (EPA 1980b).

4. Engineering Support Branch Standard Operating Procedures and Quality Assurance Manual, U.S. Environmental Protection Agency, Athens, Georgia (EPA 1991c).

5. Soil Investigation and Sampling by Auger Borings, American Society for Testing and Materials, ANSI/ASTM D 1452-80, Philadelphia, Pennsylvania (ASTM 1980).

\subsubsection{Collection of Deep Strata Samples}

Deep strata coring will be done in accordance with Special Conditions and Specifications for Geotechnical Service Subcontracts, Oak Ridge National Laboratory, Oak Ridge K-25 Site, Oak Ridge Y-12 Plant, at Oak Ridge, Tennessee; Paducah Gaseous Diffusion Plant at Paducah, Kentucky; and Portsmouth Gaseous Diffusion Plant at Portsmouth, Ohio (Energy Systems 1993a).

Nonfluid, hollow stem auger (HSA) methods, as well as mud rotary methods, will be used to advance boreholes. Drillers will use a 3.75-in.-ID HSA with a Central Mining Equipment (CME) continuous 5-ft sampler. This equipment will advance the borehole to a depth within the clayey silt overlying the regional groundwater aquifer. Drilling will continue through the Continental deposits into the Porters Creek Clay (south sites) using hydraulic rotary methods, leaving the HSA in place as a temporary isolation casing. A complete vertical section of core 


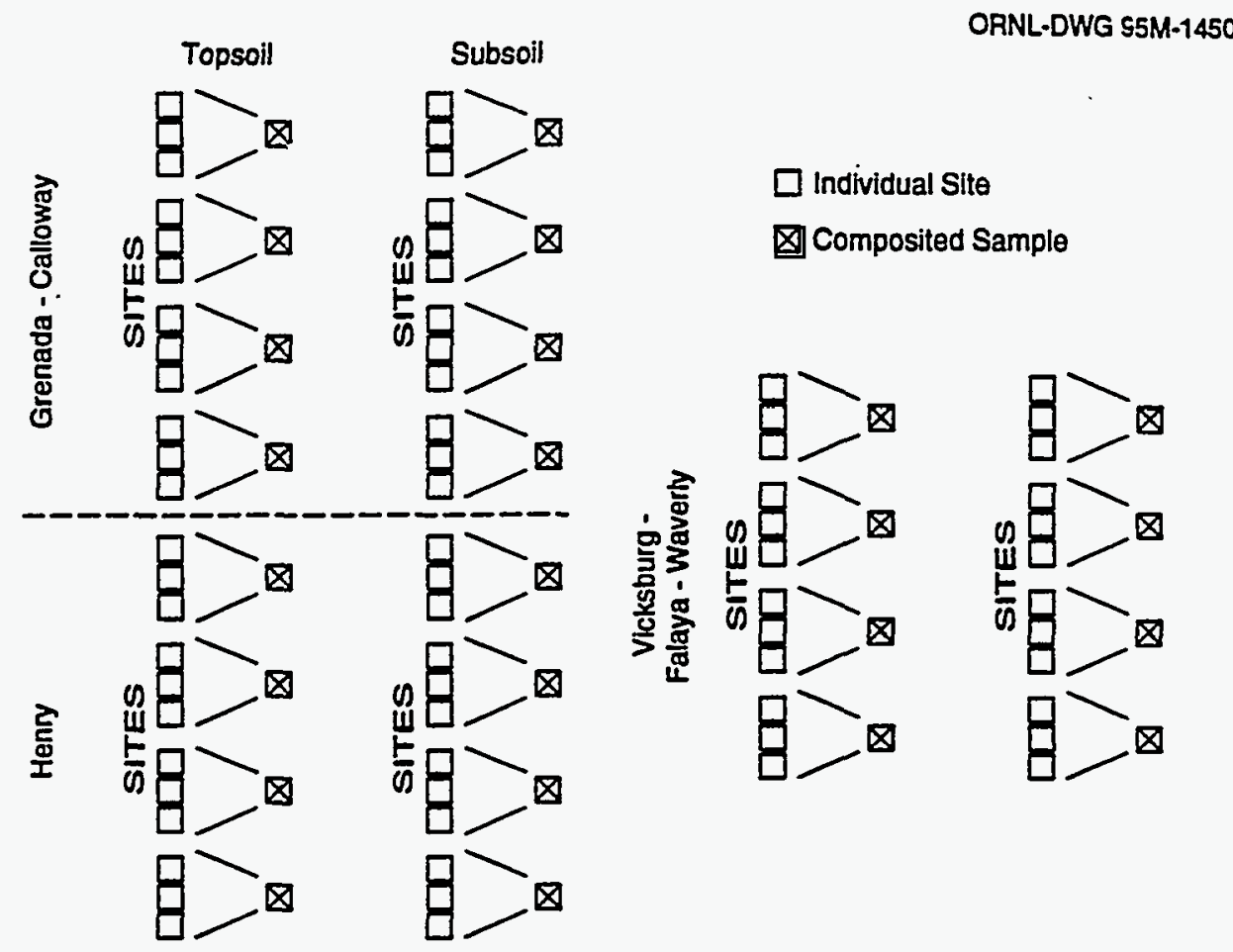

Fig. 5.1. Soil sampling and compositing approach.

will be obtained using either a shelby tube or split spoon through Unit HU1 and split spoon through the remainder of the section. Soil samples will be obtained with both 2-in. and 3-in. split spoon samplers, as well as the CME sampler. Both HSA and hydraulic rotary techniques will be utilized depending upon difficulties encountered during the drilling process, such as heaving sands or large cobbles. Figure 5.2 shows the number of samples to be collected from each hydrogeologic unit.

A drill log will be prepared by both the geologist/engineer and the pedologist/soil scientist. The pedologist will describe the core in soil science terminology, especially noting the presence of water flow zones, manganese and iron accumulations, and translocated clay or neoformed clay at depth. Soil colors will be determined with a Munsell color chart and soil textures estimated by the soil scientist. Continuous soil samples will be collected every $2 \mathrm{ft}$. It is expected that the depth of each drill hole will reach or exceed $50 \mathrm{ft}$.

Soil coring will be performed as described above. Upon completion of each soil boring, the borehole will be grouted from bottom to top using a tremie pipe. The grout will consist of high solids bentonite (30\%). Drillers will top off with a similar grout mixture any grout column that settles. Wastes generated from drilling deep soil borings will be sampled, analyzed, and properly disposed of upon completion of each soil boring.

Drillers will decontaminate drilling and sampling equipment according to Decontamination of Drilling-Related Equipment, CP4-ER-DCN4001 (Utility Services 1993). Drill rigs will be decontaminated by steam cleaning at the on-site decontamination pad after 
completing each soil boring. Drillers will also decontaminate and air-dry sampling equipment in the field after each use.

After the split spoon sampler is retrieved from the borehole, the outside of the sampler will be checked for contamination and then wiped free of soil, mud, and water. The sampler will be opened carefully so that the sample lays in half of the split spoon. The exposed surface will be scraped carefully with a clean stainless steel knife or spatula to expose the strata. A ruler will be laid adjacent to the sample, and thicknesses of individual strata will be measured. Sampling will be done after measurements have been taken. Small stainless steel spoons or spatulas will be used to transfer soil from the center of the core into glass jars.

After all sampling has been done, the remainder of the core will be used for making a precise geologic/pedologic description that is recorded in the field notebook. All sampling, including any compositing from a given thickness of section corresponding to an $\mathrm{HU}$ or formation, will be done in the field at the drill site. These deep drilling samples will be transferred once a week to the ORNL Soil Preparation Laboratory (SPL) for processing prior to being sent for analysis. Deep drill samples will be processed in the SPL in the same manner as the Ballard County topsoil and subsoil samples.

\subsubsection{Compositing Deep Strata Samples}

Each drilling area will contain two drill sites, and each drill site will be sampled separately. There will be vertical compositing of cores by hydrogeologic unit as follows:

ORN_-DWG 95M-144S

\section{DEEP STRATA SOIL SAMPLE PROFILES}

\section{SOUTH LOCATION}

2 SOUTH-SIDE SITES

Number of Samples

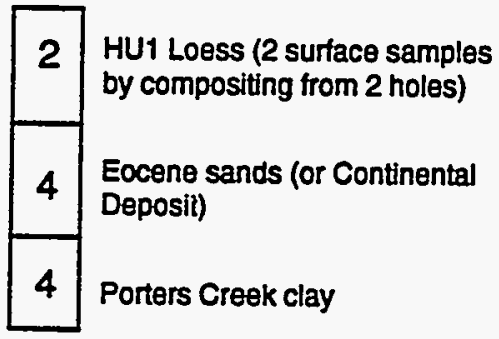

WEST LOCATION

2 WEST-SIDE SITES

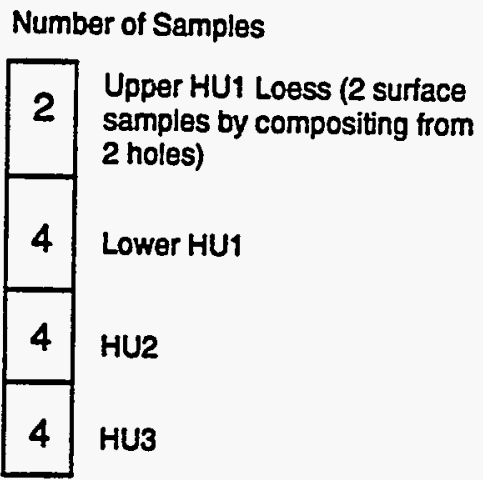

Fig. 5.2 Number of samples to be collected by hydrogeologic unit. 
HU1: A composite will be collected of the lower loess, starting at a depth of about $4 \mathrm{ft}$, to the top of the mixing zone with the upper continental deposits.

HU2: The sand and gravel bodies throughout the upper continental deposits will be composited. The fine-grained silt and clay matrix will also be composited throughout the section. Because the sand and gravel bodies are minor, the entire part of the section composed of these materials will be composited. The fine-grained part will not be sampled until after the entire section has been recovered. If the fine-grained materials comprise a thickness of several feet, subsamples will be collected systematically from the entire thickness and then composited. An alternative sampling scheme for the fine-grained material is to obtain a small discrete sample above and below each sand and gravel body and then composite.

HU3: This fine-grained stratum will be sampled if encountered. If several strata exist in HU3, a composite sample will be collected, as per the PGDP Field Operations Procedures Manual (Utility Services 1993). Sand or gravel bodies within this unit will not be sampled.

Porters Creek Clay: A sample will be obtained of the upper $4 \mathrm{ft}$ of this formation but beneath any mixing zone with the strata above.

If Eocene sand is encountered in the south drilling area, it will also be sampled. Sampling will be done according to current QA/QC standards. Duplicate and replicate samples will be obtained, as required, for statistical analysis.

\subsubsection{Handling of Soil Samples}

Field operations and sample handling are governed by the "Sample Handling and Shipping Procedures" in Sect. VIII of PGDP ERWM Field Operations Procedures Manual (Utility Services 1993). These procedures will be modified to some extent for the BSPP. Section 3.6.3.2 of this reference describes field sampling methods. The following paragraph reiterates some of the basic procedures along with modifications for the soils and conditions of this project.

1. Soil samples will be placed into suitable glass jars using precleaned stainless steel utensils.

2. A label will be made at the time of sample collection and placed onto the side of the container. A custody seal will be placed across the top of each container or on each cooler. The sample number, description of the sample, and other pertinent data will be entered onto a chain-of-custody form at the time of sampling.

3. A unique numbering system will be established for each sample collected. Each sample will have its own identifier whether or not the sample is ever analyzed.

4. Bound notebooks will be used in the field to record all pertinent information in waterproof ink at each sample site. Data about each collected sample will be entered into the logbook including sample numbers so that a complete record can be obtained and maintained. Field notebooks will be organized and maintained according to current QA/QC procedures. 
5. Soil-contaminated sampling tools will not be reused in the field until after they are thoroughly cleaned in a designated PGDP laboratory that has a source of suitable deionized distilled water or in the SPL at ORNL.

6. Samples will remain in the custody of the field sampling leader until custody is transferred either to the technical coordinator or to the analytical coordinator.

7. The field sampling team leader will spend a week at a time on-site collecting samples. On Friday of each sampling week, samples will be transported back to the SPL at ORNL and placed in a secured room.

8. A separate SPL bound notebook will be used to enter all sample numbers and all other pertinent information required for $\mathrm{QA} / \mathrm{QC}$ purposes. Compositing of topsoil and subsoil samples will be done in the SPL, and a new numbering system unique for composited samples will be established. The compositing procedure will be the same as that used for the Oak Ridge Reservation BSCP, including air drying, passing the sample through a No. 4 sieve, thoroughly mixing the composited samples in a stainless steel bowl, and filling the necessary number of glass jars. A new chain-of-custody form will be filled out for composited samples as these represent a new sample (the original samples having been destroyed in the compositing procedure). This form will be the same as that used for the Oak Ridge Reservation BSCP.

Additional procedures will be followed for samples collected for mercury analysis. The samples will be maintained at $4^{\circ} \mathrm{C}$. A separate small soil sample (50-100 g) will be collected at each site and at appropriate depths, placed into a glass jar, and the jar placed in a cooler of ice. Compositing of topsoil and subsoil samples will be done in the field by taking equal volumes of soil from each of the designated sites to be composited and placing the field-composited sample into a new clean jar. The composited mercury samples will be kept on ice or in an on-site refrigerator for a maximum of 5 days. The mercury samples will be shipped directly to the analytical laboratory from Paducah in an ice-filled cooler or with dry freezer packs along with the appropriate chain-of-custody forms. The soil sampling SOP will be modified to support this.

Deep drill samples will also be collected for mercury determination in the same manner except that no site compositing will be required.

\subsection{SAMPLE IDENTIFICATION, HANDLING, AND TRANSPORT}

\subsubsection{Sample Identification}

Each individual sample will be given a unique number identifier as it is collected in the field. The identifier will be recorded in the field notebook, and the number will be affixed to

all sample containers used for that sample. The identifier will appear on the chain-of-custody documentation accompanying the sample. 


\subsubsection{Soil Sample Numbering System}

Each soil and water/rinsate sample obtained from field operations will be given a unique, sequential number for identification and tracking purposes. The sequential numbering system for all samples will begin with 101 . Composite samples mixed in the soils laboratory will be given new sequential numbers, beginning with 301 .

All numbers will be entered appropriately into logbooks and used to reference field notes and verbal descriptions. Waterproof ink will be used on all sample bottles and containers. In addition, a site location map will be affixed to the logbook showing the location of the samples at the site.

\subsubsection{Prevention of Cross Contamination}

Cross contamination of samples will be controlled by adherence to established procedures for equipment preparation and decontamination before and after each site is sampled. Separate pieces of equipment will be used to sample individual soil horizons at each site, and all equipment will be cleaned in the soils laboratory (using suitable detergent and distilled water) after each work day. Cleaning procedures will be done according to a BSPP-developed procedure based on Decontamination of Field Equipment, CP4-ER-DCN4002 (Utility Services 1993). Cleaning activities will be recorded in the field logbook.

\subsubsection{Shipping, Handling, and Storage of Samples and Data}

Shipping, handling, and storage of samples and data resulting from field activities will adhere to custody and safety procedures and will ensure that sample integrity for analytical purposes is maintained. Sample shipping and handling will be done in accordance with Sample Packaging and Shipping, CP4-ER-SAM2003 (Utility Services 1993). Sample preservation and choice of container materials will be in accordance with Table 5.4.

\subsubsection{Field Data Management}

Field records will be legibly recorded in permanent black ink. The records will be complete enough to permit reconstruction of data-gathering activities by a qualified individual (other than the originator). Field notebook entries should be factual, detailed, and objective. The field records will be the basis for later written reports. The method of data reduction will be identified and recorded. The field team leader will review the field entries for completeness and accuracy, initial each page, and fax copies back to the technical coordinator.

\subsubsection{Sample Custody}

Sample custody will be documented from the time the sample is collected in the field until final disposition (archive). The documentation will trace sample possession through all transfers of custody. A sample is considered to be under a person's custody if any of the following conditions are met:

1. the sample is in the person's physical possession,

2. the sample is in line of sight of the person after he/she has taken possession,

3. the sample is secured by that person so any tampering can be detected, or 
Table 5.4. Recommended sample containers, sample preservation, sample size, and sample holding time requirements for analytical samples

\begin{tabular}{|c|c|c|c|c|c|c|}
\hline Parameter & Matrix & $\begin{array}{l}\text { Holding time } \\
\text { (d) }\end{array}$ & $\begin{array}{l}\text { Preservative } \\
\left({ }^{\circ} \mathrm{C}\right)\end{array}$ & $\underset{\text { size }}{\text { Minimum sample }}$ & $\begin{array}{c}\text { Minimum } \\
\text { field sample } \\
\text { size }\end{array}$ & Container \\
\hline Metals (ICP-MS) & Water & 180 & $\begin{array}{c}4 \\
\left(\mathrm{HNO}_{3} \text { to } \mathrm{pH}<2.0\right)\end{array}$ & $100 \mathrm{~mL}$ & $300 \mathrm{~mL}$ & Poly \\
\hline Metals (ICP-MS) ${ }^{b}$ & Soil & 180 & 4 & $10 \mathrm{~g}$ & $30 \mathrm{~g}$ & Glass jar \\
\hline Mercury (CVAA) ${ }^{b}$ & Soil & 28 & 4 & $10 \mathrm{~g}$ & $30 \mathrm{~g}$ & Glass jar \\
\hline Gamma Spec & Water & 180 & $\stackrel{4}{\left(\mathrm{HNO}_{3} \text { to } \mathrm{pH}<2.0\right)}$ & $1 \mathrm{~L}$ & $1 \mathrm{~L}$ & Glass \\
\hline Gamma Spec & Soil & 180 & 4 & $500 \mathrm{~g}$ & $150 \mathrm{~g}$ & Glass \\
\hline Alpha/Beta Emitters ${ }^{c}$ & Soil & 180 & 4 & $450 \mathrm{~g}$ & $1000 \mathrm{~g}$ & Poly \\
\hline NAA & Soil & 180 & ambient & $1 \mathrm{~g}$ & $30 \mathrm{~g}$ & Poly \\
\hline
\end{tabular}

a From time of collection.

- These metal samples can be put in one $500 \mathrm{~mL}$ clear glass bottle.

c Alpha/beta emitters consist of strontium-90, technetium-99, neptunium-237, plutonium, and uranium (isotopic). 
4. a sample is secured by the person in possession in an area which only authorized personnel can enter.

All sample custody procedures will be in accordance with ESP-501 (Rev. 0), "Manual Chain of Custody Procedures" (Energy Systems 1988).

\subsubsection{Sample Turnaround Time}

Sample turnaround time will be mandated by appropriate clauses in the statement of work with the laboratories performing the analyses. Such mandate will be driven by shelf life and sample holding times for the various analyses as listed in Table 5.4 in order to obtain meaningful data from the samples. The mandate will also take into account the project schedule as outlined in Fig. 1.3 in order to keep the schedule for project deliverables on time.

\subsection{SAMPLE ANALYSIS}

The objective of this section is to provide the analytical procedures required for the analysis of soil samples collected for the BSPP. The choice of analytical procedures has been based on assumptions detailed in Sect. 5.2 of this plan. The analytical procedures have been taken from HASL-300 (1990), EPA CLP Statement of Work, March 1990, EPA (1990); EPA (1991d); and AEC (1972).

Selection of parameters for analysis and selection of analytical laboratory methodologies were determined based on the following project assumptions:

- The laboratory analytical methods and techniques selected for this study will be those usually required by regulations and/or normally used for characterization and compliance analyses. These methods and procedures are those associated with such laws as: the Clean Water Act, Safe Drinking Water Act, RCRA, and CERCLA.

- Detection limits required for this study are those attained by accepted analytical methods and techniques for soils. Detection limits are listéd in Tables 5.1 and 5.2.

- The parameters to be determined are those normally found in soils and sediments of natural origin, which are indicative of contamination when found above natural background. They include select metals and radionuclides that are used in or generated by industrial, agricultural, and production activities associated with PGDP.

- Parameters that do not occur in nature are assumed to have a priori concentrations equivalent to zero background and are below analytical detection limits. Radionuclides are an exception in this category. Whereas nuclear activation and fission products do not occur in nature, they may have been added to natural background soils by fallout processes (atmospheric deposition).

Composite samples for mercury analyses will be prepared in the field. Composite samples for all other analyses will be prepared in the SPL at ORNL and will then be sent to the contract laboratory for complete analyses of metals and radionuclides. Table 5.3 shows the number of samples from each source and QC samples. 
Analytical laboratories will be selected from the Analytical Projects Office pool of preapproved laboratories that are experienced in the routine analysis of characterization and compliance samples. The laboratories are preapproved based on their reliability and accuracy, review of their laboratory QA plan per requirements of ES/ER/TM-4/R4 (Energy Systems 1994), ability to run the required methods and deliver required reports, and audits against the laboratory QA plan. Cost will be considered only after prequalification is determined.

\subsubsection{Analytical Procedures}

Metals. Inductively coupled plasma-mass spectroscopy (ICP-MS) will be used in this project to analyze metals. Table 5.1 provides the analytical methods and detection limits for the analytes of interest.

Radionuclides. The radionuclides to be analyzed for this project are listed in Table 5.2. This table provides the suggested method and detection limit for each radionuclide. For the radionuclides that do not have methods, the laboratory will provide methods for approval (the total dissolution of alpha and beta emitters is required). The contracted laboratory will be required to provide the methods and detection limits for each analyte prior to receipt of samples. Neutron activation analysis and gamma spectroscopy techniques will also be used for select radionuclide analyses. Gamma analysis will be done at the ESD Low Level Radioanalytical Laboratory of ORNL.

\subsection{SAMPLE TRACKING AND RECORDS}

This section describes the records management procedures for field sampling. The objectives of the records management program are to provide organization, protection, retrievability, and accountability of the data and documents generated by the field sampling activities and soil analyses. These procedures will also ensure that $\mathrm{QA}$ objectives are met, as specified by the QA/QC plan. Data and records management activities are described in Sect. 7. A detailed description of field data entry is in Field Operation Procedures for Site and Field Content and Control, CP4-ER-A1101 (Utility Services 1993).

\subsubsection{Logbooks}

Bound, registered logbooks with numbered pages will be used to record all information concerning the collection, handling, and current location of samples. Data will be recorded directly in an official logbook or on a sequentially numbered data form. Charts and other printed material of suitable size will be glued or otherwise securely fastened in the logbook. Pages that are too large to go in the logbook will be kept in a designated place that will be referenced in the logbook. All logbook entries will be made in indelible ink with a single line drawn through errors. Changes will be initialed and dated by the individual making the correction. Either the sampling team leader or a responsible designee will be the custodian of the logbook. Each new page will be signed by the recorder daily upon completion of entries of that page and reviewed and signed by the team leader. 


\subsubsection{Sample Custody Documentation}

The technical coordinator will establish and maintain the chain-of-custody control system (depicted in Fig. 5.3). The system actually requires the use of two forms, one for field samples and the other for laboratory samples. A sequentially numbered chain-of-custody form will accompany all samples as they are transferred from one custodian to another and will be signed and dated by the person who relinquishes custody, as well as the person who accepts custody. If samples are subdivided or separated into groups for transfer to a different custodian, a separate chain-of-custody form will be prepared for each group.

When samples are sent to another laboratory for analysis, a chain-of-custody form will accompany the samples. These forms will be filled out by the sample custodian, and a copy of the form will be sent to the laboratory coordinator. The technical coordinator will then deliver the samples to the appropriate analytical laboratory and transfer custody to the person in charge. Upon final disposition of the samples, the completed original chain-of-custody form will be returned to the BSPP manager and then submitted to the DMC [see Sample Chain-ofCustody, CP4-ER-SAM2002 (Utility Systems 1993)].

\subsection{DATA REDUCTION, VALIDATION, AND REPORTING}

\subsubsection{Field Data Reduction and Reporting}

Field data generated by the BSPP will be primarily descriptive in nature and will be in the form of handwritten notes recorded in the field notebooks. Such data will not be subjected to any kind of mathematical reduction techniques. The field data will be validated according to DQ screening data, as specified in Sect. 5.2.2. The nature and format of the descriptions generated will be obvious, but the person entering the data will flag the description of each new sample in the margin with the comment "Begin sample description." If new data or comments are generated for that sample later, the margin comment will read "Additional data for sample (Page ___." The page number will be in reference to the page where the original material is recorded.

The field notebooks will be reviewed weekly and signed off by the BSPP technical coordinator. Verification and validation of the field data (soil description and classification) will result from interactions between the technical coordinator and the field staff during technical report preparation. Standard soil taxonomy (USDA 1975) will be used as a validation criterion for the field data.

Technical reports will be reviewed by the ER manager, the BSPP manager, and appropriate technical editing staffs and will be subject to peer review for technical content, completeness, and accuracy before publication. Scheduling of the delivery of the technical reports resulting from BSPP data is given in Sect. 1.4.2.

All pertinent project records and data will be maintained to support report generation, risk assessment, and any further administrative actions (Sect. 7). 
MARTIN MARIETTA

MAPTW MARIETA ENEROY SYSTEMB, WKC.

CHAIN OF CUSTODY RECORD

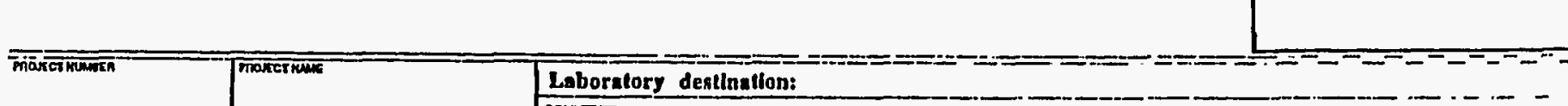

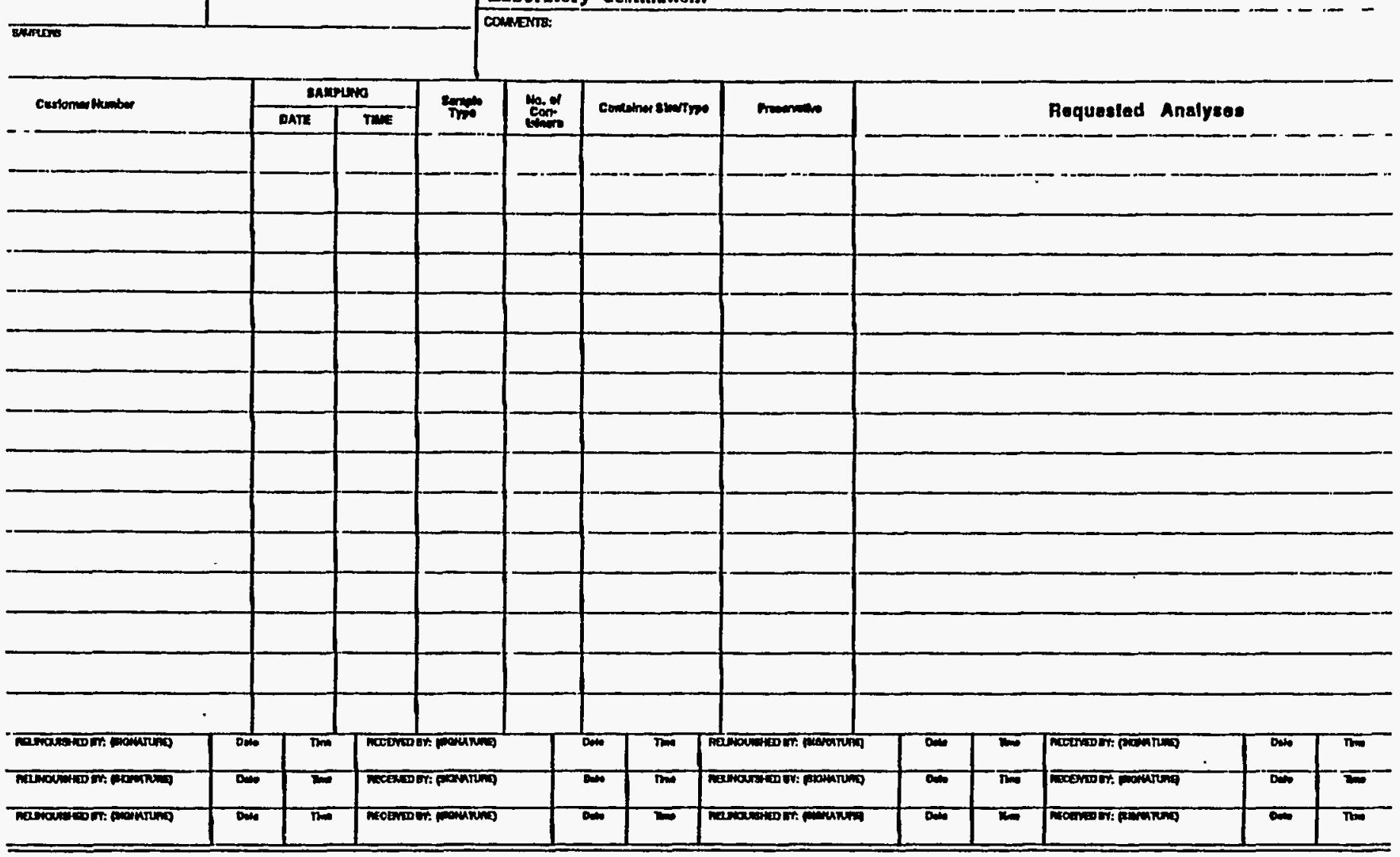

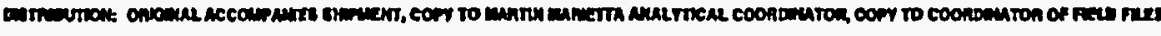

Fig. 5.3. Chain-of-custody form. 


\subsubsection{Laboratory Data Reduction and Reporting}

The specific deliverables for this project are based on the data deliverables detailed in the CLP Statement of Work, March 1990 (EPA 1990). For analytical parameters not under the CLP Statement of Work, the deliverables included in Table 5.5 are required for all samples, blanks, standards, and QC samples. Photocopied pages of laboratory notebooks and worksheets which refer to sample weights, dilutions, concentrations, data reduction, sample cleanup, sample preparation logs and worksheets, and instrument calibration logs must be included. All laboratory control sample results and/or control charts must be supplied with the data package. All data will be sent to the technical coordinator for screening. Initial screening will determine if any analysis must be redone before the holding time expires.

In addition, the following will be observed:

- All data will be included in data packages regardless of CLP or other QA/QC noncompliances, such as missed holding times.

- Blank corrections (field blank, trip blank, method blank, etc.) are not allowed.

- A narrative will be provided with each data package. This narrative will describe circumstances where the QC criteria were not met and any instrumental, technical, and administrative problems encountered during the analysis of the samples. In addition, the corrective actions and resolutions to these problems will be provided.

- All entries and corrections must be made in indelible black ink with a single line drawn through errors and changes initialed and dated by the individual making the changes.

- All data will be qualified using the nomenclature and "flags" described in the CLP Statement of Work (EPA 1990). Other flags used by the laboratory must be described and provided in the data package.

- All chain-of-custody forms and pertinent shipping information will be included in the data package.

- All results will be expressed in the significant figures and units discussed in the CLP Statement of Work (EPA 1990).

- Percent moisture content (at $105^{\circ} \mathrm{C}$ ) will be reported for all soil samples.

\subsection{Data Validation}

The data will be shipped to the analytical service coordinator where the data will be screened against the project plan and statement of work (contract compliance screen). Upon completion of the contract compliance screen, the data will be delivered for validation.

Data validation is the process of screening data and accepting, rejecting, or qualifying data on the basis of pre-established criteria. At a minimum, data generated from the laboratory analyses will be validated according to the criteria as outlined in the following documents:

- $\quad$ EPA 1991c, Hazardous Site Control Division, Laboratory Data Validation Functional Guidelines for Evaluating Inorganic Analyses, latest edition.

- Metals and radionuclides will be validated against the guidelines consistent with validation guidelines in ES/ER/TM-16 (Energy Systems 1992) and a modification to guidelines in ES/ER/TM-75 (Energy Systems 1993b). 
Table 5.5. Deliverables for the BSPP

Method requirements

Deliverables

Requirements for all methods

- Holding time information and methods requested

Signed chain-of-custody forms

- Discussion of laboratory problems

Case narratives

- Laboratory control samples (LCS) with results on control charts. Run with each batch of samples processed

Control Charts

Metals

- Sample results

CLP Form 1 or equivalent

- Initial and continuing calibration

CLP Form 2 or equivalent and dates of analyses and calibration curve, and the correlation coefficient factor

- Method blank taken through digestion (one per 20 samples of same matrix)

CLP Form 3 or equivalent and dates of analyses

- Spike sample recovery (one per 20 samples of similar matrix)

- Postdigestion spike for GFAA

CLP Form 5A or equivalent

- Duplicates (one per 20 samples) will be split and digested as separate samples)

- LCS

Recovery will be noted on raw data

CLP Form 6 or equivalent

CLP Form 7 or equivalent

- Standard addition. The decision process outlined in CLP Page E-3 will be used to determine when standard additions are required.

- Holding times

CLP Form 10 or equivalent

Radionuclides

- LCS (one/batch)

Control Chart

- Method blank (one/batch)

Report result

- Sample results

Report result

- Spike/spike duplicate or calibration information

- Initial calibration

Report result (\% recovery and \% RPD), if applicable

Calibration curve and correlation coefficient

- Continuing calibration check; report \% relative standard deviation or \% difference from calibration

Report percent or percent difference

- Run log

Copy of run log 


\subsection{INTERNAL QUALTTY CONTROL CHECKS}

\subsubsection{Field QAVQC Samples}

The QA/QC protocols for this project require the use of field QA/QC samples to verify the soundness of sample handling techniques, equipment and container decontamination procedures, chain of custody, and chemical analysis results. The following types of samples will be prepared and sent to the analytical laboratory.

1. Duplicate samples will be collected at a rate of $10 \%$ of the total number of samples taken to determine the variability in sampling technique and method.

2. One blank of distilled water that will serve as the source for equipment rinsate water will be submitted for analysis.

3. Equipment rinsate blanks will be collected to determine the effectiveness of cleaning procedures and to ensure that samples are not being affected by the equipment used to collect them. One equipment blank will be collected from each piece of equipment used in the sampling process at a sampling site. One equipment blank will be collected prior to start of sampling at the sites, for $5 \%$ of total number of samples.

Equipment rinsate blanks will consist of distilled water that has been poured over the cleaned sampling tools, then collected into an appropriate sample container, and handled as outlined in the soil sampling procedures. The technical coordinator or his designee will determine which equipment needs to be included in the rinse blank for each site.

\subsubsection{Laboratory QAVQC Samples}

This section outlines the requirements for the QA program. Analytical laboratory data documentation in this project corresponds to EPA definitive data, which requires that the QA/QC be in accordance with the CLP Statement of Work for Inorganics, March 1990 (EPA 1990). There are methods in this project that do not currently have EPA CLP methods available. This project requires that these methods be run under "CLP-like" procedures, with the minimum QC for radiochemicals being that listed below.

\section{Sample Preparation (Excluding Gamma Spectroscopy)}

Sample Batch (consists of ten samples):

1. 5\% of a sample batch should consist of a reagent blank.

2. $5 \%$ of a sample batch should consist of a control standard sample.

3. $5 \%$ of a sample batch should consist of a sample duplicate.

4. $5 \%$ of a sample batch should consist of a sample spike. 


\section{Gas Proportional Counter}

Daily Check:

Count an instrument blank and check sources (NIST traceable) to monitor instrument performance. QC plots for instrument background, counting efficiency, and cross-talk should be recorded and reported.

Annually or if required:

1. Determination of operating voltage:

- Required when a P-10 gas cylinder is changed out. Doing this will check the consistency of the counting gas.

- Required when an out-of-control situation arises due to instrument failure or to the failure of a daily instrument performance check.

- Required when the yearly instrument calibration is due.

2. Determination of counting efficiencies and attenuation curves for various radionuclides.

\section{Liquid Scintillation Counting}

Daily Check:

Count unquench instrument blank and check sources (NIST traceable) to monitor instrument performance and to normalize the quench factors. $\mathrm{QC}$ plots for instrument background and counting efficiency should be recorded and plotted for the region of interest.

Annually or if required:

1. Develop quench curves for the isotopes, total volume, and spectrum region that are of interest. A NIST-traceable source with varying amounts of chemical and color quenching agents should be used. This should be implemented yearly or daily if the analytical coordinator requires calibration.

2. Develop a background quench curve to be used as a blank subtraction.

\section{Alpha and Gamma Spectrascopy}

\section{Daily Check:}

Count an instrument check source (NIST traceable) to monitor instrument performance. Centroid (KeV/channel), full width/half-max (FWHM), and efficiency should be plotted daily for a few peaks. The out-of-control limits should be based on software requirements for peak identification. 
Weekly Check:

An instrument background should be checked and plotted.

Annually or if required:

An energy, efficiency (and FWHM) calibration should be done with a mixed source, or, in the case of alpha spectroscopy, use single isotope sources for the region of interest. 


\section{QUALITY ASSURANCE PROJECT PLAN}

This section meets the requirements of QAMS-005/80 (EPA 1980a), DOE Order 5700.6C, and the Environmental Restoration Division Quality Assurance Program Plan, ES/ER/TM-4/R4 (Energy Systems 1994). The format follows the guidance provided in Sect. 6 of QAMS-005/80 but is cross-referenced to DOE Order 5700.6C and ES/ER/TM-4/R4. Most of the QA/QC protocols are addressed as an integral part of the project plan. A quality assurance project plan (QAPP) locator, a modular profile, and a cross-reference chart are found in Table 6.1 to direct the reader to the appropriate pages and sections where each of the 16 essential QAPP elements is described. QAPP elements not found elsewhere in this report are presented in this section. The order of presentation follows the sequence established in the QAPP locator. Elements not found in this section are listed to provide continuity.

\subsection{QA TRAINING AND AWARENESS}

Alk LMES and subcontractor personnel working on the BSPP will be properly trained and qualified individuals. QA awareness will be addressed at information sessions and through distribution of the project QA plan. The technical coordinator will be responsible for conducting the sessions and distributing the plan. Receipt of information will be documented by attendance and document sign-out sheets. Prior to the commencement of work, all sampling team personnel will be given specific instructions covering the following areas:

- training needs assessment;

- organization and lines of communication and authority;

- data collection requirements;

- overview of the sampling and analysis plan, the QA/QC plan, the health and safety program, and the data management plan;

- documentation requirements;

- personnel protection procedures;

- waste management procedures;

- decontamination procedures; and

- emergency procedures.

Field sampling personnel for the BSPP will receive project-specific training in all applicable project SOPs, LMES procedures, the QAPP, and the health and safety program in accordance with Implementation of ER Traning Program Requirements for Environmental Restoration Program Personnel, ER/C-P1613 (Rev. 0, PCN-1.0, 1993). Such training will be documented in accordance with this procedure.

Field data sets will contain enough information to clearly identify sampling in the context of the overall project. The data should be traceable to the originating documents. Field data sets will contain a unique sample number, sample location, sampling date and time, names of persons collecting samples, sample handling and storage information, preservation method, sample transportation preparation information, and remarks about sample characteristics. 
Table 6.1. Modular profile and cross-reference of ER Division QA Program Plax, EPA QAMS-005/80 and DOE Order 5700.6C

\begin{tabular}{|c|c|c|c|c|}
\hline EPA QAMS-005/80 element ${ }^{a}$ & DOE order $5700.6 \mathrm{C}^{b}$ & $\begin{array}{l}\text { ES/ER/TM-4/R4 } \\
\text { section }\end{array}$ & ERD/BSPP procedure & $\begin{array}{l}\text { Location in this } \\
\text { plan }\end{array}$ \\
\hline 1. Title Page & 4. Documents Control and Records & $4.0,4.1 .3$ & ER/C-P1103 & Pg. $i$ \\
\hline 2. Table of Contents & 4. Documents Control and Records & $4.0,4.1 .3$ & ER/C-P1103 & Pg. iv-ix \\
\hline 3. Project Description & $\begin{array}{l}\text { 1. Program } \\
\text { 4. Documents Control and Records }\end{array}$ & $\begin{array}{l}1.6 .1,1.6 .2 \\
4.0,4.1 .3\end{array}$ & ER/C-P1103 & $\begin{array}{l}\text { Sect. } 1,5 \\
\text { Sect. } 5.7,7\end{array}$ \\
\hline 4. Organizational Responsibility & 1. Organization Program & 1.5 & & Sect. 1.4 \\
\hline $\begin{array}{l}\text { 5. QA Objectives for Measurement of } \\
\text { Field and Laboratory Data }\end{array}$ & 6. Design & 6.0 & & Sect. $2,5.2$ \\
\hline 6. Sampling Procedures & $\begin{array}{l}\text { 5. Work Processes } \\
\text { 4. Documents Control and Records }\end{array}$ & $\begin{array}{l}5.1,5.2,5.3,5.4 \\
5.5 \\
4.1\end{array}$ & $\begin{array}{l}\text { BSPP-SOP-01, } \\
\text { Rev 1, ESP-900 } \\
\text { ER/CR- } \\
\text { SOP1000 }\end{array}$ & $\begin{array}{l}\text { Sect. } 4,5,5.3 \text {, } \\
5.4,5.5,5.6 \\
\text { Sect. } 5.4,5.5,5.6 \text {, } \\
7.5\end{array}$ \\
\hline 7. Sample Custody & $\begin{array}{l}\text { 5. Work Processes } \\
\text { 4. Documents Control and Records }\end{array}$ & $\begin{array}{l}5.5 \\
4.0,4.1 .3\end{array}$ & BSPP-SOP-02, Rev 0 & Sect. $5.4,7.3$ \\
\hline 8. Calibration Procedures and Frequency & 5. Work Processes & 5.4 & $\begin{array}{l}\text { RASCAL 04-60 } \\
\text { Series }^{d}\end{array}$ & Sect. 5.2.5, 5.8.2 \\
\hline 9. Analytical Procedures & $\begin{array}{l}\text { 5. Work Processes } \\
\text { 4. Documents and Records } \\
\text { 6. Design }\end{array}$ & $\begin{array}{l}5.1,5.3,5.3 .3 \\
4.1 .3 \\
6.0,6.1 .3\end{array}$ & $\begin{array}{l}\text { EPA (CL-SOW) } \\
\text { Hasl-300 } \\
\text { EPA SW-846 } \\
\text { HASL-300 }\end{array}$ & $\begin{array}{l}\text { Sect. } 5.6 \\
\text { Sect. } 7 \\
\text { Sect. } 2\end{array}$ \\
\hline
\end{tabular}


Table 6.1 (continued)

\begin{tabular}{|c|c|c|c|c|}
\hline EPA QAMS-005/80 element " & DOE order $5700.6 \mathrm{C}^{6}$ & $\begin{array}{l}\text { ES/ER/TM-4/R4 } \\
\text { section }\end{array}$ & ERD/BSPP procedure & $\begin{array}{l}\text { Location in this } \\
\text { plan }\end{array}$ \\
\hline $\begin{array}{l}\text { 10. Data Reduction, Validation and } \\
\text { Reporting }\end{array}$ & $\begin{array}{l}\text { 6. Design } \\
\text { 5. Work Processes }\end{array}$ & $\begin{array}{l}5.3 .4 \\
5.2\end{array}$ & & $\begin{array}{l}\text { Sect. 5.7, 6.4, 7.3, } \\
7.5,7.6,9\end{array}$ \\
\hline 11. Internal QC Frequency & $\begin{array}{l}\text { 8. Inspection and Acceptance } \\
\text { Testing }\end{array}$ & 5.3 .5 & & Sect. 5.8 \\
\hline 12. Performance Audit and Frequency & $\begin{array}{l}\text { 10. Independent Assessment } \\
\text { 9. Management Assessment }\end{array}$ & $\begin{array}{l}10.0 \\
9.3\end{array}$ & ER/C-P1600 & Sect. 6.2 \\
\hline 13. Preventive Maintenance Procedures & 5. Work Processes & 5.4 & & Sect. 6.3 \\
\hline 14. Statistical Assessment of Data Quality & 3. Design & 5.3 .4 & & Sect. 8,9 \\
\hline $\begin{array}{l}\text { 15. Nonconformance and Correction } \\
\text { Action Procedures }\end{array}$ & $\begin{array}{l}\text { 9. Management Assessment } \\
\text { 10. Independent Assessment }\end{array}$ & 3.2 & $\begin{array}{l}\text { ESS-OP-301 } \\
\text { ESP-QA-16.1 } \\
\text { ESS-16.0 } \\
\text { ER/C-P1300, Rev } 0\end{array}$ & Sect. 6.4 \\
\hline 16. QA Reports to Management & $\begin{array}{l}\text { 1. Program } \\
\text { 9. Management Assessment } \\
\text { 10. Independent Assessment }\end{array}$ & $\begin{array}{l}1.6 .2 \\
3.5 \\
3.5\end{array}$ & & Sect. $6.5,7.5,7.6$ \\
\hline
\end{tabular}


Table 6.1 (continued)

\begin{tabular}{|l|l|l|l|l|}
\hline \multicolumn{1}{|c|}{ EPA QAMS-005/80 element * } & \multicolumn{1}{|c|}{ DOE order 5700.6C ${ }^{b}$} & $\begin{array}{l}\text { ES/ER/TM-4/R4 } \\
\text { section }^{c}\end{array}$ & $\begin{array}{c}\text { ERD/BSPP procedure } \\
\text { plan }\end{array}$ & $\begin{array}{l}\text { Location in this } \\
\text { plan }\end{array}$ \\
\hline $\begin{array}{l}\text { 17. Other QA/QC measures to meet DOE } \\
\text { order 5700.6C guidelines }\end{array}$ & $\begin{array}{l}\text { 7. Procurement } \\
\text { 2. Personnel Training and } \\
\text { Qualification } \\
\text { 3. Quality Improvement }\end{array}$ & $\begin{array}{l}7.0 \\
\text { Sect. } 6.1\end{array}$ \\
Sect. 6.4 \\
\hline
\end{tabular}

a EPA (1980a)

- ASME (1989)

c Energy Systems (1991)

${ }^{`}$ RASCAL $=$ ORNL Radiation Standards Calibration Laboratory (RASCAL) Standard Operating Procedure 


\subsection{PERFORMANCE AND SYSTEM AUDITS}

\subsubsection{Field}

Prior to the onset of field sampling activities, a readiness review will be conducted with input from BSPP project participants and PGDP oversight organizations. This project will not involve dealing with any significant contaminants usually encountered in remedial actions projects, and it has been determined that 29 CFR 1910.120 is not applicable to the BSPP.

Internal field surveillances will consist of on-site observation of soil sampling activities by the project field QAVC coordinator. One combined internal surveillance by a quality assurance specialist (QAS) is planned during field operations of the project as indicated in Table 6.2. This surveillance will be done and documented in accordance with ER/C-P1600, Rev. 0, Performance of Environmental Restoration Division Surveillance Activities, but distribution of surveillance reports generated will be limited to the BSPP manager and technical coordinator. The purpose of these surveillances will be to aid in refining the project sampling activities in preparation for formal surveillances by the ER, PGDP, or ESD QASs.

Typical surveillance activities will include

- performing a review of procedures, instructions, and associated documents applicable to the project, and

- observing field sampling activities and associated QA/QC activities to verify that these work activities are being performed in accordance with project documents.

The results of field surveillances will be discussed with the persons observed. The results of the surveillance will be documented in accordance with ER/C-P1600, Rev. 0 and signed by the field $Q A / Q C$ representative. The resulting surveillance reports will be distributed to the BSPP manager; the technical coordinator; the project files; and the ER, PGDP, or ESD QASs as appropriate.

BSPP field and technical staff are required to inform the BSPP manager and the technical coordinator of all nonconformances or quality failures. The BSPP manager and the technical coordinator will document and immediately report any nonconformances or quality issues or failures to the QAS. It is the responsibility of the QAS to report all quality-related activities to the Paducah ER Program QA manager and the Paducah ER Program line manager.

Formal surveillances and audits by ER, PGDP, or ESD QASs will be performed and documented in accordance with ER/C-P1600, Rev. 0 and reported as appropriate in the ER Program.

The proposed surveillance schedule for the BSPP is presented in Table 6.2. Specific dates in the surveillance schedule may be adjusted because of operational and weather-related impacts and are represented here as "to be determined." Specific dates in Table 6.2 will be set as soon as practical after the field work begins. 
Table 6.2 Background soil characterization project-1995 schedule of surveillance activities

\begin{tabular}{ccll}
\hline Date $^{\circ}$ & Lead & \multicolumn{1}{c}{ Surveillance activity } & \multicolumn{1}{c}{ Comments } \\
\hline TBD & $\begin{array}{l}\text { J. Blewitt } \\
\text { T. Koepp }\end{array}$ & Field sampling activities & Project/ER surveillance \\
TBD & T. Hatmaker & Verification of lab data validation & Project surveillance \\
TBD & T. Koepp & $\begin{array}{l}\text { Project/QA records } \\
\text { Validation of lab data } \\
\text { Verification of lab data }\end{array}$ & ER Surveillance \\
\hline
\end{tabular}
work.

a Dates will be determined upon approval of the QAPP and project plan and after start of field

\subsubsection{Laboratory}

Internal and external performance and systems audits by the Analytical Projects Office are means of monitoring the capability and performance of the laboratory analytical measurement and data documentation system. The laboratory must successfully pass an on-site systems inspection before the laboratory is authorized to perform project analyses. The inspection serves to define laboratory capabilities and its compliance with project requirements and with its own QA program. The laboratory inspection covers sample receiving, handling, and storage; performance of analytical procedures and adherence to protocols; documentation such as records of instrument calibration, sample preparation and run logs, maintenance logs, and standards traceability; standard operating procedures; and other areas of technical or regulatory interest. The laboratory QA plan for the laboratory performing the work should describe the auditing practices followed.

\subsection{PREVENTIVE MAINTENANCE}

\subsubsection{Field}

The soil sampling equipment to be used by the BSPP has been procured, and sufficient backup equipment will be on hand or readily available within the time frame of the project. The instrumentation to be used will require only minor on-site calibration by the field crew. Radiological or industrial hygiene instrumentation will be obtained from PGDP Health Physics or Industrial Hygiene and will be covered by the LMES preventive maintenance programs.

\subsubsection{Laboratory}

A program of preventive maintenance reduces the likelihood of analytical problems and unexpected delays resulting from equipment failure. The following comprise the preventive maintenance system: 
- Determination and listing of measurement system components that require preventive maintenance.

- For each measurement component, development of a schedule of routine tasks that must be carried out to minimize downtime.

- Notation of preventive maintenance activities in a maintenance log.

- Inventory of critical and frequently required spare parts.

The responsibility for routine preventive maintenance is assigned to particular individuals. More specialized maintenance is provided by a trained instrument technician.

\subsection{QUALITY MMPROVEMENT}

\subsubsection{General}

Continual improvement in all aspects of the project is the goal of the BSPP. All employees are encouraged to offer suggestions regarding improvement of any processes used in accomplishing project goals and objectives. The LMES quality policy endorses a no-fault environment where personnel have the freedom and responsibility to identify nonconforming activities, items, and procedures without fear of reprisal. Results of management-assessment and self-assessment activities will be continually evaluated, and lessons learned will be applied to improve organizational performance by preventing problems and improving quality. The focus of quality improvement is to reduce the number of variables capable of affecting the quality of the product or service being offered. All efforts will be made to continually institute measures that promote improvement in quality.

\subsection{Control of Nonconforming Items}

Control of nonconforming items is necessary to ensure that nonconforming activities or items are identified, reported, segregated, addressed, and corrected and that proper personnel and organizations are notified. Items that could be identified as nonconforming may include computer hardware and software. Services performed by the BSPP or through subcontract also may be identified as nonconforming. Corrective actions are necessary to prevent further processing, delivery, installation, or use of nonconforming items until the affected organizations are notified, and the proposed technical disposition and corrective actions are approved. Management will actively encourage BSPP staff to identify and suggest means of improvement and will foster a no-fault attitude to further promote the process.

All BSPP staff are responsible for identifying nonconforming work items and processes. Nonconformance reports must be completed by the BSPP staff upon discovering the nonconformance item, and these nonconformance reports must be submitted to the BSPP project manager. The BSPP manager is responsible for monitoring the status of nonconforming items and proceeding with corrective actions, as needed. All nonconformances in the BSPP will be reviewed by the BSPP manager and other ER Program personnel, as needed, whether the nonconformances were generated by the BSPP or by its subcontractors.

Additional quality requirements for control of nonconforming items are identified in the latest issuances of Energy Systems Standards ESS-QA-15.0, Control of Nonconforming Items (and Services), and ESS-QA-15.1, Preparation of a Nonconformance Report. 


\subsubsection{Corrective Actions}

Corrective actions will be taken when conditions adverse to quality may affect safety, health, the environment, or the reliability of BSPP activities or data. The root cause of significant conditions adverse to quality must be determined and corrected to prevent recurrence, and such conditions must be properly documented and reported to management in a timely manner. It is important that adverse conditions be identified and corrected quickly to prevent further decline in the situation. BSPP management must be involved from the identification of the adverse conditions to the implementation of corrective actions. Corrective actions will not be taken without the approval of the BSPP manager. Any corrective action needed or taken within the BSPP will be reviewed for lessons learned and potential applicability to other elements of the ER Program. The BSPP manager will ensure that proper focus is given to the adequacy of resources necessary to provide for timely resolution and correction of identified problems.

Conditions that are adverse to quality are those that exceed predetermined acceptability limits, deviate from prescribed methods, fail to meet performance requirements or DQ requirements or objectives, or fail to meet customer or regulatory requirements and expectations. Nonconformances, occurrences, management reviews, appraisals, audits, and problem investigations, as well as external appraisals, reviews, surveillances, etc., may identify conditions that require corrective action.

Results obtained from the internal surveillances and noncompliance reports will be collected and reviewed in an ongoing effort to identify, trend, and correct quality deficiencies. Quality deficiency reports will be developed using these results. Direct and root causes will be determined, and a corrective action plan to correct the deficiencies and prevent their reoccurrence will be developed. The BSPP manager will review the report and share the lessons learned with the BSPP staff at the same time that corrective actions are put in place.

Additional quality requirements for corrective action and occurrence reporting are identified in the latest issuances of Energy Systems Standards ESS.16.0, Corrective Actions; ESS-QA-16.1, Corrective Action Program; and ESS-OP-301, Occurrence Reporting System.

\subsubsection{Variance System}

The sampling procedures outlined in Sect. 5.3 allow a certain amount of flexibility to deal with a range of field conditions; however, the need for variances should be minimal. Variances from established procedures and field changes will be documented using the Change Request/Variance Form (Fig. 6.1). Variances are defined as being applicable to field operations on all sites, whereas field changes apply only to specific instances at sites.

Most likely, field changes or modifications to SOPs will be necessary to accommodate site conditions. The field samplers will strive to avoid major variances in the procedure, if possible. Should variances become necessary, however, the field sampler will contact the technical coordinator to discuss the situation before proceeding. Where necessary, the Change Request/Variance Form can be faxed to the technical coordinator, and the signed form faxed back to the field crew so that the project can proceed. 
Field Change

Variance

Change Number:

Date:

Site:

Affected Method:

Substituted Method:

Impact on Data Quality:

Justification:

Approvals a

Project Manager (Variances Only):

Date:

Technical Coordinator:

Date:

Field QAVC Coordinator:

Date:

Other Approvals

Name/Organization:

Date:

Name/Organization:

Date:

a Approval signatures can be after-the-fact for changes but must be in advance for variances.

Fig. 6.1. Change request/variance form. 
Changes should be discussed with the technical coordinator as soon as possible and noted in the logbook. These changes should not hold up sampling, provided the change does not affect the actual collection of a sample. All changes that affect the manner in which a sample is taken or handled will be treated as variances.

The technical coordinator will keep a log of variances/changes and will hold periodic meetings with the various project coordinators and the BSPP manager to discuss the implications of the variances/changes for project data. Results from the discussion will support a decision to resample where the variance/change occurred.

When it is decided that a variance will become a part of the SOPs, as a special case procedure for example, the new procedure will be attached as an addendum to the project plan.

\subsection{QUALITY ASSURANCE REPORTS TO MANAGEMENT}

Reports will be prepared as needed for ER Program management that provide evidence of the quality, cost, and schedule of the project. A list of possible reports and their content follows.

\subsubsection{Formal Written Reports}

- Audit and surveillance reports will be prepared and submitted by the auditor or surveillant.

- Reports on significant quality problems, recommended solutions, and results of corrective actions will be prepared by the BSPP manager.

\subsubsection{Project Reports}

Reports will be prepared by project personnel designated by the BSPP manager. The reports will identify the status of the following:

- record of field activities;

- document preparation and approvals;

- $\quad$ scheduled versus actual completions of field sampling and laboratory analyses;

- accuracy and precision of laboratory analyses;

- amount, type, and location of field-generated wastes; and

- actual cost and schedule versus planned.

Regardless of whether reports are presented to management in writing or verbally, records of activities will be maintained by the personnel responsible for presenting the report.

\subsection{PURCHASED ITEMS AND SERVICES CONTROL}

This criterion (DOE Order 5700.6C, Criterion 7) ensures that quality is maintained in purchasing items or services. Purchasing for the BSPP will be accomplished through normal 
ORNL procedures. These procedures implement DOE Order $5700.6 \mathrm{C}$ procurement control requirements.

The deliverables for work done by contract laboratories for the BSPP are defined in Table 5.5. Section 5.7 outlines the validation of data generated for the project. 


\section{DATA AND RECORDS MANAGEMENT PLAN}

\subsection{INTRODUCTION}

The background soils investigation will generate data sets from sources including field measurements, laboratory analyses of environmental samples, and output from statistical analyses and risk analysis activities. A data set is a structured collection of data items that are stored in and retrieved from a computer file by computer software (such as spreadsheet or database software).

Records of collection, analysis, and disposition of the samples and data will be generated. Data records are electronic or hard copy documents with entries describing data items and their attributes.

\subsection{OBJECTIVES}

The objectives of the data management plan in this section are to provide organization, integrity, security, traceability, and consistency of the data sets and data records generated during the BSPP. Organization will ensure that data and documents are adequate to describe the procedures and results of the investigation. The data and documents must be able to support any future legal or administrative actions. Data sets, programs, and data records will be processed and maintained to minimize introduction of errors resulting from faulty entry, transcription, storage, or management. Thus, accurate and complete data will be available for statistical analyses, reporting, and modeling. Data sets, programs, and data records will be protected from unauthorized access, deletion, and modification.

Information will be recorded in sufficient detail to allow traceability of the data as they evolve from one form to another. For instance, identification values will associate original hard copy sources to values in data sets and to reported summary tables.

Data values will be consistent. For instance, different data values or attributes should not have the same meaning, and like values should not have different meanings.

\subsection{DATA MANAGEMENT}

Data management for this project will develop the BSPP database for management and storage of field, analytical, and risk analysis data. Computer software programs and procedures will be developed to manipulate and store data, summarize and reduce data. The BSPP database will be manipulated primarily with SAS software and stored as SAS data sets on an ER designated Unix workstation. The structure of the database will conform reasonably to EIMS, the Paducah database design to facilitate the transfer of BSPP data to the Paducah database system. The principal steps for processing data for the BSPP database are identified in Fig. 7.1. 


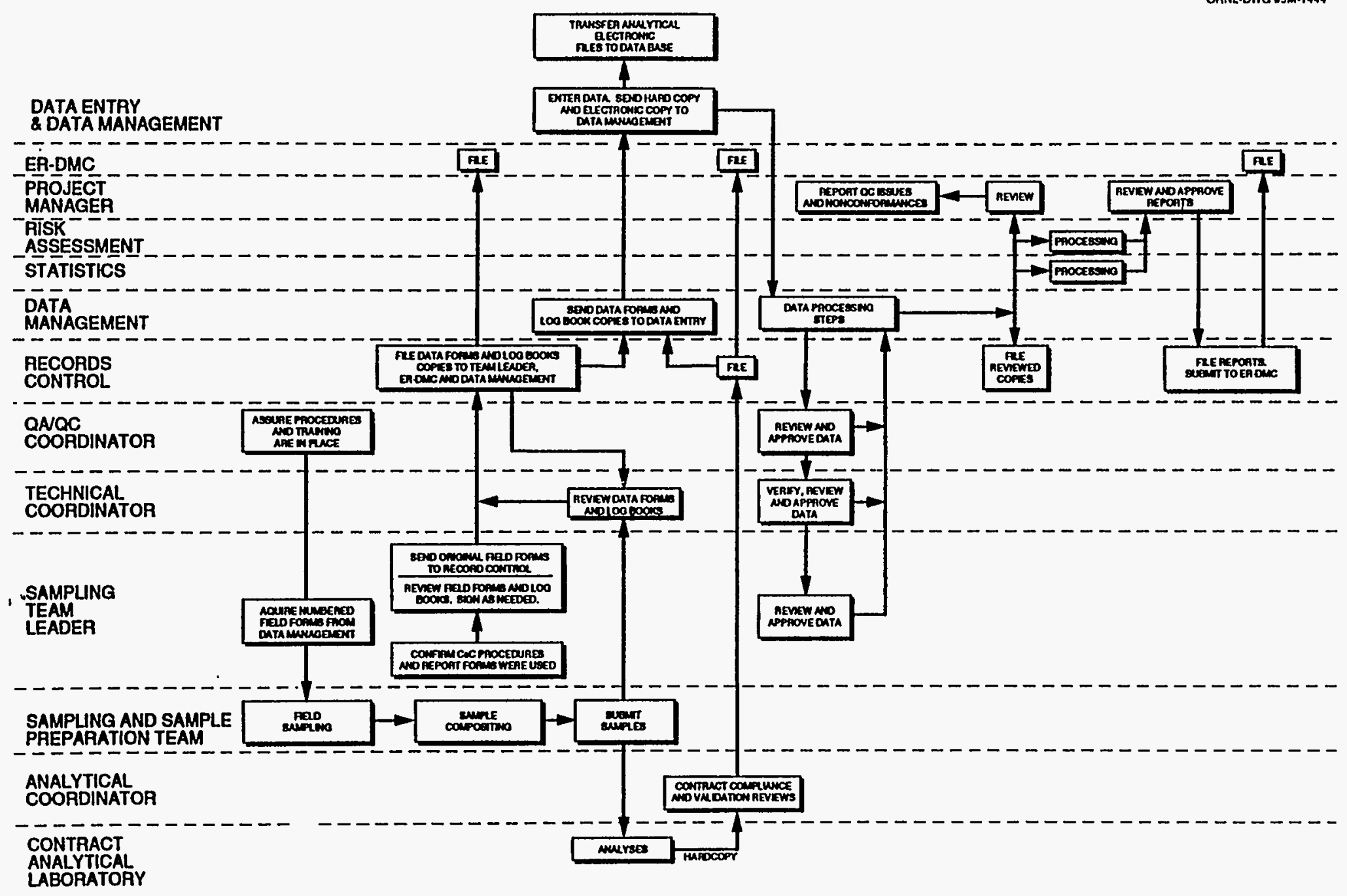

Fig. 7.1. Responsibility matrix and process flow of BSPP samples, data, and documents. 


\subsubsection{Data Collection}

\subsubsection{Field data measurements and observations}

A total of 53 soil samples and 9 water samples will be taken. Field data, such as location, type of sample, and soil type, will be recorded on hard copy and transferred to an electronic database by key entry and hand verification.

\subsubsection{Laboratory analytical data}

Analytical data will be provided by the analytical laboratories in the electronic form Contract Laboratory Protocol Format A-Form 1. Analytical data will be transferred to the BSPP database using computer software. A random subset of the data will be verified. Validation codes and results will be provided in electronic and printed forms.

Analytical laboratories will provide data forms of analytical results and quality control results (such as blanks, spikes, duplicates) as specified in Table 5.5. The analytical laboratory will maintain BSPP sample identification numbers and lab identification numbers in the data forms.

\subsubsection{Project records management}

Field logbooks and notebooks and laboratory transfer records will be furnished to the DMC at PGDP by the technical coordinator. Hard copy analytical laboratory results will be given to the DMC by the analytical coordinator. Hard copy records of verification of electronic data will be given to the DMC by the data manager. If required, records of statistical calculations and risk analyses will be given to the DMC by the statistical analysis and risk analysis coordinators.

\subsubsection{Data Encoding}

Standardized identification codes will be used to facilitate match-merging of data of the BSPP database and other databases, such as EIMS. Variables such as analysis name will have standard values. A sufficient number of variables will be provided in order to define the result and its conditions and assumptions. Values of variables will be consistent. Sample measurements that are accidentally lost or that were not completed will be denoted as missing values. Censored values (nondetectable laboratory results) will be consistently flagged in separate qualifying fields. A remarks field will be available for all field and analytical data.

\subsubsection{Data Traceability}

Information will be recorded in sufficient detail to allow it to be traced to the project and location where the data were obtained. The date and time of data acquisition will be recorded. The measuring instrument will be referenced by serial number and type. The laboratory method will be recorded. The names of the members of the sampling team will be recorded. When data are entered into the BSPP database, the field form control number and document control number will be recorded to provide the necessary link to the original hard copy record. 


\subsubsection{Data Security and Availability}

Read, write, delete, and execute access to computer data files and program files on the host computer will be controlled by the data management staff. Validated field and analytical data will be transferred to the Paducah ER database with the approval of the BSPP manager. Other ER Program projects needing background soil concentration data may obtain copies of the data from EIMS, the Paducah ER database.

\subsection{DOCUMENT CONTROL}

Document control is the process of ensuring that documents are reviewed for adequacy, approved for release by authorized personnel, and distributed to and used at the location where the prescribed activity is performed. Document control is essential to BSPP activities to ensure the precision and integrity of the sampling activities, laboratory analyses, and resulting conclusions. The BSPP manager has the responsibility of identifying the documents to be controlled (consistent with the QAPP) and their specific distributions.

These procedures clearly define the process to be followed from initiation through distribution for their respective document types. Distributions will be handled by either the Paducah ER DMC or the BSPP. Experienced staff will follow procedures ensuring that once a reproducible copy of the document has been received, the document will be reproduced in sufficient quantity and distributed with return receipts for numbered copies, and that copies are returned when no longer needed.

\subsection{RECORDS MANAGEMENT SYSTEM}

All information necessary to provide a complete and accurate history of the project organization, sample collection, and analysis activities will be controlled in a records management system. A hard copy repository (the BSPP files) and associated index database provide for organization, protection, retrievability, and accountability of project records. All requests for access to BSPP information require the approval of the BSPP manager.

Protocols for communication of necessary documents and data between the BSPP files and the DOE Administrative Record will be implemented as part of BSPP data management activities.

\subsubsection{Records Control Process}

Records to be controlled, along with the responsible personnel and organizations, are shown in Table 7.1. All BSPP staff are responsibile identifying record items and forwarding appropriate information to project files. 
Table 7.1. Records to be included in the Paducah DMC and BSPP files; items of record (duplicate or original) are to be transmitted to the BSPP project manager for inclusion in the DMC

\begin{tabular}{|c|c|c|}
\hline Record origination & Items of record & Comment \\
\hline \multicolumn{3}{|c|}{ Records prepared by or for the BSPP and under direct project control } \\
\hline BSPP project manager & Project plans and correspondence & $\begin{array}{l}\text { Plans to be } \\
\text { prepared, reviewed, } \\
\text { and approved }\end{array}$ \\
\hline BSPP technical coordinator & $\begin{array}{l}\text { Field and laboratory notebooks } \\
\text { Personnel training reports } \\
\text { Analysis procedures } \\
\text { Sampling procedures }\end{array}$ & $\begin{array}{l}\text { Duplicates kept by } \\
\text { technical } \\
\text { coordinator; } \\
\text { originals transmitted }\end{array}$ \\
\hline $\begin{array}{l}\text { BSPP field and laboratory } \\
\text { technical support staff }\end{array}$ & $\begin{array}{l}\text { Field and laboratory notebooks } \\
\text { Request-for-analysis forms }\end{array}$ & $\begin{array}{l}\text { Duplicates are kept } \\
\text { by staff; originals are } \\
\text { transmitted to DMC }\end{array}$ \\
\hline BSPP analytical coordinator & $\begin{array}{l}\text { Chain-of-custody forms } \\
\text { Analytical results } \\
\text { QA/QC results }\end{array}$ & $\begin{array}{l}\text { Originals are } \\
\text { transmitted to DMC }\end{array}$ \\
\hline Quality assurance & $\begin{array}{l}\text { Audits and results } \\
\text { Corrective actions } \\
\text { Readiness review } \\
\text { Surveillance reports }\end{array}$ & $\begin{array}{l}\text { Originals are } \\
\text { transmitted to the } \\
\text { project manager and } \\
\text { transferred to DMC }\end{array}$ \\
\hline
\end{tabular}

Records which may be maintained by others in support of the BSPP and may be requested by the Project Manager

ORNL medical

ORNL industrial safety
Employee physician statements

Inspections reports
Duplicates transmitted at project manager's request through S\&H

Duplicates transmitted at project manager's request through S\&H 
Table 7.1 (continued)

\begin{tabular}{|c|c|c|}
\hline Record origination & Items of record & Comment \\
\hline \multicolumn{3}{|c|}{$\begin{array}{c}\text { Records that may be maintained by others in support of the BSPP and may be requested by the } \\
\text { Project Manager }\end{array}$} \\
\hline $\begin{array}{l}\text { ORNL technical resources and } \\
\text { training }\end{array}$ & $\begin{array}{l}\text { Training/qualification records } \\
\text { OSHA training } \\
\text { RCRA training } \\
\text { Employee training } \\
\text { Category III training }\end{array}$ & $\begin{array}{l}\text { Duplicates } \\
\text { transmitted at } \\
\text { project manager's } \\
\text { request through } \\
\text { S\&H }\end{array}$ \\
\hline ORNL industrial hygiene division & $\begin{array}{l}\text { Personnel monitoring } \\
\text { Equipment monitoring } \\
\text { Logbooks } \\
\text { Routine surveillance reports }\end{array}$ & $\begin{array}{l}\text { Duplicates } \\
\text { transmitted at } \\
\text { project manager's } \\
\text { request through } \\
\text { S\&H }\end{array}$ \\
\hline $\begin{array}{l}\text { ORNL radiation protection } \\
\text { department (health physics) }\end{array}$ & $\begin{array}{l}\text { Personnel monitoring } \\
\text { Equipment monitoring } \\
\text { Decontamination records } \\
\text { Unusual occurrence reports } \\
\text { Routine surveillance reports } \\
\text { Logbooks }\end{array}$ & $\begin{array}{l}\text { Duplicates } \\
\text { transmitted at } \\
\text { project manager's } \\
\text { request through } \\
\text { S\&H }\end{array}$ \\
\hline $\begin{array}{l}\text { Environmental monitoring and } \\
\text { compliance division (EMC) }\end{array}$ & $\begin{array}{l}\text { ALARA memoranda } \\
\text { Engineering permits } \\
\text { Environmental documents } \\
\text { (ADM, EAM) }\end{array}$ & $\begin{array}{l}\text { Duplicates } \\
\text { transmitted at } \\
\text { project manager's } \\
\text { request through } \\
\text { S\&H }\end{array}$ \\
\hline
\end{tabular}


7.5.2 Document Archive and Index

The operation of the ER DMC is described in Identification, Distribution, and Maintenance of Environmental Restoration Records (Long 1995). This procedure will be implemented for the BSPP. The record copy will be maintained at the Paducah DMC, and the duplicate copy will be forwarded to the ESD at ORNL. The index database associated with the DMC serves as a computerized index for retrieval of record documents generated by the project. Backup files of the document index will be created throughout each day during which new records are created or existing records edited. All documents submitted will be indexed to meet project needs and document retention schedules.

\subsubsection{Document Accessibility}

BSPP documents are under the control of the ER DMC staff as specified in the ER DMC operating procedure. BSPP staff may request copies of documents at any time. Access to BSPP records by others requires the approval of the project manager.

\subsection{ADMINISTRATIVE RECORD}

When BSPP data and documents become part of other project administrative records, DOE will maintain and preserve the complete administrative record, including supporting BSPP documents, for a minimum of 30 years following the completion of the project. DOE will notify EPA, the Kentucky Department of Environmental Protection (KDEP), and the Kentucky Department for Health Services (KDHS) at least 90 days before the destruction of any such records or documents. DOE will upon request by EPA, KDEP, or KDHS make such documents (or copies) available. 


\section{STATISTICAL SAMPLING DESIGN AND ANALYSIS}

\subsection{INTRODUCTION}

PGDP background data will be used to compute upper and lower tolerance bounds* and mean values and standard errors for background constituents, particularly radionuclides. These parameters and statistics are illustrated in Fig. 8.1. Related data from other sources, as available, will be used in conjunction with the BSPP data to guide analysis and to determine project activities.

This section discusses statistical sampling and data analysis. Section 8.1 considers the statistical sampling plan and fulfills DQO Step 7, "optimize the design." For the purpose of the statistical design, it is assumed that tolerance bounds are the parameters of primary interest. Section 8.2 discusses other aspects of the data analysis.

\subsection{SAMPLING PLAN DESIGN}

When data are plentiful-for example, 20 or more separately analyzed soil samples per formation and depth-sample percentiles can be used to compute nonparametric tolerance bounds that are valid under very general conditions (see Bonczek et al. 1995). Unfortunately, the expense of the collection and analysis of so many samples precludes this approach for the BSPP. Therefore, our tolerance bounds will be premised on the underlying constituent distribution having a particular parametric form (such as normal or lognormal), the choice of which will be based on characteristics of the data. For the purpose of sample-size determination, we will assume the data are distributed lognormally, which is consistent with earlier work in the BSCP conducted on the Oak Ridge Reservation.

The BSCP and preliminary information on the relative costs of and variability due to laboratory analysis and field sampling at PGDP indicate that soil samples should be composited to reduce the variability of survey estimates. For the BSCP, composites of three worked well, so the same composite size will be used for the BSPP as well. To get preliminary estimates of the variances of such composites, which are needed for estimating minimal necessary sample sizes, the components of variance of background sample results need to be estimated- $\sigma_{\mathrm{S}}{ }^{2}$ due to spatial variation and $\sigma_{\mathrm{L}}{ }^{2}$ due to laboratory error. The variance of a composite of $m$ (e.g., for $m=3$ ) is $\sigma_{\mathrm{L}}{ }^{2}+\sigma_{\mathrm{S}}{ }^{2} / m$. $\dagger$

Because uranium is one of the main radionuclide contaminants of concern at PGDP, this discussion focuses on it for the purpose of sample size determination. There are few preliminary background PGDP radionuclide data in existence. A plot of some PGDP data for ${ }^{234} \mathrm{U}$ is presented in Fig. 8.2. These data are from the Phase I and II Site Investigations

\footnotetext{
*A tolerance bound is a confidence bound for a distribution percentile, for example, a 95\% lower confidence bound for the 90 th percentile of the distribution. (The probability is then 0.95 that at least $10 \%$ of the distribution will be above the tolerance bound.) scale.

$\dagger$ Because of local linearity of the log function, the same is approximately true on the log
} 


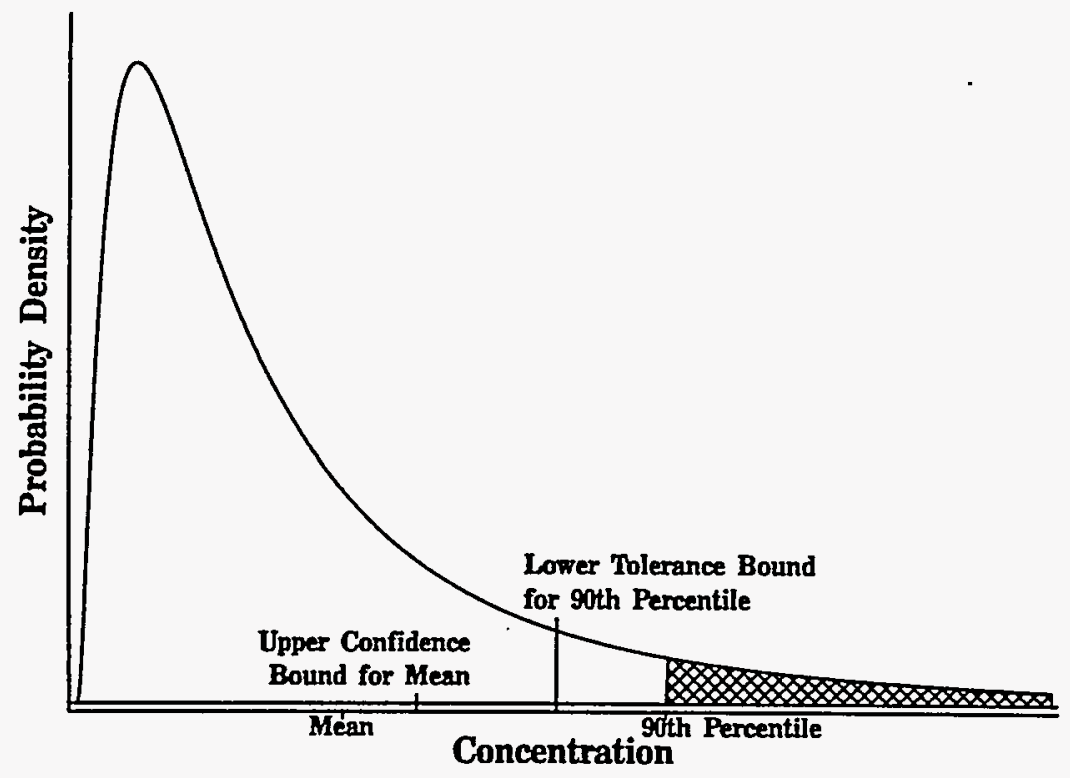

Fig. 8.1. Parameters and statistics for a hypothetical background distribution and sample.

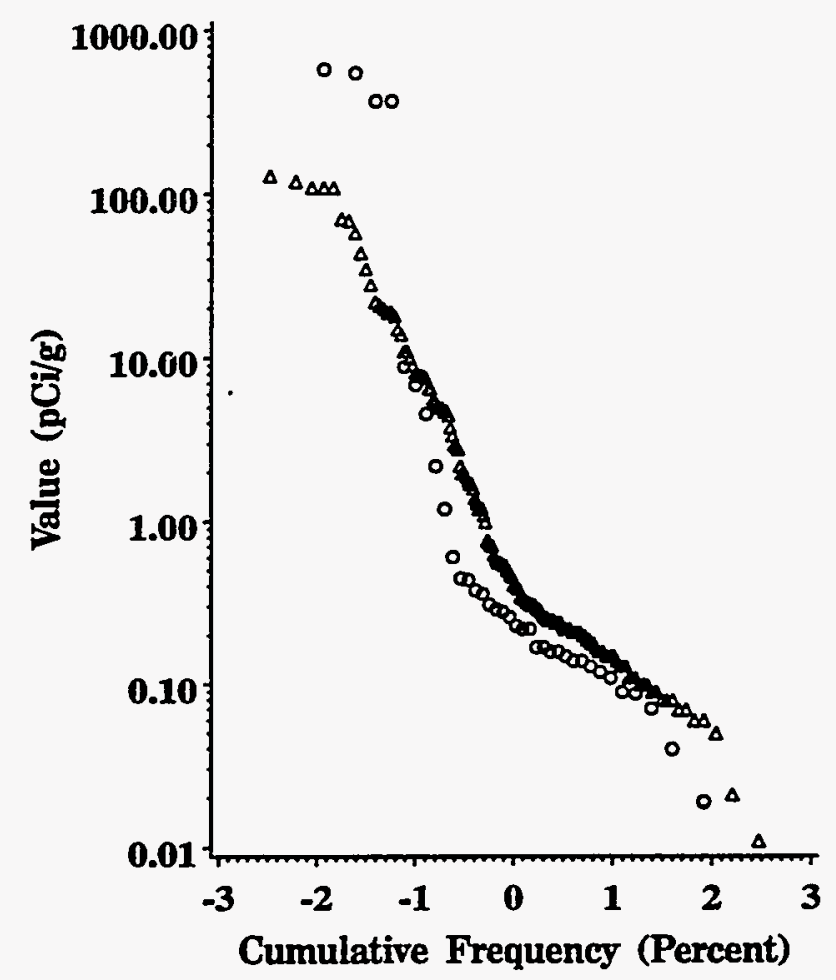

Depth: $\circ \circ \circ$ more than $5 \mathrm{~cm}$

$\Delta \Delta \Delta 5 \mathrm{~cm}$ or less

Fig. 8.2. Probability plot for the PGDP ${ }^{234} U$ data. The normal score is the quantile of the normal distribution corresponding to the percentile of the raw data. This plot would be roughly linear for lognormal data. 
(CH2M Hill 1992). This data set was used because it is the largest available data set from PGDP that is of known quality and that contains information from both surface and subsurface soils (see Appendix A for a complete description of this data set). Plots for ${ }^{235} U$ and ${ }^{238} \mathrm{U}$ are similar to Fig. 8.2. These data are from samples collected across PGDP, including areas of known uranium contamination, and contamination is evident in the data. To obtain an approximate background sample, for the purpose of sample size determination only, these data were used, but values for ${ }^{234} \mathrm{U}$ and ${ }^{238} \mathrm{U}$ exceeding $0.3 \mathrm{pCi} / \mathrm{g}$ and values for ${ }^{235} \mathrm{U}$ exceeding $0.03 \mathrm{pCi} / \mathrm{g}$ were excluded. The numbers of observations remaining after these exclusions were 82 for ${ }^{234} \mathrm{U}, 29$ for ${ }^{235} \mathrm{U}$, and 79 for ${ }^{238} \mathrm{U}$. Using these PGDP data and BSCP data for the same analytes, we estimated necessary sample sizes as follows.

The PGDP data in Fig. 8.2 and the data for ${ }^{235} U$ and ${ }^{238} U$ had very few duplicates. Therefore, BSCP data were used to estimate the laboratory variance component $\sigma_{\mathrm{L}}{ }^{2}$ (see Sect. 5.10 of the BSCP report). Variances for deep $(>5 \mathrm{~cm})$ and surface $(\leq 5 \mathrm{~cm})$ soils were essentially the same, so these results were combined (Table 8.1).

For sample size determination, we focus on $90 \%$ lower tolerance bounds for upper 90 percentiles. These tolerance bounds are for composites of three. (For noncomposites or composites of other than three, a more complicated variance components analysis is necessary.) The upper tail of the background distribution is of particular interest because it represents the possible gray area between background and contamination. Lower confidence bounds for upper percentiles are of interest because they are statistically safe determinations of how low the true upper tail of the background distribution might be. (Using lower confidence bounds in background assessment is consistent with using upper confidence bounds in exposure assessment.)

Under the assumption that a distribution is lognormal, its percentiles have the form $e^{\mu+2 a}$, where $\mu$ is the $\log$-scale mean, $\sigma^{2}$ is the log-scale variance, and $a$ indexes the percentiles. For a random sample from a lognormal distribution with all detects, ${ }^{*}$ tolerance bounds are of the form $e^{\bar{x}+k s}$, where $\overline{\mathrm{x}}$ is the $\log$-scale sample mean and $s^{2}$ is the log-scale sample variance. The constant $k$ is determined to satisfy the probability statement,

Table 81. Variance estimates for uranium (base-ten log of pCi/g)

\begin{tabular}{cccc}
\hline Analyte & $\begin{array}{c}\alpha_{\mathrm{S}}{ }^{2} \\
\text { (from PGDP) }\end{array}$ & $\begin{array}{c}\alpha_{\mathrm{L}}{ }^{2} \\
\text { (from ORNL) }\end{array}$ & $\alpha_{\mathrm{S}}{ }^{2} / 3+\alpha_{\mathrm{L}}{ }^{2}$ \\
\hline $\mathrm{U}-234$ & 0.073 & 0.0045 & 0.029 \\
$\mathrm{U}-235$ & 0.050 & 0.0109 & 0.028 \\
$\mathrm{U}-238$ & 0.075 & 0.0037 & 0.029 \\
\hline
\end{tabular}

*Nondetects are considered in Sect. 8.3. 


$$
P\left(e^{\bar{x}+k s} \leq e^{\mu+a \alpha}\right)=1-\alpha
$$

for some prespecified $\alpha$ (e.g., $\alpha=0.1$ ). The constant $k$ does not depend on $\mu$ or $\sigma$ and can be determined* for any sample size $n$, any $a$, and $\alpha$.

Subject to Eq. $1, \bar{x}+k s$ must behave consistently with other criteria, for example that

$$
P\left(e^{\bar{x}+k s}>\gamma e^{\mu+a g}\right)
$$

is large for values of $\gamma$ between 0 and 1 . That is, the probability that the lower tolerance bound exceeds values less than the true percentile must be as large as possible. These values are represented as $\gamma$ times the true percentile, which is $e^{\mu+a \sigma}$. (The factor $\gamma$, which is just a proportionality constant, indexes values less than the true percentile.) The probability (Eq. 2) is also the power of a certain statistical hypothesis test, and it is referred to as such. $\dagger$

For example, for a sample size $n=4$, the power at 0.66 of the 90 th percentile $(\gamma=0.66)$ is 0.72 . This means that our lower tolerance bound, which with probability 0.90 will be below the true 90th percentile, will also exceed two-thirds of the true percentile with probability 0.72 . Now 0.72 is a reasonably high probability, but it also reflects considerable uncertainty. However, the power is 0.97 for $\gamma=0.5$; our lower tolerance bound will also exceed one-half of the true percentile with probability 0.97 . Thus for $n=4$, we are very confident that the tolerance bound will be at least one-half the true percentile. If the true 90 th percentile is 0.3 $\mathrm{pCi} / \mathrm{g}$, for example, then we are $97 \%$ confident that the tolerance bound will be at least 0.66 $=0.15 \mathrm{pCi} / \mathrm{g}$. It may well be higher, but it will with $97 \%$ certainty be at least $0.15 \mathrm{pCi} / \mathrm{g}$.

What does the sample size of 4 and the power of 0.97 buy us? To see this, first note that the lower tolerance bound is a value that we can confidently (in this case at level 0.90 ) assume does not overestimate the true percentile. This is important, because if we overestimate the percentile, our reckoning of that percentile-and of the gray area where background ends and contamination begins-will be too high. Then we would interpret future contaminated samples as background. But if, because of statistical uncertainty, the lower tolerance bound is too low, our reckoning of the 90 th percentile will be too low. This would make many future samples that are at true background levels appear to be above background.

*Using the non-central t-distribution.

$\uparrow$ Here, the power, for any $\mu$ or $\sigma$, is the rejection probability of the test of the hypothesis that the true lognormal percentile is $\gamma e^{\mu+\infty}$ or less, against the alternative that it is more than that value, at the particular alternative $e^{\mu+\infty}$. The probability or power (Eq. 2) can be determined in a calculation similar to the one for $k$. 
For $n=4$, we are confident that our tolerance bound for the 90 th percentile will be between one-half that percentile and the percentile itself.*

For $\sigma=0.17$ from Table 8.2, we computed the power (Eq. 2) for $\gamma=0.5,0.66,0.75$, and 0.9 and for sample sizes $n$ from 2 to 10 (Table 8.2). Here $n$ represents the number of composites of three (i.e., number of samples actually sent to the laboratory).

These power calculations represent the minimal power for data from one analysis group (e.g., formation and depth). Data may be combined in various ways (as in analysis of variance) to provide more degrees of freedom for variance estimates (and thus more power). On the basis of this and Table 8.2, we believe that four composites of three is a reasonable number of samples for each sampling area (e.g., formation). Where this is not feasible, as with soil borings, data combination techniques will be used.

Stipulations about sampling areas, sample sizes, and laboratory duplicates, field splits, and field ("step-aside") duplicates are presented in Sect. 5. Simple random sampling will be used within each area. Due to the minimal requirements of the field sampling program design, field splits, which help to estimate laboratory error and sample granularity, should be favored over

Table 8.2 Estimates of power (Eq. 2) for PGDP uranium ( $\sigma=0.17$ ).

\begin{tabular}{cccccc}
\hline $\begin{array}{c}\text { Sample size } \\
(n)\end{array}$ & $\begin{array}{c}\text { Tolerance } \\
\text { coefficient } \\
(k)\end{array}$ & $\begin{array}{c}\text { Power for } \\
\gamma=0.5\end{array}$ & $\begin{array}{c}\text { Power for } \\
\gamma=0.66\end{array}$ & $\begin{array}{c}\text { Power for } \\
\gamma=0.75\end{array}$ & $\begin{array}{c}\text { Power for } \\
\gamma=0.9\end{array}$ \\
\hline 2 & 0.4026 & 0.861 & 0.538 & 0.379 & 0.177 \\
3 & 0.5348 & 0.939 & 0.640 & 0.451 & 0.195 \\
4 & 0.6171 & 0.973 & 0.718 & 0.513 & 0.211 \\
5 & 0.6753 & 0.988 & 0.780 & 0.567 & 0.226 \\
6 & 0.7194 & 0.995 & 0.828 & 0.615 & 0.239 \\
7 & 0.7545 & 0.998 & 0.865 & 0.657 & 0.252 \\
8 & 0.7833 & 0.999 & 0.895 & 0.694 & 0.264 \\
9 & 0.8076 & 1.00 & 0.918 & 0.727 & 0.276 \\
10 & 0.8284 & 1.00 & 0.936 & 0.757 & 0.287 \\
\hline
\end{tabular}

*The probability 0.97 may seem unnecessarily high, but it is not because one-half the true 90th percentile is a low concentration in the following sense: The probability that a new concentration (composite of three) is below gamma multiplied by the true 90 th percentile can be shown to be $\Phi(1.28+\log \gamma / \sigma)$, where $\Phi$ is the standard normal cumulative distribution function. If $\sigma$ is 0.17 (the value for the ${ }^{234} U$ data), then for $\gamma=0.5$, the new-sample probability is about 0.31 , which is not very high. (For $\gamma=0.66,0.75$, and 0.90 , the probabilities are $0.60,0.71$, and 0.84 .) 
field duplicates, which confound small-scale spatial variability with these other sources of variability.

\subsection{DATA ANALYSIS}

Statistical data analysis will involve (1) a preliminary graphical inspection to determine statistical outliers and to ensure data quality; (2) calculation of summary statistics-means, tolerance bounds, variances, and variance components-primarily under the assumed parametric model (most likely lognormal); and (3) formal statistical comparisons (e.g., with respect to depths or formations). Unless all or nearly all of the observations for a particular constituent are nondetects, the mean, variance, and other parameters of the constituent distribution can be estimated from data with nondetects, with basically the same approach as for all-detect data. (The method of maximum likelihood generalizes to account for nondetects.) The SAS Lifereg procedure handles data with nondetects for various parametric distributions including the normal and lognormal and can be used to compute percentile estimates and standard errors, from which confidence bounds for percentiles can be constructed. If necessary, the same approach can be used to estimate variance components when there are nondetects.

By the nature of background, the possibility of all or nearly all nondetects for a particular constituent is an important issue. If all or nearly all of the data are nondetects, there will be few options for the statistical analysis. If all or nearly all of the data are nondetects, upper confidence bounds can still be computed for the probability that an observation exceeds the largest detection limit. These confidence bounds, which are based only on the binomial distribution, do not require the assumption of an underlying parametric form for the distribution. Unfortunately, for small sample sizes these upper confidence bounds are never small. In fact, it can be shown that if all of the background data are nondetects, then the upper confidence bound $U$ is $1-\propto^{1 / n}$, where $1-\propto$ is the confidence level and $n$ is the sample size. For $\propto=0.1$ and $n=4, U$ is 44 . Even without compositing, that is, if $n=12$, $U$ would still be 0.17 . Thus, for this approach to be useful, data from several depths or formations will have to be combined. 


\section{DATA INTERPRETATION PLAN}

\subsection{INTRODUCTION}

This section presents approaches for technical evaluation of the BSPP data to maximize its usefulness for other PGDP ER projects.

Chemical compounds, minerals, elements, and radionuclides in soils can have several sources. Current EPA extraction procedures remove differing amounts of various soil constituents. The location of the soil in the landscape can also affect data. Interpretation of these data must be done very carefully.

Radionuclides and metals in soils are complex to interpret. Some components are definitely inherited from the underlying geologic formations, and others have both a geologic source and an anthropogenic source either from global fallout or from local and regional sources. Higher concentrations of metals in the A horizon than in the B horizon or parent material are often an indicator of anthropogenic contamination. An exception to this statement may be biocycled elements that are used by plants and become concentrated in the A horizon, or where upward translocation has concentrated some inorganics near the surface. Concentrations of local anthropogenic radionuclides above background levels should be taken as indicators of potential contamination from local sources.

\subsection{APPROACH FOR DATA EVALUATION}

One objective of BSPP data evaluation and interpretation is to present comprehensive, valid, and defensible background concentration levels of selected metals and radionuclides in surface soils and deep soil core samples near PGDP for determining cleanup levels of the contaminants. To accomplish this objective, the analysis data of surface soil and soil core samples will be carefully evaluated and interpreted. Evaluation of the validated data from analytical laboratories will be conducted by plotting and comparing the data set to:

- find outliers by plotting metal distribution and isotopic ratios among the samples,

- find data trends for different horizons of soil and depths of alluvium samples,

- compare disturbed and undisturbed soils, and

- compare with existing data sets in the region.

If there are no obvious outliers of the data set and it shows a reasonable trend given sets of parameters or conditions, the data set will be treated statistically and interpreted.

\subsection{DATA INTERPRETATION AND COMPARISONS}

The selection of soil sampling sites and analytes was dictated by the project objectives. Therefore, technical data interpretation will focus on the distribution, trends, and differences of groups to accomplish the project objectives. The results will be interpreted by the following factors influencing the metal and radionuclide concentrations: 
- Landscape and Parent Material Consideration. The soil series selected are representative of two different landscape positions and two different parent materials (see Sect. 4). Soillandscape variables can affect the distribution of target components. The location of a soil in the landscape can be affected by adjacent soils. Rainfall that has infiltrated or runoff from higher soils can move laterally below the surface and affect soils downslope. The criteria for selecting upland soil sampling sites are that each site is (1) geomorphically stable and (2) located in the highest part of the landscape to minimize effects from immediately adjacent soils. Stream terraces are selected to compare to the upland soils.

- Soil Horizon Development Factor. Samples will be taken from the A horizon and the B horizon. The A horizon contains the most organic carbon and also the highest biotic activity. Here, soil organisms can decompose or transform one compound into another, or inorganic compounds can be transformed into more mobile organometallic complexes.

The B horizon of most soils, commonly known as the upper subsoil, is the soil zone where there is a net accumulation of soil clay minerals, iron-manganese oxides, or carbonates. Here, soil organisms tend to degrade organic compounds that have been translocated from the A horizon above, releasing metal ions from an organic form to an inorganic form. Respiration in this part of the soil tends to be aerobic on ped surfaces and along root channels and anaerobic within peds. Dissolved organic carbon moves into and through this soil horizon. Whether or not it is degraded and releases any metal ions depends on its rate of movement and time of residence. When making a comparison, the best interpretation of results involves having a set of data from the A and B horizons of a particular site under similar vegetation to observe trends. In principle, inorganic and natural radionuclide data from one formation should not be used as background data of another formation because samples from different geologic formations can have different levels of inherited metals and natural radionuclides unless the statistical interpretation would indicate otherwise.

- Consideration of Different Geologic Formations. The deep soil core sample data set will be composed of three different formations, loess (unaffected by pedogenesis), upper continental deposit, and Porters Creek Clay. Considerable differences of radionuclide concentrations among the formations are expected because of the differences of source material, texture, and mineralogy.

Data interpretation based on statistical trends, as well as pedogenic, landscape, and geologic factors, will aid in understanding the meaning of data variations and will make the database more useful to other ER projects. 


\section{RISK ANALYSIS PLAN}

\subsection{INTRODUCTION}

This section describes the risk analysis plan for the BSPP. It discusses the importance of performing the risk analysis and describes the method that will be used to perform it.

\subsection{IMPORTANCE}

Background activity levels for radionuclides and background concentrations for inorganic analytes will be used to screen lists of detected analytes in future site and remedial investigations at PGDP. In this screening, any analyte found to exceed its respective background activity or concentration in any single soil sample taken from a site will be retained for further analysis as a contaminant of potential concern for all media at that site (EPA 1991b). Because this screen is an integral part of the data reduction steps of both screening risk evaluations and baseline risk assessments, attention must be paid to the uncertainties brought to the risk evaluation or assessment by screening data.

\subsection{METHODS}

The risk analysis for the BSPP will consist of two parts. In part one, background activities and concentrations will be compared to human health risk-based screening criteria and ecological benchmarks. In part two, the uncertainties associated with the use of the background activities and concentrations in future risk evaluations and assessments will be discussed.

\subsubsection{Comparison to Human Health Risk-Based Screening Criteria and Ecological Benchmarks}

In this portion of the risk analysis, background activities and concentrations determined by statistical analysis and evaluation will be compared to human health risk-based screening criteria and ecological benchmarks for direct exposure to soil. The human health risk-based screening criteria that will be used for the comparison will be the preliminary remediation goals for direct soil exposure presented in Preliminary Remediation Goals for Use at the U.S. Department of Energy Oak Ridge Operations Office (Energy Systems 1995) or the most recent revision of this document. The ecological benchmarks that will be used in the comparison will be those found in Toxicological Benchmarks for Wildlife: 1994 Revision (Opreska et al. 1994), Toxicological Benchmarks for Screening Potential Contaminants of Concern for Effects of Terrestrial Plants: 1994 Revision (Will and Suter 1994a), and Toxicological Benchmarks for Screening Potential Contaminants of Concern for Effects on Soil and Litter Invertebrates and Heterotrophic Process (Will and Suter 1994b) or the most recent revisions of these documents. Because each of these documents contain extensive sections discussing the sources of or methods used to calculate their respective screening values, and because these sources and methods may change between now and when the BSPP report is prepared, the methods which will be used to determine the human health risk-based screening criteria and ecological 
benchmarks will not be presented. However, any methods used when the data report is prepared will be consistent with federal guidance (e.g., EPA 1989, 1991a) and state regulations.

In addition to performing the simple comparison discussed in the preceding paragraph, this section of the BSPP report will interpret and discuss the results of the comparisons. For both the comparison of background values to human health risk-based screening criteria and to ecological benchmarks, the discussion will focus on the magnitude of background concentrations or activity levels in relation to the human health-based screening criteria and potential reasons for not observing health or environmental effects, even when the background concentration or activity level exceed the screening criteria or benchmarks.

\subsubsection{Uncertainties in Using Background Concentrations and Activities to Select Contaminants of Potential Concern}

In this portion of the risk analysis, uncertainties in the use of background concentrations and activities to reduce the data set of detected analytes will be discussed. Specific uncertainties to be addressed are:

- the effect of using the maximum detected value in any sample in screening detected analytes,

- the significance of ignoring analyte speciation in comparing detected analyte concentrations and activities to background concentrations and activities, and

- the importance of allowing for the geochemical interpretation of the results from the comparison of background activities and concentrations to detected analyte concentrations. 


\section{HEALTH AND SAFETY PROGRAM}

\subsection{INTRODUCTION}

\subsubsection{Purpose}

This section addresses health and safety issues associated with the BSPP. Health and safety requirements and procedures outlined within this plan are intended to address in-field sampling activities. The goals of this plan are to minimize avoidable accidents and injuries, eliminate worker exposure to chemicals and radionuclides greater than natural background levels in the performance of sampling activities, and provide contingencies that may arise during soil sampling.

\subsubsection{Applicability}

The provisions of this health and safety section are mandatory for all on-site personnel and visitors engaged in surface soil sampling activities. Subcontractors will require an Energy System Project Safety and Health Checklist (PC-164) be approved prior to commencement of work. All on-site personnel will be provided copies of the BSPP project plan (which includes this health and safety section). A copy of the project plan will be on site with each field team. All work will be completed in accordance with this plan. A review of this plan by all sampling staff is required prior to conducting field activities. The technical coordinator will resolve any questions regarding health and safety before sampling commences. All perspective on-site personnel will sign and date the field logbook to verify that they were provided a copy of the plan and that they will conduct work in accordance with the plan.

All drilling operations for deep strata sampling will be conducted by a geotechnical service contractor. The specific hazards and controls associated with the drilling will be addressed in the PC-164 and the service contractor's corporate health and safety program. The health and safety program will be in accordance with Special Conditions and Specifications for Geotechnical Service Subcontracts. Oak Ridge National Laboratory, Oak Ridge K-25 Site, Oak Ridge Y-12 Plant, in Oak Ridge, Tennessee; Paducah Gaseous Diffusion Plant, in Paducah, Kentucky; Portsmouth Gaseous Diffusion Plant, in Portsmouth, Ohio (Energy Systems 1993a).

\subsection{SITE INFORMATION}

\subsubsection{General}

Sites chosen for soil sampling will be checked for radioactivity and VOCs by project personnel to ensure that concentrations are not above background. Any indication of contamination or disturbance will dictate that the site be removed from the list of sampling site candidates. Sampling sites will be chosen in accordance with Sect. 4.2 of this plan. Paducah site locations were coordinated with the PGDP Engineering Department to preclude contact with buried utility lines or piping. All potential sampling sites are located outside the DOE Reservation, and the Paducah Industrial Hygiene HAZWOPER (Hazardous Waste 
Operations and Emergency Response) representative has determined that these sampling activities do not fall under the scope of 29 CFR 1910.120. Sampling sites are located in Ballard County in a rural setting away from structures and facilities. In addition,

- All on-site personnel will have read the project plan and discussed the health and safety issues with the field team leader. In addition, all personnel will be briefed as to on-site conditions and any potential safety hazards before being permitted access to the site by the technical coordinator.

- Hard hats, safety glasses, gloves, and safety shoes will be required when sampling is being conducted using power equipment. Otherwise, only work gloves and appropriate field work clothes are required.

- Sampling crews will have an operable field radio with them when sampling. A mobile telephone will be available, and a telephone in closest proximity to the sampling sites will be noted. A listing of appropriate radio numbers and/or phone numbers is given in Sect. 11.5. All personnel will be briefed on the location and route to the nearest medical facility on a site-by-site basis.

- The BSPP technical coordinator or his designee will be informed as to the sampling crew(s) intended sampling sites for each given day. The crew will endeavor to inform the BSPP technical coordinator or his designee as to progress and changes in field plans, as necessary.

\subsubsection{Physical Hazards}

Physical hazards expected to be encountered during sampling include (1) machinery-related hazards when rotating equipment, such as power augers or drill rigs, are used; (2) site-related hazards, such as uneven surfaces, trees, and other obstacles, mud, and slippery conditions; and (3) transportation-related hazards.

Before sampling activities begin, the technical coordinator or his designee will verify that a penetration/excavation permit has been acquired. A copy of this permit will be provided to the field team leader. This permit, once reviewed and signed by the appropriate personnel at Energy Systems, serves to inform that sampling sites have been selected in areas where underground utilities or obstructions should not be encountered.

The technical coordinator will ensure that sampling is carried out safely and in accordance with this project plan. Personnel involved in operating equipment and collecting samples, and the technical coordinator will be allowed to approach the sampling operation when power equipment is operating. The technical coordinator will limit the number of personnel that may be in close proximity to the sampling equipment in a manner that is consistent with the safe operation of the equipment.

Sampling will not be attempted during periods of precipitation, subfreezing temperatures, or when illumination of the sampling site is insufficient. Sampling operations in progress may continue after onset of such ambient conditions if only a short time is required to complete the task and if work can proceed safely-that is, light is available and all monitoring equipment is functional. 


\subsection{SITE TASK HAZARD ANALYSIS}

The purpose of the site task hazard analysis is to identify potential health and safety concerns that may be encountered by sampling personnel and the personal protective equipment required for the task. The site task hazard analyses described are minimum requirements.

\subsubsection{Site Requirements}

Sites selected for sampling will be rural settings in either woods or fields, and for the most part sampling will be done using hand tools. A power auger and a drill rig will be used for sampling the deep soil horizons. Pre-entry health and safety briefings in the form of team "tailgate" meetings will be held at each site to assess each site for potential hazards and site-specific setup and layout of equipment and operations to minimize hazards and optimize sampling efficiency.

Protective Level D is required only for sampling with power equipment. Protective clothing will be worn by personnel handling fuel for the power auger or drill rig. In addition, hard hats, hearing protection, safety glasses, gloves, and safety shoes will be required for those working around the drill rig or power auger (Table 11.1).

The surface sampling sites are not located within the DOE Reservation; therefore, company-issued clothing will not be required, but work clothes appropriate to the activity will be donned. For drill locations, company-issued DOE khakis will be required.

Inadequate health and safety precautions on the part of any on-site personnel or the belief that personnel are or may be exposed to an immediate health hazard will be sufficient cause for the field team leader to suspend site work and require personnel to evacuate a potentially hazardous area.

Table 11.1. Protective equipment for on-site activities

\begin{tabular}{|c|c|c|}
\hline Activity & Level & Protective equipment \\
\hline $\begin{array}{l}\text { Sampling using power } \\
\text { augers and drill rigs }\end{array}$ & D & $\begin{array}{l}\text { Hard hat } \\
\text { Safety glasses } \\
\text { Safety shoes } \\
\text { Field work clothes } \\
\text { Work gloves }\end{array}$ \\
\hline $\begin{array}{l}\text { Equipment precleaning } \\
\text { Cleaning (laboratory) }\end{array}$ & & $\begin{array}{l}\text { Rubber gloves } \\
\text { Water-resistant clothing } \\
\text { Safety glasses } \\
\text { Lab coat }\end{array}$ \\
\hline Normal sampling & & $\begin{array}{l}\text { Field work clothes } \\
\text { Work gloves } \\
\text { Work shoes }\end{array}$ \\
\hline
\end{tabular}


Soil sampling for the BSPP will occur through FY 1996. The actual dates for sampling individual sites are dependent upon weather and logistical factors. The technical coordinator has determined that the time set aside for sampling is adequate to accommodate any anticipated delays.

\subsubsection{Suspected Contaminants}

Sites sampled for the BSPP are selected and will be checked to ensure that radioactivity is below expected background and that no VOCs are present. In addition, periodic monitoring will be employed to demonstrate the contaminant levels remain as stated.

\subsubsection{Hazard Evaluation}

Hazard evaluation was performed with the following tabulated results:

$\begin{array}{lllllll}\text { Waste types: } & \text { Liquid/Free } & \underline{\text { No }} & \text { Solid } & \underline{\text { No }} & \text { Sludge } & \underline{\text { No }} \\ \text { Characteristics: } & \text { Corrosive } & \underline{\text { No }} & \text { Ignitable } & \underline{\text { No }} & \text { Radioactive } & \underline{\text { No }} \\ & \text { Volatile } & \underline{\text { No }} & \text { Toxic } & \underline{\text { No }} & \text { Reactive } & \underline{\text { No }} \\ \text { Unknown } & \underline{\underline{N o}} & & & & \\ \text { Hazards: } & \text { Chemical } & \underline{\text { No }} & \text { Physical } & \underline{\text { Yes }} & \text { Radiological } & \underline{\text { No }}\end{array}$

\subsubsection{Sampling}

Level D protective clothing will be required only when sampling is being conducted using power equipment. In other cases the sampling crew will be responsible for wearing clothing sufficient to protect them from ambient conditions and poison ivy during site preparation. Because the sites will be selected on the basis of no contamination, there is no need for requiring personal protective equipment measures above Level $D$.

LMES Industrial Hygiene will perform a noise survey and establish hearing protection requirements for any noise source greater than $85 \mathrm{~dB}$. Gloves will be worn when fueling the equipment. All personnel not required for equipment operation and sampling will be kept out of the 20-ft radius or the height of the mast of the drill rig, whichever is greater, from the sampling area during power equipment operation and mobilization/demobilization. The drill rig operator and the field team leader will verify that the drill rig will not be located so that any part of the rig is within $10 \mathrm{ft}$ of any electrical transmission lines. The voltage of a transmission line in close proximity to sampling site should be determined. Table 11.2 should then be consulted in order to determine the distance required for safe operation of the drill rig when in proximity to transmission lines.

\subsubsection{Equipment Cleaning}

Equipment cleaning will be done to prevent cross contamination of samples between sites even though contaminants in hazardous concentrations, or above regulatory limits, are not believed to be present at the sampling sites. Equipment will be cleaned according to PGDP ERWM Field Operation Procedure (FOP) CP4-ER-DCN4002, Decontamination of Field Equipment (Utility Services 1993). The drilling rig, when used, will be washed with a pressure washer or hose and potable water on-site in accordance with PGDP ERWM FOP CP4-ER- 
Table 11.2 Safe working distances from electrical transmission lines for drill rigs

\begin{tabular}{cc}
\hline $\begin{array}{c}\text { Normal (phase-to-phase) voltage } \\
(\mathrm{kV})\end{array}$ & $\begin{array}{c}\text { Minimum clearance } \\
\text { required } \\
(\mathrm{ft})\end{array}$ \\
\hline
\end{tabular}

When operating near high voltage power lines

0 to 50 10

50 to 200 17

200 to 350 22

350 to 500 27

500 to 750 35

750 to 1000 44

While in transit with mast lowered

All voltages 10

Source: Crawler locomotive and truck cranes [29 CFR 1910.180j(1)].

DCN4001, Decontamination of Drilling-Related Equipment (Utility Services 1993). Personal protective equipment will be Level $\mathrm{D}$, except water-resistant clothing will be worn and hearing protection may be required.

\subsection{SPECIAL HAZARDS}

All site investigation personnel may potentially be exposed to the hazards outlined here.

\subsubsection{Temperature Extremes}

Sampling activities may be physically demanding during the winter and summer months. Physical demands may be compounded through the use of protective clothing and equipment, moderate to heavy workloads, ambient air temperatures, relative humidity, wet or rainy conditions, wind speed, and exposure to nonionizing radiation (sunlight).

Two important factors will help personnel function in hot environments: acclimatization and consumption of fluids. Acclimatization is a physical and psychological adjustment that workers experience during the first two weeks. During this period especially, workers should concentrate on maintaining a balanced diet, consuming plenty of fluids throughout the day, and remaining aware of telltale signs of heat-related stress. Headaches, dizziness, high body temperature, and increased heart rate are all early warning signals of heat stress. It is 
imperative that the technical coordinator be informed of this condition if a worker experiences these signs.

In cold environments, the two important factors that will help personnel function are acclimatization and proper clothing. Especially during the first two weeks, workers should concentrate on maintaining a balanced diet, consuming plenty of fluids throughout the day, and remaining aware of signs of cold-related stress, such as headaches, numbness in extremities, dizziness, low body temperature, and decreased heart rate. It is again imperative that the technical coordinator be informed if a worker experiences these symptoms.

All sampling will be done by a crew of at least two persons at the investigative site, which will incorporate a "buddy" system, and as sampling continues, all personnel should be apprised of their buddy's condition with respect to heat. A work regimen will be instituted, if necessary, to help in combatting heat- and cold-related disorders during extreme weather, if present. The technical coordinator may develop work/rest regimens in accordance with his/her best professional judgment and the guidelines published by the American Conference of Governmental Industrial Hygienists and may consult PGDP Industrial Hygiene for assistance.

\subsubsection{Biological Stress}

Field conditions may present a variety of biological stresses. It is the responsibility of investigative personnel to inform the technical coordinator of pre-existing health conditions they have that may be affected by on-site biological stresses. Examples of these stresses include bee stings, ticks, snakes, and poison ivy. Asthmatic conditions may be affected by exposure to certain pollens, grasses, etc.

\subsubsection{Illumination}

Normal operating conditions for the BSPP will involve conducting field activities during daylight hours. Lumination of about $5 \mathrm{ft}-\mathrm{c}$ will be required to conduct field activities; however, actual field measurements of illumination will not be collected. A conservative guideline may be that field work will commence $15 \mathrm{~min}$ after sunrise and conclude $15 \mathrm{~min}$ prior to sunset.

\subsubsection{Dust}

Based upon previous experience associated with sampling activities, it is likely that dust generation will be minimal. A generic rule of thumb is that a visible cloud of dust will constitute an action limit. An engineering control may be employed to control dust, such as wetting the auguring area with deionized water that is sprayed as a fine mist from a garden sprayer. In the unlikely event that engineering controls are unsuccessful, the appropriate Industrial Hygiene organization will be summoned to assess the situation and to provide guidance.

\subsubsection{Ergonomics}

Potential hazards related to the interaction of personnel with their working environment may be present during sampling. The primary ergonomic hazards may be lifting heavy loads, equipment vibrations, body positioning, and physical obstacles associated with traversing ditches and brush. Personnel should always position themselves properly and lift from the legs 
when attempting to lift equipment. Personnel should rely on their "buddy" to assist in lifting loads that are too heavy for one person to properly lift and carry. Back strain, the most common ergonomic hazard in the field, may be easily avoided, provided the on-site workers always ask for assistance when they need it.

A certain degree of vibration may be encountered by sampling personnel when operating the power auger. If any numbness is encountered, appropriate work/rest regimens will be employed by the technical coordinator within his/her best professional judgment. If any ergonomic symptoms are encountered in the field, the technical coordinator should be notified immediately.

\subsubsection{Physical Sampling Location Hazards}

These hazards may include, but are not limited to, movement of equipment around the site, mechanical equipment malfunctions, unestablished roads, and potential noise hazards. Personal hazards, such as tripping or falling, can also have an adverse effect on the health and safety of personnel.

Overhead electrical transmission lines may cross some sampling locations. Prior to placing a drilling rig at an auger hole location, the sampling crew leader or his designee will verify that the rig will not be operated when any part of the drill rig mast enters within a minimal radial distance of $10 \mathrm{ft}$ from electrical transmission lines or as specified in Table 11.2. All personnel should stay clear of overhead work and temporarily suspended or moving equipment whenever possible. The sampling locations will be certified clear of all known underground hazards by LMES Civil Engineering prior to sampling.

\subsection{EMERGENCY PROCEDURES}

For on-site emergencies, the Plant Protection and Shift Operations divisions of PGDP provide 24-hour emergency response coverage, which is the responsibility of the plant shift superintendents (PSSs). The shift superintendents on duty are assisted by well-trained plant emergency squads and are the overall coordinators responsible for directing the response to emergencies, such as fires, accidents, injuries, natural disasters, sabotage, etc.

As most of the sampling activities will occur away from PGDP facilities, the sampling crew will carry a mobile telephone and field radios (at least one) tuned to the PGDP A-1 network for communications in case of emergency. The PSSs on duty are the designated Plant Emergency Directors who are responsible for coordinating and responding to all PGDP emergency situations. In the event that an off-site emergency occurs, 911 should be dialed on the mobile phone or should be called from the nearest available phone. The PSS should be notified after obtaining assistance from 911 for an off-site emergency. Any member of the sampling crew can notify or assign someone to notify the PSS of an emergency situation as soon as possible.

For medical emergencies during deep strata sampling, personnel report to PGDP Medical. For off-site emergencies during surface soil sampling in Ballard County, personnel will proceed to Lourdes Hospital, Paducah, Kentucky. The technical coordinator will decide and brief personnel on a site-by-site basis as to the best evacuation route to Route 60 . From 
Route 60, travel east to I-24 East. Continue on I-24 to Exit 7. Turn left at the second traffic light on to Lone Oak Road. Lourdes Hospital is on the right, immediately after crossing the interstate (see Fig. 4.1 for the Paducah vicinity map).

\subsubsection{Plant Shift Superintendent}

EMERGENCIES: Plant Phone: 555

Off-Reservation Occurrences: Phone: 911

To call PGDP from off-site: (502) 441-6211

(Identify that it is an off-site emergency call.)

PGDP Radio Network: $\quad$ A-1

For on-site emergencies, contact the Plant Shift Superintendent (PSS) first The PSS is the trained emergency response director.

Listed below are emergency groups and their telephone numbers. A cellular phone will be present in the field and available for use when workers are not in close proximity to a plant phone.

PGDP Emergency Numbers

Environmental Management

(502) 441-5052

Guard Department/ Security

(502) $441-6246$

Health Physics

(502) $441-5043$

Industrial Hygiene/HAZWOPER

(502) 441-5048

Medical (On-site)

(502) $441-6266$

Public Relations

(502) 441-5099

Safety

(502) $441-5045$

Lourdes Hospital

Lourdes Hospital 24-hour Ambulance

(502) 444-2444

Ballard County 24-hour Ambulance

(502) 444-2444

11.5.2 Reporting an Emergency

(502) 665-5000

\section{Telephone}

- If a plant telephone is accessible, dial 555. With an off-site (cellular) phone, dial (502) 441-6211 and state that it is an off-site emergency call. With a plant radio, call the PSS on A-1. When operating off the Paducah Reservation, dial the local 911 to obtain emergency assistance prior to contacting the PSS.

- Describe the type of emergency.

- Identify the location of the emergency.

- Identify who is calling.

- In case of an injury, tell whether an ambulance is needed.

- Listen to and follow any instructions that are given. 


\section{Fire Alarm Pull Boxes}

Pulling a fire alarm box automatically transmits the location of the emergency to the Fire Department and the Emergency Control Center. The person pulling the alarm should remain at the alarm box and supply any needed information to the responding emergency squad.

\section{Radio}

By calling Alpha 2, the Plant Shift Superintendent will be alerted of the emergency. Alpha 1 alerts the Central Control Center. Give the following information.

- There is an emergency.

- Type of emergency.

- Location of the emergency.

- Identify who is calling.

- Listen for any instructions

\section{Important Reminders}

- Know the telephone and radio numbers of the appropriate PSS: 911, or Alpha 1/Alpha 2

- Dial the local 911 in the event that an emergency occurs off the Paducah Reservation. After notifying the local 911 and obtaining assistance, the PSS should be notified.

- Know how to summon an ambulance (in plant, someone has gone to a phone): Dial 911 and give the location. Wait at the location specified by the PSS to meet the arrival of the first-aid personnel.

- To summon the plant emergency squad at a fire alarm box, pull the fire alarm and wait for the arrival of the Emergency Response Team at the box.

\subsection{SITE MONITORING}

Representative monitoring of volatile organics and beta/gamma radiation will be done by site personnel. This periodic monitoring program is designed to protect all site investigative personnel from the unlikely potential of encountering volatile organic and radiological contaminants, within the best of our knowledge and the limits of our resources. The sampling sites selected are based on historical information that suggests that the background samples will be collected from locations devoid of chemical and radiological contamination posing a health and safety risk to project personnel.

\subsubsection{Instrument Calibration and Response Checks}

All applicable instruments will be calibrated within the proper time frame in accordance with the manufacturer's recommendations and specifications described in the manufacturer's SOPs and in accordance with PGDP Industrial Hygiene and Health Physics requirements. Calibration readings and the number of each radiological source will be recorded in the field logbook and flagged in the margin. Background concentrations will also be recorded in the field logbook for each individual sampling site. 
All radiation monitoring instruments will be loaned from the PGDP Health Physics Division. A Health Physics representative will be available and qualified in the use of the instrumentation that is calibrated in accordance with LMES procedures.

\subsubsection{Monitoring Equipment Action Limits}

Evaluation of site data does not warrant the anticipation of chemical or radiological contamination above background levels. Although chemical and radiological contaminants above background concentrations are not expected at the project site, precautions will be taken to minimize the possibility of exposures to site workers. Industrial Hygiene will be contacted by the technical coordinator only if VOCs are detected in the breathing zone at 5 ppm for $5 \mathrm{~min}$; work will halt, and Industrial Hygiene will be contacted to coordinate appropriate response actions. It may become necessary to abandon the location and proceed to the next sampling location.

\subsection{SITE CONTROL MEASURES-SAMPLING AREA}

Site zonation will not be used during BSPP sampling activities. Efforts will be made to restrict access to the sampling operation for the purpose of protecting the integrity of the sample and when power equipment is being used. The only area marked off will be the sampling area itself. This area will be controlled by the field team leader.

The corners of the sampling area will be marked with flags, and access will be controlled to protect the integrity of the area. Protective clothing will normally consist of work clothing and gloves necessitated by ambient conditions and site factors, such as briars, poison ivy, and insects. When power equipment is to be used, the sampling personnel involved will wear Level D protective clothing, as specified in Table 11.1.

Prohibited personnel, items, and conduct in the sampling area include the following:

- eating, drinking, smoking, or chewing anything;

- failure to inform the field team leader or technical coordinator of any illness that could affect safety or cause health-related complications;

- any individual not involved in the sampling effort;

- any conduct or item thought to be potentially dangerous to the well-being of the sampling team or the integrity of the samples; and

- application of insect spray or cosmetics, since interaction of these substances may affect the screening samples obtained for VOCs. After the VOC screening samples have been collected, insect repellents may be applied, as warranted.

\subsection{HEALTH AND SAFETY TRAINING REQUIREMENTS}

All personnel who participate in field sampling for the BSPP are subject to the following training requirements.

- All personnel working on-site must have attended the pre-entry health and safety briefing, and documentation of the training must be entered in the field logbook before 
site access will be granted. The normal scope of work does not require sampling personnel to be on the LMES radiological dosimetry program. If the scope of work changes, LMES Health Physics will be consulted. All personnel will be required to have General Employee Training.

- Documentation of project-specific health and safety training for BSPP sampling personnel will be in accordance with LMES Training Program requirements.

- All site personnel will be trained in the hazards associated with this project prior to commencement of work activities. Material safety data sheets for any fuels, solvents, and decontamination fluids will be kept on-site and available to all workers at all times. The technical coordinator will be responsible for upkeep of the material safety data sheets. 


\section{REFERENCES}

AEC (U.S. Atomic Energy Commission). 1972. Health and Safety Laboratory Procedures Manual. HASL-300. New York, New York.

ASTM (American Society for Testing and Materials). 1980. Soil Investigation and Sampling by Auger Borings. ANSI/ASTM D 1452-80.

Bonczek, R. R., J. Davidson, A. F. Diefendorf, F. G. Dolislager, N. E. Korte, C. J. Marshall, G. R. Miller, and W. L Richards. 1995. Background Concentrations and Human Health Riskbased Screening Criteria for Metals in Soil at the Paducah Gaseous Diffusion Plant, Paducah, Kentucky. KY/EM-77.

Cantaldo, D. A, T. R. Garland, and R. E. Wildung. 1987. Neptunium behavior in plants: Absorption, distribution, and fate. In J. E. Pinder III, J. J. Alberts, K. W. McLeod, and R. G. Schreckhise (eds.), Environmental Research on Actinide Elements. DE86008713. U.S. Department of Energy.

CH2M Hill. 1991. Results of the Site Investigation, Phase I, at the Paducah Gaseous Diffusion Plant, Paducah, Kentucky. KY/ER-4. Prepared by CH2M Hill, Oak Ridge, Tennessee for the U.S. Department of Energy.

Clausen, J. L., J. W. Douthitt, K. R. Davis, and B. E. Phillips. 1992. Report of the Paducah Gaseous Diffusion Plant Groundwater Investigation, Phase III. KY/E-150.

DOE (U.S. Department of Energy). 1989. General Environmental Protection Program. DOE Order 5400.1. U.S. Department of Energy, Washington, D.C.

DOE (U.S. Department of Energy). 1993a. Background Soil Characterization Project at the Oak Ridge Reservation, Oak Ridge, Tennessee. DOE/OR/01-1175. Prepared by Environmental Sciences Division, Oak Ridge National Laboratory, Oak Ridge, Tennessee.

DOE (U.S. Department of Energy). 1993b. Management Strategy for Surface Water Integrator Units at PGDP. U.S. Department of Energy, Washington, D.C.

DOE (U.S. Department of Energy). 1995. RCRA Field Investigation Work Plan for Waste Area Groupings 1 and 7 at the Paducah Gaseous Diffusion Plant. DOE/OR/07-1147\&D2. U.S. Department of Energy, Washington, D.C.

EPA (U.S. Environmental Protection Agency). 1980a. Interim Guidelines and Specifications for Preparing Quality Assurance Project Plans. EPA QAMS-005/80. Quality Assurance Management Staff. Washington, D.C.

EPA (U.S. Environmental Protection Agency). 1980b. Samplers and Sampling Procedures for Hazardous Waste Streams. EPA/600/2-80/018. Washington, D. C. 
EPA (U.S. Environmental Protection Agency). 1987. A Compendium of Superfund Field Operations Methods. EPA/540/P-87/001. Washington, D.C.

EPA (U.S. Environmental Protection Agency). 1988. Manual Chain of Custody Procedures. ESP-501. Washington, D.C.

EPA (U.S. Environmental Protection Agency). 1989. Risk Assessment Guidance for Superfund, Volume 1, Human Health Evaluation Manual, Part A. Office of Emergency and Remedial Response. EPA/540/1-89-002. Washington, D.C.

EPA (U.S. Environmental Protection Agency). 1990. Contract Laboratory Program Statement of Work for Inorganics. Las Vegas, Nevada.

EPA (U.S. Environmental Protection Agency). 1991a. Human Health Evaluation Manual, Supplement Guidance: "Standard Default Exposure Factors." OSWER Directive 9285.6-03. Office of Solid Waste and Emergency Response. Washington, D.C.

EPA (U.S. Environmental Protection Agency). 1991b. Engineering Support Branch Standard Operating Procedures and Quality Assurance Manual. Region IV. Athens, Georgia.

EPA (U.S. Environmental Protection Agency). 1991c. Test Methods for Evaluating Solid Waste. SW-846, 3rd Edition. Washington, D.C.

EPA (U.S. Environmental Protection Agency). 1993. Data Quality Objectives Process for Superfund. EPA/540/R-93/071. Washington, D.C.

Energy Systems (Martin Marietta Energy Systems, Inc.). 1988. Environmental Surveillance Procedures Quality Control Program. ES/ESH/INT-14. Martin Marietta Energy Systems, Inc., Oak Ridge, Tennessee.

Energy Systems (Martin Marietta Energy Systems, Inc.). 1989. Paducah Gaseous Diffusion Plant Site Environmental Report for 1988. ES/ESH-8/V3. Produced for the United States Department of Energy by Martin Marietta Energy Systems.

Energy Systems (Martin Marietta Energy Systems, Inc.). 1990. Paducah Gaseous Diffusion Plant Site Environmental Report for 1989. ES/ESH-13/3. Produced for the United States Department of Energy by Martin Marietta Energy Systems.

Energy Systems (Martin Marietta Energy Systems, Inc.). 1992. Requirements for Quality Control of Analytical Data for the Environmental Restoration Program. ES/ER/TM-16. Energy Systems Environmental Restoration Program, Oak Ridge, Tennessee.

Energy Systems (Martin Marietta Energy Systems, Inc.). 1993a. Special Conditions and Specifications for Geotechnical Service' Subcontracts, Oak Ridge National Laboratory, Oak Ridge K-25 Site, Oak Ridge Y-12 Plant at Oak Ridge, Tennessee, Paducah Gaseous Diffusion Plant at Paducah, Kentucky; and Portsmouth Gaseous Diffusion Plant at Portsmouth, Ohio. Portmouth, Ohio. 
Energy Systems (Martin Marietta Energy Systems, Inc.). 1993b. Validation Procedures Used in Background Soil Characterization Project on the Oak Ridge Reservation. ES/ER/TM-75. Energy Systems Environmental Restoration Program, Oak Ridge, Tennessee.

Energy Systems (Martin Marietta Energy Systems, Inc.). 1994. Environmental Restoration Quality Program Plan. ES/ER/TM-4/R4. Energy Systems Environmental Restoration Program, Oak Ridge, Tennessee.

Energy Systems (Martin Marietta Energy Systems, Inc.). 1995. Preliminary Remediation Goals for Use at the U.S. Department of Energy Oak Ridge Operations Office. Martin Marietta Energy Systems, Inc., Oak Ridge, Tennessee.

HASL-300. 1990. Environmental Measurements Laboratory Procedures Manual. Edition 27, Vol. 1. N. A. Chieco, D. C. Bogen, and E. O. Knutson (eds.). U.S. Department of Energy.

Hoffman, F. O., J. W. Huckabee, D. M. Lucas, C. T. Garten, T. G. Scott, R. L. Walker, P. S. Gouge, and C. V. Holmes. 1986. Sampling of Technicium-99 in Vegetation and Soils in the Vicinity of Operating Gaseous Diffusion Facilities. ORNL/TM-7386. Oak Ridge National Laboratory, Oak Ridge, Tennessee.

Long, D. 1995. Identification, Distribution, and Maintenance of Environmental Restoration Records. ERWM/ER-P1110. Environmental Restoration and Waste Management, Paducah Gaseous Diffusion Plant, Paducah, Kentucky.

Opreska, D. M., B. E. Sample, and G. W. Suter II. 1994. Toxicological Benchmarks for Wildlife: 1994 Revision .ES/ER/TM-86/R1. Oak Ridge National Laboratory, Environmental Sciences Division.

ORAU/ESSAP (Oak Ridge Associated Universities/Environmental Survey and Site Assessment Program). 1992. Isotopic determination of $\mathrm{Am}, \mathrm{Pu}, \mathrm{U}$, and $\mathrm{Th}$ in soil, water, air filters, and biotic material. In Field Sampling and Analysis Plan for the Remedial Investigation of Waste Area Grouping 2 at the Oak Ridge National Laboratory, Oak Ridge, Tennessee. DOE/OR-1070\&D2. Oak Ridge, Tennessee.

Powell, T. B., and R. N. Morris. 1992. Quality Assurance Grading Guidelines for Research and Development at DOE Facilities, DOE Order 5700.6C. ORNL/M-2359. Oak Ridge National Laboratory, Oak Ridge, Tennessee.

SCS (Soil Conservation Service). 1976. Soil Survey of Ballard and McCracken Counties, Kentucky. Soil Conservation Service. U.S.D.A. Washington, D.C.

USDA (U.S. Department of Agriculture). 1975. Soil Taxonomy, A Basic System of Soil Classification for Making and Interpreting Soil Surveys. Agriculture Handbook No. 436, Soil Conservation Service. U.S.D.A. Washington, D.C.

Utility Services (Martin Marietta Utility Services, Inc.). 1993. Paducah Gaseous Diffusion Plant Environmental Restoration and Waste Management Field Operations Procedures Manual. Paducah, Kentucky. 
98

Walker, C. R., B. W. Short, and H. S. Spring. 1980. The determination of technetium-99 by liquid scintillation counting. pp. 101-110. In W. S. Lyon (ed.), Radioelement Analysis Progress and Problems. Ann Arbor Science, Ann Arbor, Michigan.

Will, M. E., and G. W. Suter II. 1994a. Toxicological Benchmarks for Screening Potential Contaminants of Concern for Effects on Soil and Litter Invertebrates and Heterotrophic Process. ES/ER/TM-126/R1. Oak Ridge National Laboratory, Environmental Sciences Division.

Will, M. E., and G. W. Suter II. 1994b. Toxicological Benchmarks for Screening Potential Contaminants of Concern for Effects of Terrestrial Plants:1994 Revision. ES/ER/TM-85/R1. Oak Ridge National Laboratory, Environmental Sciences Division. 
Appendix A

STATUS OF EXISTING BACKGROUND SOIL INFORMATION AT THE PADUCAH GASEOUS DIFFUSION PLANT 
. 


\section{STATUS OF EXISTING BACKGROUND SOIL INFORMATION AT THE PADUCAH GASEOUS DIFFUSION PLANT}

\section{A.1 INTRODUCTION}

In order to complete site and remedial investigations at the Paducah Gaseous Diffusion Plant (PDGP) and to select appropriate remedies for environmental cleanup, background analyte concentrations and activities are needed. This appendix discusses the history and current status of programs to establish background concentrations and activities and presents the various background concentrations and activities used at the plant.

\section{A.2 HISTORY AND CURRENT STATUS OF PROGRAMS TO ESTABLISH BACKGROUND CONCENTRATIONS AND ACTIVITIES}

\section{A. 2.1 Environmental Monitoring Reports}

As early as the late 1950s, the Atomic Energy Commission (AEC), a federal agency that preceded the U.S. Department of Energy's (DOE) ownership and management role at PGDP, determined the importance of setting background concentrations and activities of analytes that could be released to the environment through processes at PDGP. To address this need, PGDP established a routine monitoring program that sampled grass and air from four locations at the plant perimeter (identified as perimeter north, perimeter east, perimeter south, and perimeter west), eight locations between one-half and one mile from the plant perimeter (identified as 1 north, 1 northeast, 1 east, 1 east southeast, 1 southeast, 1 south, 1 west, and 1 northwest), and four locations approximately five miles from the plant (identified as 5 northeast, 5 southeast, 5 southwest, and 5 northwest). For grass samples the analyte list was limited to fluoride. For air samples, the analyte list included fluoride, uranium (estimated by alpha activity) and beta activity (Baker and Russell 1965).

By 1971 (Union Carbide Corporation 1972), the routine monitoring program had been expanded to include surface soil samples taken at four locations at the plant perimeter (identified as perimeter north, perimeter east, perimeter south, and perimeter west) and at five locations (identified as off-site) between one-half and one mile from the plant perimeter (identified as 1 north, 1 east, 1 southeast, 1 south, and 1 west). Concentrations of uranium in these samples (dry soil) were 11.0, 24.0, 3.6 and 3.9 $\mu \mathrm{g} / \mathrm{g}$, respectively, in the perimeter samples, and $2.2,1.6,1.1,0.9$, and $1.4 \mu \mathrm{g} / \mathrm{g}$, respectively, in the off-site samples. The locations were selected to coincide with the air sampling stations at the aforementioned locations. At each location, the soil sample was taken to a depth of four inches, and the analyte list for these samples was limited to total uranium, which was quantified by mass spectrometry. It is interesting to note that the environmental monitoring report for 1971 (Union Carbide Corporation 1972) lists a background concentration of $0.9 \mu \mathrm{g} / \mathrm{g}$ for uranium. in a soil sample (dry) taken 12 miles from the plant; however, the source of this value is not reported. 
In 1973 (Union Carbide Corporation 1974), the locations of sampling were changed. In that year, samples were taken from the perimeter locations mentioned above, at four locations five miles from the plant perimeter (north, east, south and west), and at two locations 12 miles from the plant (south and west). Concentrations of uranium in these samples (dry soil) were $2.1,1.7,1.6$, and $1.8 \mu \mathrm{g} / \mathrm{g}$, respectively, in the perimeter samples, $1.0,0.9,1.0$, and $0.9 \mu \mathrm{g} / \mathrm{g}$, respectively, in the samples taken five miles from the plant, and 1,0 and $0.9 \mu \mathrm{g} / \mathrm{g}$, respectively, in samples taken 12 miles from the plant. Unlike the 1971 samples, these samples were not taken at the air monitoring locations; however, sampling and analytical methods and the analyte list (i.e., uranium only) matched those reported in the 1971 environmental monitoring report (Union Carbide Corporation 1972). It is interesting to note that the 1973 report (Union Carbide Corporation 1974) states that the samples taken 12 miles from the plant were taken to "check background concentrations" (page 6).

In 1975 (Union Carbide Corporation 1976), the analytical method (but not the sampling method) used in the monitoring program changed from mass spectrometry to gamma spectroscopy. In the environmental report for 1975, it is reported that this change was made because gamma spectroscopy was a more sensitive analytical method. This document also states that the increased sensitivity resulted in the reporting of values that were lower than those presented in the earlier reports. The results for uranium analyses of dry soil samples in the 1975 report were 5.2, 3.9, 4.1, 4.3, 14.0, 3.0,3.4, 3.5, 4.1, and $2.6 \mu \mathrm{g} / \mathrm{g}$ for samples taken at the four perimeter locations (north, east, south, and west), the four locations five miles from the plant perimeter (north, east, south, and west), and the two locations 12 miles from the plant (south and west), respectively. Also in the 1975 report, it is noted that the uranium assay for the samples varied from depleted to natural uranium and that the lower limit of detection for the analyses was $0.5 \mu \mathrm{g} / \mathrm{g}$ (page 21).

From 1975 until 1985, the environmental monitoring program for soils continued as described previously. That is, soil samples continued to be collected by using a soil cutter to produce 10 plugs of soil $9 \mathrm{~cm}$ in diameter and $10 \mathrm{~cm}$ deep at each of the 10 locations. These samples were dried, pulverized, and composited prior to analysis for total uranium via gamma spectroscopy (lower limit of detection reported to be $0.5 \mu \mathrm{g} / \mathrm{g}$ ) (Union Carbide 1976). Concentrations reported at the "background" locations, or those locations located 12 miles $(19 \mathrm{~km})$ from the plant are presented in Table A.1.

In 1986, significant changes were reported to have occurred in the soil monitoring program. The environmental report for that year states that the analyte list for soil samples was expanded from only uranium to ${ }^{230} \mathrm{Th},{ }^{237} \mathrm{~Np},{ }^{239} \mathrm{Pu}$, and isotopic uranium (Energy Systems 1987, page 83), that the analytical method for uranium was changed from gamma spectroscopy to isotope dilution mass spectrometry, and that the method of sampling was changed from ten surface samples taken at each of ten locations to eight surface samples taken from each of ten locations. However, neither the locations of sampling nor the types of samples collected (samples collected to a depth of $5 \mathrm{~cm}$ after the vegetative cover was removed) were reported to have been changed. Although these changes were reported, the data presented in the 1986 report (Energy Systems 1987) are not consistent with these changes. As in earlier reports, only uranium concentrations are presented and discussed in these reports. Uranium concentrations in the "background" samples (i.e., samples taken at $19 \mathrm{~km}$ from the plant boundary) in the resulting samples were 2 and $3 \mu \mathrm{g} / \mathrm{g}$ for the south and west "background" samples, respectively. 
Table A.1. Uranium concentrations $(\mu \mathrm{g} / \mathrm{g})$ reported at background locations in environmental site reports for 1975 to 1985

\begin{tabular}{ccc}
\hline $\begin{array}{c}\text { Year of } \\
\text { sampling }\end{array}$ & $\begin{array}{c}\text { Concentration at south } \\
\text { sampling site }\end{array}$ & $\begin{array}{c}\text { Concentration at west } \\
\text { sampling site }\end{array}$ \\
\hline 1975 & 4.1 & 2.6 \\
1977 & 2.7 & 4.6 \\
1979 & 3.8 & 3.9 \\
1980 & 3.0 & 5.0 \\
1981 & 2.8 & 3.8 \\
1982 & 3.3 & 4.2 \\
1983 & 2.0 & 2.0 \\
1984 & 1.0 & 1.0 \\
1985 & 1.0 & 2.0 \\
\hline
\end{tabular}

Sources: Union Carbide (1976, 1978, 1980, 1981, 1982, 1983) and Energy Systems (1984, 1985, 1986).

In 1987, only minor changes were reported to have occurred in the soil monitoring program (Energy Systems 1988) compared to 1986. The environmental report for that year indicates that the analyte list was reduced back to only uranium and that the "background" sampling locations were moved. In 1987, the "background" locations were reported to be only $13 \mathrm{~km}$ south and $15 \mathrm{~km}$ west of the plant versus $19 \mathrm{~km}$ to the south and west in earlier years. However, the reported methods of sampling and analysis for uranium were reported to be that used in 1986. Uranium concentrations in "background" samples in the 1987 report were 2.4 and $2.9 \mu \mathrm{g} / \mathrm{g}$ for the south and west sites, respectively.

Starting in 1988 and continuing through the present (1993), the radionuclide analyte list for soil samples taken as part of the environmental monitoring programs was expanded (Energy Systems 1989, 1990, 1991, 1992, and 1994) versus that used in earlier years. Throughout these years, the radionuclide analyte list included total uranium, ${ }^{235} \mathrm{U},{ }^{137} \mathrm{Cs},{ }^{40} \mathrm{~K}$, ${ }^{237} \mathrm{~Np},{ }^{239} \mathrm{Pu}$, ${ }^{230} \mathrm{Th}$, and ${ }^{99} \mathrm{Tc}$. Results for samples taken from the "background" locations for each analyte are presented by year in Table A.2.

Also beginning in 1988 and continuing through 1993, analyses were performed for 36 metals (35 metals in 1993) (Energy Systems 1989, 1990, 1991, 1992, and 1994). Metals included in the analyte list were aluminum, antimony, arsenic, barium, beryllium, bismuth, calcium, cadmium, chromium, cobalt, copper, iron, lead, lithium, magnesium, manganese, mercury, molybdenum, nickel, niobium, phosphorus, potassium, ruthenium, silver, sodium, silicon, strontium, tantalum, thallium, thorium, tin, titanium, tungsten, vanadium, zinc, and zirconium. The analytical results of these analyses are not summarized in the aforementioned reports. However, the Environmental Information Management System (EIMS) at the PGDP does contain these data. The results obtained from EIMS are presented in Table A.3. 
Table A.2. Uranium concentrations $(\mu \mathrm{g} / \mathrm{g})$ and radionuclide activities ( $\mathrm{pCi} / \mathrm{g})$ reported at background locations in environmental site reports for 1988 through 1993

\begin{tabular}{cccccccccccc}
\hline \multirow{2}{*}{ Analyte } & \multicolumn{2}{c}{1988} & \multicolumn{2}{c}{1989} & \multicolumn{2}{c}{1990} & \multicolumn{2}{c}{1991} & \multicolumn{3}{c}{1993} \\
\cline { 2 - 10 } & South & West & South & West & South & West & South & West & South & West \\
\hline Uranium & 2.5 & 2.1 & 0.8 & 0.7 & 2.2 & 2.7 & 2.8 & 2.9 & 2.1 & 2.6 \\
${ }^{235} \mathrm{U}(\mathrm{wt} \%)$ & 0.65 & 0.68 & 0.57 & 0.65 & 0.71 & 0.71 & 0.71 & 0.71 & NA $^{\circ}$ & NA \\
${ }^{137} \mathrm{Cs}$ & 0.340 & 0.137 & 0.216 & 0.111 & 4.000 & 0.233 & 0.948 & 0.161 & 0.204 & 0.221 \\
${ }^{40} \mathrm{~K}$ & 12.98 & 17.90 & 10.26 & 11.61 & 16.10 & 18.56 & 15.4 & 6.90 & 10.55 & 14.47 \\
${ }^{237} \mathrm{~Np}$ & $<06$ & 0.002 & 0.003 & $<0$ & $<0$ & 0.007 & 0.003 & $<0$ & 0.083 & 0.021 \\
${ }^{239} \mathrm{Pu}$ & 0.005 & $<0$ & 0.008 & $<0$ & $<0$ & 0.006 & 0 & 0 & 0.007 & 0 \\
${ }^{230} \mathrm{Th}$ & 0.192 & 0.221 & 0.297 & 0.513 & 1.090 & 2.295 & 0.506 & 0.385 & 0.380 & 0.513 \\
${ }^{95} \mathrm{Tc}$ & 0 & 0 & 0.014 & $<0$ & 0.032 & 0.040 & 0 & 0 & 0.404 & 0.445 \\
\hline
\end{tabular}

Sources: Energy Systems (1989, 1990, 1991, 1992, 1994).

a NA = results for that analyte were not available for that year's sampling.

${ }^{b}<0=$ reported result is a negative value. 
Table A.3. Metal concentrations (mg/kg) reported at "background" locations in environmental site reports for 1988 through 1993

\begin{tabular}{|c|c|c|c|c|c|c|c|c|c|c|}
\hline \multirow{2}{*}{ Analyte } & \multicolumn{2}{|c|}{1988} & \multicolumn{2}{|c|}{1989} & \multicolumn{2}{|c|}{1990} & \multicolumn{2}{|c|}{1991} & \multicolumn{2}{|c|}{1993} \\
\hline & South & West & South & West & South & West & South & West & South & West \\
\hline Aluminum & 20000 & 20000 & 17070 & 18277 & 8300 & 10740 & 16800 & 12020 & 9196 & 14403 \\
\hline Antimony & $<1000$ & $<1000$ & $<1$ & $<1$ & $<0.6$ & 0.6 & 8.6 & 12.4 & $<4.0$ & 25.6 \\
\hline Arsenic & $<3000$ & $<3000$ & 4.4 & $<0.05$ & $\mathbf{N A}^{*}$ & NA & NA & NA & NA & NA \\
\hline Barium & $<800$ & $<800$ & 113 & 171 & 80 & 122 & 98.2 & 149 & 75.1 & 130.7 \\
\hline Beryllium & $<6$ & $<6$ & $<1$ & $<1$ & $<0.4$ & $<0.4$ & 0.6 & 0.6 & $<2$ & 0.8 \\
\hline Bismuth & $<200$ & $<200$ & $<1$ & $<1$ & $<2$ & $<2$ & $<5$ & $<5$ & $<2$ & $<43.2$ \\
\hline Cadmium & $<600$ & $<600$ & $<1$ & $<1$ & $<0.2$ & $<0.2$ & $<0.6$ & $<0.6$ & $<6.01$ & $<4.12$ \\
\hline Calcium & 2000 & 2000 & 1548 & 3174 & 1148 & 2220 & 1950 & 2608 & 1352 & 1893 \\
\hline Chromium & $<300$ & $<300$ & 21 & 27.5 & 10 & 16 & 20 & 17.2 & 821 & 14.4 \\
\hline Cobalt & $<100$ & $<100$ & 8 & 12 & 6 & 10 & 7.4 & 8.8 & 9.02 & 12.3 \\
\hline Copper & $<30$ & $<30$ & 3 & 13 & 8 & 14 & 12.2 & 14.4 & 8.01 & 12.3 \\
\hline Iron & 6000 & 6000 & 13497 & 23484 & 11020 & 19680 & 19700 & 22100 & 10117 & 17016 \\
\hline Lead & $<300$ & $<300$ & 16 & 27 & 4 & 8 & NA & 162 & 447.8 & 714 \\
\hline Lithium & $<2000$ & $<2000$ & 11 & 14.74 & 6 & 10 & 13.6 & 10.2 & 8.01 & 12.3 \\
\hline Magnesium & 2000 & 2000 & 1727 & 3400 & 1054 & 2520 & 1970 & 2670 & 1112 & 1564 \\
\hline Manganese & 300 & 300 & 587 & 925 & 634 & 682 & 458 & 726 & 499.8 & 1770 \\
\hline Mercury & NA & NA & $<0.2$ & $<0.2$ & NA & NA & NA & NA & NA & NA \\
\hline Molybdenum & $<100$ & $<100$ & 2 & $<1$ & $<0.6$ & $<0.6$ & $<1.6$ & $<1.6$ & $<7.01$ & $<7.2$ \\
\hline Nickel & $<100$ & $<100$ & 4 & 16 & 138 & 20 & 31.6 & 26.4 & 25 & 21.6 \\
\hline Niobium & $<400$ & $<400$ & $<1$ & $<1$ & $<1.4$ & $<1.4$ & $<1.2$ & $<1.2$ & $<10$ & $<10.3$ \\
\hline Phosphorus & $<8000$ & $<8000$ & 222 & 421 & 364 & 542 & 314 & 508 & 167.3 & 258.2 \\
\hline Potassium & $<30000$ & $<30000$ & 2104 & 3064 & 586 & 986 & 1406 & 1490 & 844.4 & 860.1 \\
\hline Ruthenium & $<600$ & $<600$ & 10 & 23 & 14 & $<1$ & 11.4 & 126 & $<18$ & $<18.5$ \\
\hline Silicon & 100000 & 100000 & $<1$ & $<1$ & 902 & 1110 & 61.2 & $<24$ & 16 & 39.1 \\
\hline Silver & NA & NA & $<1$ & $<1$ & 1.4 & $<0.8$ & $<0.6$ & $<0.6$ & $<0.6$ & $<0.6$ \\
\hline Sodium & $<3000$ & $<3000$ & 9.0 & 112 & 68 & 90 & 160 & 143 & 298.5 & 509.3 \\
\hline Strontium & 40 & 40 & 16.8 & 35.3 & 8 & 22 & 16.2 & 26 & 10 & 11.3 \\
\hline Tantalum & $<1000$ & $<1000$ & $<1$ & $<1$ & $<40$ & 100 & $<10.4$ & NA & $<71.1$ & $<73$ \\
\hline Thallium & $<200$ & $<200$ & $<1$ & $<1$ & $<6$ & 22 & $<124$ & $<12.4$ & 41.1 & 53.6 \\
\hline Thorium & NA & NA & $<1$ & $<1$ & 8 & 4 & $<4$ & $<4$ & $<18$ & $<18.5$ \\
\hline Tin & $<300$ & $<300$ & $<1$ & $<1$ & $<1.6$ & $<1.6$ & $<3.8$ & 5.4 & $<30.1$ & $<30.9$ \\
\hline Titanium & 3000 & 3000 & 291 & 466 & 198 & 348 & 320 & 342 & 148.3 & 156.4 \\
\hline Tungsten & $<2000$ & $<2000$ & $<1$ & $<1$ & $<24$ & $<24$ & 40.6 & 48.4 & $<36.1$ & $<37$ \\
\hline Vanadium & $<80$ & $<80$ & $<1$ & $<1$ & $<20$ & $<2$ & 84 & 78.2 & 54.1 & 94.7 \\
\hline Zinc & $<1000$ & $<1000$ & 40 & 64 & 34 & 50 & 40.8 & 49.6 & 35.1 & 59.7 \\
\hline Zirconium & 300 & 300 & 10 & 10.81 & 4 & 6 & 9 & 9.6 & $<1$ & 1.03 \\
\hline
\end{tabular}

Sources: Energy Systems 1989, 1990, 1991, 1992, and 1994

- NA = results for that analyte were not available for that year's sampling. 
Finally, beginning in 1988 and continuing to the present, soil samples were analyzed for total polychlorinated biphenyls (PCBs). At both "background" locations, results are reported as $<0.1 \mathrm{mg} / \mathrm{kg}$ for all years (Energy Systems 1989, 1990, 1991, 1992, 1994).

\section{A.22 Phase I and II Site Investigations Reference Sampling}

In 1988, contamination apparently originating from the PGDP was found in residential wells north and off of the United States Department of Energy (DOE) reservation. In response to this finding, the United States Environmental Protection Agency (EPA) and DOE entered into an Administrative Order by Consent to address the situation. This Consent Order defined the mutual objectives of the EPA and DOE to

- determine the nature and extent of the threat to human health or welfare and the environment caused by the off-site contamination of the groundwater at the PGDP;

- see that the environmental effects associated with the releases and threatened releases are thoroughly investigated and that appropriate action is taken to protect public health and welfare and the environment;

- establish a work plan and schedule(s) for developing, implementing, and monitoring response actions; and

- facilitate the cooperation, exchange of information, and participation of the parties in such action (CH2M Hill 1990).

As part of the effort to address these objectives, a Site Investigation was performed in two phases. Phase I focused on evaluating the extent of off-site contamination and selected on-site sources of technetium-99, trichloroethylene, and polychlorinated biphenyls (PCBs). Phase II focused on further characterizing the on-site sources, refining the estimated extent of off-site contamination, and evaluating alternatives for remediation of off-site contamination. Phase I was completed with delivery of the Phase I report in March 1991 (CH2M Hill 1991). Phase II was completed with delivery of the Phase II report in April 1992 (CH2M Hill 1992).

During the completion of Phase I and II of the Site Investigations, the need for background or reference concentrations for inorganic analytes and reference activities radionuclides was recognized. To meet this need, the Site Investigations included the collection of soil samples from areas outside known plant influence.

To establish reference activities for radionuclides, 33 surface soil samples (from 0 to 12 inches in depth) were collected from areas at least 5 miles east and southeast of the plant in May and June of 1990. The locations of sampling and the results of this work are presented in both CH2M Hill 1991 (Volume 1; Table 4-11) and CH2M Hill 1992 (Volume 2; Table 4-4; page 7 of 7). A portion of the information presented in these reports is reproduced in Table A.4. 
Table A.4. Radionuclide activities (pCi/g) in background surface soil samples reported in Phase I and II site investigations

\begin{tabular}{lccc}
\hline \multicolumn{1}{c}{ Radionuclide } & $\begin{array}{c}\text { Minimum }^{\text {detected }}{ }^{a} \\
\text { Gross Alpha }\end{array}$ & $\begin{array}{c}\text { Maximum } \\
\text { detected }^{a}\end{array}$ & $\begin{array}{c}\text { Frequency } \\
\text { of } \\
\text { detection }^{b}\end{array}$ \\
\hline Gross Beta & 1.7 & 15.8 & $33 / 33$ \\
Neptunium-237 & 1.7 & 27 & $33 / 33$ \\
Plutonium-239 & $<0.5$ & 0.75 & $7 / 33$ \\
Technetium-99 & $0.39 \mathrm{~J}$ & $<0.05$ & $1 / 33$ \\
Thorium-230 & 0 & 1.57 & $25 / 33$ \\
Uranium-234 & $<0.05$ & $7.26 \mathrm{~J}$ & $7 / 33$ \\
Uranium-235 & $<0.05$ & 1.24 & $20 / 33$ \\
Uranium-238 & $\mathrm{NA}$ & $\mathrm{NA}$ & $0 / 33$ \\
\hline
\end{tabular}

Sources: CH2M Hill $(1991,1992)$.

$\mathrm{J}=$ value for the radionuclide is an estimated value.

$<=$ radionuclide was not detected at the minimum detectable activity.

a Values as reported in Table 4-11 of Volume 1, CH2M Hill (1991).

${ }^{b}$ Values as reported in Table 4-4, page 7 of 7, Volume 2, CH2M Hill (1992).

To establish reference activities for inorganic analytes (i.e., metals), five surface samples (from 0 to 6 inches in depth) were taken in areas near the PGDP but outside areas suspected to be influenced by the plant during the Phase II Site Investigation. To reflect the potential range of naturally occurring conditions, these samples were taken from the three soil types found on the plant: Henry Silt Loam, Calloway Silt Loam, and Grenada Silt Loam. The results of the analyses are presented in CH2M Hill 1992 (Volume 2; Table 4-4; pages 5 and 6 of 7). A portion of the information presented in this report is reproduced in Table A.5.

\section{A.23 The Moore Report and KY/EM-77}

In 1995, G. K. Moore of the Environmental Sciences Division, Oak Ridge National Laboratory, produced a report (ORNL 1995, termed the "Moore Report") which examined inorganic soil and groundwater chemistry near PGDP. Although this report was written to characterize the inorganic chemistry of groundwater and soils near PGDP using data from the Phase I and II Site Investigation and to determine if these data indicated that contamination with inorganic constituents existed at PGDP, it was posited soon after the draft report was produced that the methods used in the report could be used to reevaluate the Phase I and II Site Investigations data to determine background concentrations of organic and inorganic analytes and background activities of radionuclides in soil at PGDP. Subsequently, it was 
Table A.5. Inorganic analyte concentrations $(\mathrm{mg} / \mathrm{kg})$ in background surface soil samples reported in the Phase II site investigation

\begin{tabular}{lccc}
\hline \multicolumn{1}{c}{ Analyte } & $\begin{array}{c}\text { Minimum } \\
\text { detected }^{a}\end{array}$ & $\begin{array}{c}\text { Maximum } \\
\text { detected }^{a}\end{array}$ & $\begin{array}{c}\text { Frequency of } \\
\text { detection }^{b}\end{array}$ \\
\hline Aluminum & 5680 & 15700 & $5 / 5$ \\
Antimony & 0.39 & 0.39 & $1 / 5$ \\
Arsenic & $5.2 \mathrm{~J}$ & 11.8 & $5 / 5$ \\
Barium & $78 \mathrm{~J}$ & $157 \mathrm{~J}$ & $5 / 5$ \\
Beryllium & $7.6 \mathrm{~J}$ & $17.8 \mathrm{~J}$ & $5 / 5$ \\
& & & \\
Cadmium & $0.86 \mathrm{~J}$ & $2.6 \mathrm{~J}$ & $5 / 5$ \\
Calcium & $1210 \mathrm{~J}$ & $2400 \mathrm{~J}$ & $5 / 5$ \\
Chromium & $11.9 \mathrm{~J}$ & 17.2 & $5 / 5$ \\
Cobalt & $5.9 \mathrm{~J}$ & $14.1 \mathrm{~J}$ & $5 / 5$ \\
Copper & $7.7 \mathrm{~J}$ & 15.8 & $5 / 5$ \\
& & & \\
Cyanide & $\mathrm{ND}$ & $\mathrm{ND}$ & $0 / 5$ \\
Iron & $12300 \mathrm{~J}$ & $27700 \mathrm{~J}$ & $5 / 5$ \\
Lead & $14.3 \mathrm{~J}$ & $30.9 \mathrm{~J}$ & $5 / 5$ \\
Magnesium & $777 \mathrm{~J}$ & $2460 \mathrm{~J}$ & $5 / 5$ \\
Manganese & $553 \mathrm{JN}{ }^{*}$ & $2700 \mathrm{~J}$ & $5 / 5$ \\
Mercury & & & \\
Nickel & ND & ND & $0 / 5$ \\
Potassium & $7.7 \mathrm{~J}$ & 21 & $5 / 5$ \\
Selenium & $377 \mathrm{~B}$ & 889 & $5 / 5$ \\
Silver & $0.2 \mathrm{JB}$ & $0.49 \mathrm{JB}$ & $3 / 5$ \\
& $1.6 \mathrm{~J}$ & $1.9 \mathrm{~J}$ & $2 / 5$ \\
Sodium & & & $5 / 5$ \\
Thallium & $26.5 \mathrm{JB}$ & $82.8 \mathrm{~B}$ & $2 / 5$ \\
Vanadium & $0.3 \mathrm{~B}$ & $0.44 \mathrm{~B}$ & $5 / 5$ \\
Zinc & $21.6 \mathrm{~J}$ & 37.3 & $5 / 5$ \\
\hline & $27.6 \mathrm{~J}$ & $54.4 \mathrm{JNE}$ & \\
\hline
\end{tabular}

Source: CH2M Hill (1992).

* = duplicate analysis was not within control limits.

$B=$ analyte was found in the samples associated blank.

$E=$ value is estimated because of interference.

$\mathrm{J}=$ value is an estimated value.

$\mathbf{N}=$ spike recovery for the sample was not within control limits.

- Values as determined by examining data contained in Volume 4B of CH2M Hill (1991).

${ }^{b}$ Values as reported in Table 4-4, pages 5 and 6 of 7, Volume 2, CH2M Hill (1992).

${ }^{c} \mathrm{ND}=$ analyte was not detected in any sample. 
determined that the approach could be used to determine the organic and inorganic analyte background but not radionuclide background. How the approach was applied to determine organic and inorganic analyte background in soil is presented in Appendix B of the Moore Report and KY/EM-77 (Bonczek et al. 1995), respectively. Reasons why the approach could not be used for radionuclides are presented in Appendix $C$ of the Moore Report and earlier in the this project plan.

Generally, the methods employed to determine background concentrations for organic analytes (Appendix B of the Moore Report) and inorganic analytes (KY/EM-77) and to evaluate the data sufficiency for radionuclide analytes (Appendix $C$ of the Moore Report) used a combination of a graphical data evaluation method, professional judgement, and, for inorganic analytes, a nonparametric statistical technique (i.e., "bootstrap"). In the first phase of all analyses, the Phase I and II Site Investigations data were segregated into two populations by the depth at which samples were collected. These populations were near surface (i.e., sample collected from 0 to 1 foot below ground surface) and subsurface (i.e., sample collected below 1 foot below ground surface). In the second phase of the analyses, the surface and subsurface populations were plotted by concentration. In the third phase of the analyses, the plots were examined to determine if the distribution of background concentrations could be delimited. For organic and radionuclide analytes, analyses of the plots showed that the data were inadequate to delimit the background distribution from the contaminated distribution; therefore, these data were not analyzed further. (See Sect. A.3 for a discussion of data inadequacies.) For inorganic analytes, analyses of the plots showed that data for most analytes were adequate to delimit the populations. In the fourth phase of the analyses, a threshold value for the background distribution was calculated for each inorganic analyte. These values were calculated using a "bootstrap" statistical analysis and were the upper limits of the $90 \%$ confidence interval of the 99 th percentile of the background distribution of each analyte. The threshold concentrations calculated in EM-77 are presented in Table A.6.

Subsequently, comments were received from the Commonwealth of Kentucky and Region 4 of United States Environmental Protection Agency concerning these threshold values and their derivation. In these comments, both regulatory agencies agreed that the statistical technique used to develop the threshold values was appropriate, but both regulatory agencies questioned the use of the Phase I and II Site Investigations data set in the analysis. After consultation with the regulatory agencies, the PGDP agreed to produce a revised KY/EM-77 containing additional explanations concerning the analytical methods used to segregate the background from the contaminated populations and the adequacy of the Phase I and II Site Investigation's data set. Revision of this document is ongoing at this time (August 1995). In the revised document, the threshold values may be slightly different from those presented in Table A.6. 
Table A.6. Inorganic analyte concentrations $(\mathrm{mg} / \mathrm{kg})$ in background surface soil samples reported in near-surface and subsurface soils (Moore 1995)

\begin{tabular}{|c|c|c|}
\hline \multirow[b]{2}{*}{ Analyte } & \multicolumn{2}{|c|}{ Background concentration } \\
\hline & Near-surface soil & Subsurface soil \\
\hline Aluminum & 16,000 & 15,000 \\
\hline Antimony & 13 & 20 \\
\hline Arsenic & 15 & 15 \\
\hline Barium & 200 & 290 \\
\hline Beryllium & 24 & 1.8 \\
\hline Cadmium & 9.7 & 4.3 \\
\hline Calcium & 290,000 & 110,000 \\
\hline Chromium & 140 & 88 \\
\hline Cobalt & 30 & 48 \\
\hline Copper & 59 & 52 \\
\hline Cyanide & NA & NA \\
\hline Iron & 28,000 & 39,000 \\
\hline Lead & 40 & 65 \\
\hline Magnesium & 8,300 & 2,700 \\
\hline Manganese & 2,700 & 1,900 \\
\hline Mercury & 2.5 & 0.49 \\
\hline Nickel & 85 & 41 \\
\hline Potassium & 1,900 & 1,400 \\
\hline Selenium & 2.9 & 2.1 \\
\hline Silver & 4.8 & 7.5 \\
\hline Sodium & 520 & 620 \\
\hline Sulfide & NA & NA \\
\hline Thallium & 1.4 & 1.0 \\
\hline Tin & NA & NA \\
\hline Vanadium & 70 & 51 \\
\hline Zinc & 110 & 110 \\
\hline
\end{tabular}

\section{A.3 SUMMARY}

This section discusses the inadequacies of the various soil background data sets presented in earlier sections of this appendix. This section also provides conclusions concerning the need for additional sampling to establish background concentrations for the three major classes of analytes: organic compounds, inorganic analytes, and radionuclides. To simplify the presentation, each of the data sets presented in Sect. A.2 is discussed separately. 


\section{A.3.1 Environmental Monitoring Reports Background Samples}

As noted in Sect. A.2.1, this data base was developed over a number of years. Therefore, these data hold some historical interest and can be used to qualitatively verify background numbers derived from the analysis of other data sets. However, there are five major inadequacies that preclude the use of these data to establish background soil concentrations for remedial action work at PGDP:

1. The analytical methods used to derive the values reported in the data set have not remained consistent over time. This has resulted in a data set that cannot be summarized over all years.

2. The values reported in the data set are from surface soil samples only. Information on both subsurface and surface soil is required.

3. There is no information on the soil type found at the area sampled. If the soil type at the sampling locations is not representative of the soil type found at PGDP, then summarization of these data could yield background values inappropriate for PGDP.

4. The data come from only two sampling locations. Considerable variability in the natural distributions of analytes is expected to be found in a background distribution. This variability should be described and used when background concentrations are calculated. Because the data come from only two sites, it is not known if summary statistics calculated using this data set will adequately describe and use this variability.

5. The radionuclide analyte information, especially on uranium, is relatively extensive; however, the information on other radionuclide analytes and on inorganic and organic analytes is sparse. This is especially true for organic analytes. The only organic analyte in the data set is polychlorinated biphenyls.

\section{A.3.2 Phase I and II Site Investigation Reference Sampling}

As noted in Sect. A.2.2, this data set was developed to represent the background soil concentrations and activities at PGDP. Furthermore, these data were collected per regulatory agency approved work plans. However, these data have two major technical inadequacies:

1. Only surface samples were analyzed. As noted in Sect. A.3.1, background concentrations for both surface and subsurface soils are needed.

2. The locations selected for collection of samples to establish inorganic analyte background may not have been free from plant influences. Although the locations were approved by the regulatory agencies, analytical results indicate that releases from PGDP may have impacted the locations. The regulatory agencies have noted this issue in comments on several documents which used these data to define background concentrations and activities. 


\section{A.3.3 The Moore Report and KY/EM-77}

As noted in Sect. A.2.3, the analyses in these reports used the entire data set compiled during the Phase I and II Site Investigation. Therefore, the data set used to develop the background soil concentrations and activities was extensive. However, even with this large data set, several inadequacies exist which make additional work necessary to either verify or establish background concentrations and activities. These inadequacies are discussed in the following bullets.

- For most inorganic analytes, the statistical analysis performed in KY/EM-77 allowed for the delimitation of the natural and contaminated populations. However, for thallium, the data were too sparse to be certain that the delimitation of thallium concentration data into natural and contaminated populations was appropriate. Therefore, the background soil concentrations determined for thallium are suspect.

- For two inorganic analytes, mercury and antimony, the background soil concentrations derived did not agree with the concentrations expected to be found in similar areas in western Kentucky not impacted by releases of these metals. Therefore, the background soil concentrations for mercury and antimony are suspect.

- For radionuclide analytes, the analyses indicated that the data were not adequate to establish the background activities. Appendix $\mathrm{C}$ of the Moore Report discusses these inadequacies in detail. Specific factors discussed in Appendix $\mathrm{C}$ of the Moore Report include that the data set does not contain information on several naturally occurring radionuclides (e.g., potassium-40 and radium-226) that should be considered when developing background soil activities for radionuclides, that the measurements reported in the data were not reliable as indicated by the frequency of samples in which a radionuclide was not detected, and that the natural and contaminated populations could not be reliably separated using the graphical technique.

\section{A.3.4 Conclusions}

As indicated by this summary, the data base concerning environmental concentrations of organic compounds, inorganic analytes, and radionuclide isotopes is very extensive. However, there are several data inadequacies that prevent the establishment of all background soil concentrations and activities using these data. The status of the establishment of background concentrations and activities using the existing data is summarized in the following.

- Organic compounds. The information presented in Appendix B of the Moore Report sufficiently defends the conclusion that no additional work is required to establish the background concentration of organic compounds as long as the detection limits for these compounds are not lowered markedly. The primary supporting evidence for this conclusion is the simple fact that organic compounds which could potentially not be plant related were not detected with any great frequency in samples collected during the Phase I and II Site Investigation.

- Inorganic analytes. The information in KY/EM-77 is adequate to establish the background soil concentrations for most analytes. However, the background soil concentrations for three analytes are suspect either because of an inadequate data base 
(thallium) or because the calculated background values are much higher than expected (mercury and antimony). Therefore, additional sampling is needed to verify the background soil concentration for these three analytes.

- Radionuclide isotopes. The information presented in Appendix C of the Moore Report indicates that the available data are not sufficient to establish the background soil activities. Additional samples must be collected to develop a defensible data base. 


\section{REFERENCES FOR APPENDIX A}

Baker R. C., and A. W. Russell. 1965. Environmental Monitoring Summary for the Paducah Plant for 1964. KY-484. Produced for the Atomic Energy Commission by Union Carbide Corporation.

Bonczek, R. R., J. Davidson, A. F. Diefendorf, F. G. Dolislager, N. E. Korte, C. J. Marshall, G. R. Miller, and W. L. Richards. 1995. Background Concentrations and Human Health Risk-based Screening Criteria for Metals in Soil at the Paducah Gaseous Diffusion Plant, Paducah, Kentucky. KY/EM-77.

CH2M Hill. 1990. Phase II Site Investigation Work Plan for Paducah Gaseous Diffusion Plant, Paducah, Kentucky. June 1, 1990. Prepared by CH2M Hill, Oak Ridge, Tennessee for the Paducah Gaseous Diffusion Plant.

CH2M Hill. 1991. Results of the Site Investigation, Phase I, at the Paducah Gaseous Diffusion Plant, Paducah, Kentucky. KY/ER-4. Prepared by CH2M Hill, Oak Ridge, Tennessee for the United States Department of Energy.

CH2M Hill. 1992. Results of the Site Investigation, Phase II, at the Paducah Gaseous Diffusion Plant, Paducah, Kentucky. KY/SUB/138-97777C P-03/1991/1. Prepared by CH2M Hill, Oak Ridge, Tennessee for the United States Department of Energy.

Martin Marietta Energy Systems (Energy Systems). 1984. Environmental Monitoring Report, United States Department of Energy, Paducah Gaseous Diffusion Plant, Calendar Year 1983. KY-742. Produced for the United States Department of Energy by Martin Marietta Energy Systems.

Martin Marietta Energy Systems (Energy Systems). 1985. Environmental Monitoring Report, United States Department of Energy, Paducah Gaseous Diffusion Plant, Calendar Year 1984. KY-747. Produced for the United States Department of Energy by Martin Marietta Energy Systems.

Martin Marietta Energy Systems (Energy Systems). 1986. Environmental Monitoring Report, United States Department of Energy, Paducah Gaseous Diffusion Plant, Calendar Year 1985. KY-755. Produced for the United States Department of Energy by Martin Marietta Energy Systems.

Martin Marietta Energy Systems (Energy Systems). 1987. Environmental Surveillance of the U.S. Department of Energy Paducah Reservation and Surrounding Environs during 1986. ES/ESH-1/V3. Produced for the United States Department of Energy by Martin Marietta Energy Systems.

Martin Marietta Energy Systems (Energy Systems). 1988. Environmental Surveillance of the U.S. Department of Energy Paducah Reservation and Surrounding Environs during 1987. ES/ESH-4/V3. Produced for the United States Department of Energy by Martin Marietta Energy Systems. 
Martin Marietta Energy Systems (Energy Systems). 1991. Paducah Gaseous Diffusion Plant Site Environmental port for 1990. ES/ESH-18/V3. Produced for the United States Department of Energy by Martin Marietta Energy Systems.

Martin Marietta Energy Systems (Energy Systems). 1992. Paducah Gaseous Diffusion Plant Site Environmental Report for 1991. ES/ESH-22/V3. Produced for the United States Department of Energy by Martin Marietta Energy Systems.

Martin Marietta Energy Systems (Energy Systems). 1994. Paducah Gaseous Diffusion Plant Site Environmental Report for 1993. ES/ESH-53. Produced for the United States Department of Energy by Martin Marietta Energy Systems.

Moore, G. K. 1995. Inorganic Soil and Groundwater Chemistry Near Paducah Gaseous Diffusion Plant, Paducah, Kentucky. ORNL/TM-12897.

Union Carbide Corporation. 1972. Environmental Monitoring Report, United States Atomic Energy Commission, Paducah Gaseous Diffusion Plant, Calendar Year 1971. UCC-ND-222. Produced for the Atomic Energy Commission by Union Carbide Corporation.

Union Carbide Corporation. 1974. Environmental Monitoring Report, United States Atomic Energy Commission, Paducah Gaseous Diffusion Plant, Calendar Year 1973. UCC-ND-279. Produced for the Atomic Energy Commission by Union Carbide Corporation.

Union Carbide Corporation. 1976. Environmental Monitoring Report, United States Energy Research and Development Administration, Paducah Gaseous Diffusion Plant, Calendar Year 1975. Y/UB-5. Produced for the United States Energy Research and Development Administration by Union Carbide Corporation.

Union Carbide Corporation. 1978. Environmental Monitoring Report, United States Department of Energy, Paducah Gaseous Diffusion Plant, Calendar Year 1977. Y/UB-9. Produced for the United States Department of Energy by Union Carbide Corporation.

Union Carbide Corporation. 1980. Environmental Monitoring Report, United States Department of Energy, Paducah Gaseous Diffusion Plant, Calendar Year 1979. Y/UB-14. Produced for the United States Department of Energy by Union Carbide Corporation.

Union Carbide Corporation. 1981. Environmental Monitoring Report, United States Department of Energy, Paducah Gaseous Diffusion Plant, Calendar Year 1980. KY-717. Produced for the United States Department of Energy by Union Carbide Corporation.

Union Carbide Corporation. 1982. Environmental Monitoring Report, United States Department of Energy, Paducah Gaseous Diffusion Plant, Calendar Year 1981. KY-724. Produced for the United States Department of Energy by Union Carbide Corporation.

Union Carbide Corporation. 1983. Environmental Monitoring Report, United States Department of Energy, Paducah Gaseous Diffusion Plant, Calendar Year 1982. KY-731. Produced for the United States Department of Energy by Union Carbide Corporation. 


\section{,}


Appendix B

\section{REFERENCE SOIL PROFILE DESCRIPTIONS}





\section{Appendix B}

\section{REFERENCE SOIL PROFILE DESCRIPTIONS}

All of the following soil series descriptions are from Soil Survey of Ballard and McCraken Counties, Kentucky, 1976, which was published by the National Cooperative Soil Survey with cooperation from the U.S. Department of Agriculture, the Soil Conservation Service, and the Kentucky Agriculture Experiment Station.

\section{CALIOWAY SERIES}

The Calloway series consists of somewhat poorly drained soils that formed in thick loess deposits on broad nearly level to gently sloping uplands and stream terraces in the lower Mississippi Valley. They have a seasonally high water table perched over a thick fragipan. Dominant slope gradients are between 0 and 3 percent and range to 5 percent.

TAXONOMIC CLASS: Fine-silty, mixed, thermic Glossaquic Fragiudalfs.

TYPICAL PEDON: Calloway silt loam on a 1 percent slope in forest of mixed hardwoods.

$0 \quad 0$ to $3 \mathrm{~cm}$; very dark grayish brown (2.5Y 3/2) organic matter and partially decayed leaves and twigs with many fine roots and mycelia.

A $\quad 0$ to $3 \mathrm{~cm}$; dark grayish brown (10YR 4/2) silt loam; moderate fine granular structure; very friable; many fine roots and worm holes; few black and brown concretions; strongly acid; clear smooth boundary ( 0 to $15 \mathrm{~cm}$ thick).

E 3 to $15 \mathrm{~cm}$; grayish brown (10YR 5/2) with pockets of brownish yellow (10YR 6/6) silt loam; weak medium granular structure; very friable; many fine and medium roots; few fine brown and black concretions; strongly acid; gradual wavy boundary (0 to $20 \mathrm{~cm}$ thick).

B/A 15 to $48 \mathrm{~cm}$; B portion is yellowish brown (10YR 5/4) silt loam; many medium distinct light gray (10YR 7/2) mottles which is in the A horizon portion; weak fine subangular blocky and granular structure; friable; few fine roots; few fine brown and black concretions; few fine pores; strongly acid; gradual irregular boundary (20 to $41 \mathrm{~cm}$ thick).

E' 48 to $76 \mathrm{~cm}$; light brownish gray (10YR 6/2) silt loam; many medium distinct brownish yellow (10YR 6/6) mottles; weak medium subangular blocky structure; friable; slightly compact; few fine roots; many fine brown and black concretions; many fine voids; strongly acid; gradual irregular boundary ( 5 to $31 \mathrm{~cm}$ thick).

Btx1 76 to $135 \mathrm{~cm}$; grayish brown (10YR 5/2) silt loam; many medium and coarse distinct brownish yellow (10YR 6/6) mottles; moderate coarse prismatic parting to moderate medium subangular blocky structure; firm; compact and brittle in about 75 percent 
of the volume; clay films on faces of peds and in pores; black coatings on some peds; thick friable gray (10YR 6/2) silt coatings on faces of prisms and thin silt coatings on faces of peds; common fine brow $n$ and black concretions; common fine voids; few fine roots along faces of prisms; strongly acid; gradual wavy boundary $(25$ to $76 \mathrm{~cm}$ thick).

Btx2 135 to $152 \mathrm{~cm}$; mottled yellowish brown (10YR 5/8), gray (10YR 5/1), and very pale brown (10YR 7/4) silt loam; weak coarse prismatic parting to weak coarse subangular blocky structure; firm; compact and brittle; patch clay films on faces of peds and in pores; few fine voids; friable; gray (10YR 6/2) silty material on faces of prisms; few black and brown concretions; medium acid.

RANGE IN CHARACTERISTICS: Solum thickness exceeds $152 \mathrm{~cm}$. Depth to the fragipan ranges from 36 to $97 \mathrm{~cm}$. Combined thickness of horizons having less than 10 percent sand is more than $122 \mathrm{~cm}$. Black and brown concretions range from few to many in all horizons. Reaction is medium acid through very strongly acid in the upper part of the solum. The lower part of the solum ranges from strongly acid to mildly alkaline.

The A horizon has hue of $10 \mathrm{YR}$, value of 3 or 4 , and chroma of 1 or 2 . The Ap or E2 horizons have hue $10 \mathrm{YR}$, value of 4 to 6 , and chroma of 2 to 4 . Texture is silt or silt loam.

The B, where present, or B/A horizon has hue of $10 \mathrm{YR}$ or $2.5 \mathrm{YR}$, value of 4 through 6, and chroma of 4 through 6 . Few to many mottles in shades of gray are present. Some pedons are mottles in shades of gray and brown. Texture is silt loam or silty clay loam. Clay content from a depth of $25 \mathrm{~cm}$ to the upper boundary of the fragipan ranges from 18 to 30 percent.

The E' horizon has hue of 10YR or $2.5 Y$, value of 4 to 7 , and chroma of 1 or 2 ; or hue of 10YR, value of 6 or 7, and chroma of 3. In some pedons, the E' horizon is lacking and a mixed $\mathrm{E} / \mathrm{B}$ or $\mathrm{B} / \mathrm{E}$ horizon is at the top of the lower sequum. Texture is silt or silt loam.

The Btx horizon is in hue of 10YR or $2.5 Y$, value of 5 and chroma of 2 to 6 . Texture is silt loam or silty clay loam. Material in the prisms is brittle and firm or very firm. Silty coatings on prism faces are friable and are light brownish gray, gray, or light gray. Roots are primarily restricted to this material.

COMPETING SERIES: These include the Bude and Necessity series in the same family. Series in similar families include the Edisto, Grenada, Olivier, Pheba, and Splendora series. Bude soils have similar morphology but contain more than 10 percent sand to a depth of 122 $\mathrm{cm}$. Necessity soils have an argillic horizon developed above the fragipan. Edisto soils have fine sandy loam or loamy fine sand textures in the upper $51 \mathrm{~cm}$ of the argillic horizon. Grenada soils lack mottles of chroma 2 or less within $41 \mathrm{~cm}$ of the surface. Pheba soils have 10 to 18 percent clay between $25 \mathrm{~cm}$ and the upper boundary of the fragipan and also have lower base saturation. Splendora soils have more than 15 percent fine and coarse sand in the B horizon.

GEOGRAPHIC SETTING: Calloway soils are on the smoother portions of the loess belt of the lower Mississippi Valley including areas on the stream terraces. The dominant slope gradient is between 0 and 3 percent but may range to 5 percent. The regolith is thick silty 
deposits with low sand content. The climate is warm and humid with an annual average rainfall of $127 \mathrm{~cm}$, average January temperature of $9^{\circ} \mathrm{C}$, and average July temperature of $27^{\circ}$ $\mathrm{C}$ at the type location.

GEOGRAPHICALLY ASSOCIATED SOILS: These are the Calhoun, Grenada, Henry, Loring, and Memphis soils. Calhoun soils are grayer, lack fragipans, and are in depressions and flat areas with 1 percent slopes or less. Grenada and Loring soils are browner, better drained, and in higher positions. Henry soils, which are in depressions and drainageways, are grayer and poorly drained. Memphis soils lack fragipans, are well drained, and are in higher positions.

USE AND VEGETATION: Most of the Calloway soils are cleared and used for such crops as cotton, corn, soybeans, and pasture. A small acreage is in mixed hardwoods, chiefly water oak, sweetgum, blackgum, post oak, hickory, and other water tolerant species. Shortleaf and loblolly pine are in the southern part of the range.

DISTRIBUTION AND EXTENT: Arkansas, Kentucky, Louisiana, Mississippi, Missouri, and Tennessee. The series is of moderate extent.

SERIES ESTABLISHED: Calloway County, Kentucky; 1937.

REMARKS: Diagnostic horizons and features recognized in this pedon are:

Ochric epipedon-the zone from the surface to the soil to a depth of approximately 15 $\mathrm{cm}(\mathrm{A}, \mathrm{E})$.

Aquic udalfs feature-has a horizon that has mottles of chroma 2 or less within $41 \mathrm{~cm}$ of the surface (E, B/A, E'). 


\section{COLIINS SERIES}

The Collins series consists of deep, moderately well drained, moderately permeable soils. They formed in silty alluvium on floodplains of streams in the Southern Mississippi Valley Silty Uplands Major Land Resource Area. Slopes range from 0 to 2 percent.

TAXONOMIC CLASS: Coarse-silty, mixed, acid, thermic Aquic Udifluvents.

TYPICAL PEDON: Collins silt loam - cultivated field.

Ap $\quad 0$ to $18 \mathrm{~cm}$; brown (10YR 5/3) silt loam; weak fine granular structure; very friable; many fine roots; strongly acid; abrupt smooth boundary ( 8 to $23 \mathrm{~cm}$ thick).

C1 18 to $41 \mathrm{~cm}$; yellowish brown (10YR 5/4) silt loam; massive with bedding planes and thin horizontal strata; very friable; many fine roots; few worm casts; strongly acid; clear smooth boundary.

C2 41 to $58 \mathrm{~cm}$; brown (10YR 4/3) silt loam; few fine faint pale brown and light brownish gray mottles; massive with bedding planes and thin horizontal strata; very friable; few fine roots; few worm casts; strongly acid; clear smooth boundary (combined thickness of the upper part of the $C$ horizon is 31 to 51).

C3 58 to $86 \mathrm{~cm}$; mottled pale brown (10YR 6/3), dark yellowish brown (10YR 4/4), and light gray (10YR 7/2) silt loam; massive with bedding planes; very friable; few fine roots; common fine brown concretions; strongly acid; gradual smooth boundary.

C4g 86 to $122 \mathrm{~cm}$; light brownish gray (10YR 6/2) silt loam; many coarse distinct mottles of yellowish brown (10YR 5/4), faint mottles of pale brown (10YR 6/3); massive; friable; many fine brown to reddish brown concretions; strongly acid.

RANGE IN CHARACTERISTICS: Below the plow layer bedding planes and thin horizontal stratification are evident throughout the soil. Reaction of the soil is strongly acid or very strongly acid in all horizons. The 25- to $102-\mathrm{cm}$ control section has from 5 to 18 percent clay. Sand content is as much as $\mathbf{3 0}$ percent but less than 15 percent is coarser than very fine sand.

The Ap horizon has hue of 7.5YR and 10YR, value of 4 and 5, and chroma of 2 through 4. The A horizon commonly is silt loam; less commonly it is loam, very fine sandy loam, and fine sandy loam.

The upper part of the $C$ horizon has hue of 7.5YR and 10YR, value of 3 to 5 , and chroma of 3 or 4 . Few to many mottles having chroma of 2 or less are within a depth of 51 $\mathrm{cm}$ of the surface and commonly begin at a depth of about $41 \mathrm{~cm}$. Texture is silt or silt loam.

The $\mathrm{C} 2$ horizon is similar to the $\mathrm{C} 1$ horizon except that it contains few to common light brownish gray and pale brown mottles.

The C3 horizon has similar texture to the $\mathrm{C} 1$ horizon. It is mottled in shades of brown and gray or has a matrix color of 2 chroma. 
The lower part of the $\mathrm{C}$ horizon is mottled in shades of brown and gray, or it has hue of $10 \mathrm{YR}$ or $2.5 \mathrm{Y}$, value of 5 to 7 , and chroma of 2 or less; and mottles, if present, are few to many in shades of brown or gray.

COMPETING SERIES: There are no other series in the same family. Closely related series include the Adler, Ariel, Bruin, Falaya, Iuka, Morganfield, and Vicksburg series. Adler soils are slightly acid to alkaline. Ariel and Bruin soils have a cambic horizon with subangular blocky structure; also, Bruin soils do not have bedding planes, and are slightly acid to moderately alkaline. Falaya soils are wetter and have horizons with chroma of 2 or less within a depth of $51 \mathrm{~cm}$. Iuka soils have a coarse-loamy particle size class. Morganfield soils and Vicksburg soils do not have mottles of chroma 2 or less within a depth of $51 \mathrm{~cm}$; also, Morganfield soils are slightly acid to alkaline.

GEOGRAPHIC SETTING: These are nearly level soils on floodplains and in drainageways in the Southern Mississippi Valley Silty Uplands Major Land Resource Area. Slope ranges from 0 to 2 percent. The regolith consists principally of silty alluvium derived from thick loess. Average annual temperature is $18^{\circ} \mathrm{C}$, mean January and July temperatures are $7^{\circ} \mathrm{C}$ and $28^{\circ}$ $\mathrm{C}$, respectively, and average annual precipitation is $127 \mathrm{~cm}$ near the type location.

GEOGRAPHICALLY ASSOCLATED SOILS: These include the Falaya and Vicksburg soils listed as competing series and the Arkabutla, Cascilla, and Waverly soils. Arkabutla and Cascilla soils have a fine-silty particle size class and have a cambic horizon. Waverly soils are wetter and have a grayish matrix below the A horizon. These soils are associated across the almost linear surfaces of floodplains. Well-drained Cascilla and Vicksburg soils are on natural levees and near channels. Somewhat poorly drained Arkabutla and Falaya soils are in the same to slightly lower positions as the Collins soils, and poorly drained Waverly soils are in the drainageways and depressions.

DRAINAGE AND PERMEABILITY: Moderately well drained; slow runoff; moderate permeability. The water table is within 51 to $102 \mathrm{~cm}$ of the surface during high rainfall seasons, and the soil is subject to flooding for brief to very long durations.

USE AND VEGETATION: Most areas of this soil are cleared and cropped to cotton, corn, soybeans, and small grains. Some areas are in pasture and hay crops. The native vegetation is bottomland hardwoods.

DISTRIBUTION AND EXTENT: Arkansas, Kentucky, Louisiana, Mississippi, Missouri, and Tennessee. The series is of moderate extent.

SERIES ESTABLISHED: Prairie County, Arkansas; 1906.

REMARKS: Diagnostic features recognized in this pedon are:

Ochric epipedon-the zone from the surface to depth of about $18 \mathrm{~cm}$ (Ap horizon).

Aquic feature-mottles that have chroma of 2 or less within a depth of $51 \mathrm{~cm}(\mathrm{C} 2$ horizon). 


\section{FALAYA SERIES}

The Falaya series consists of deep, somewhat poorly drained, moderately permeable soils that formed in deposits of silty alluvium from loess. These soils are on level or nearly level wide floodplains. They are subject to flooding and are saturated with water at 31 to $61 \mathrm{~cm}$ during periods of high rainfall. Slopes range from 0 to 2 percent.

TAXONOMIC CLASS: Coarse-silty, mixed, acid, thermic Aeric Fluvaquents.

TYPICAL PEDON: Falaya silt loam - cultivated.

Ap $\quad 0$ to $15 \mathrm{~cm}$; brown (10YR 4/3) silt loam; weak medium granular structure; very friable; many fine roots; medium acid; clear smooth boundary (13 to $25 \mathrm{~cm}$ thick).

A 15 to $25 \mathrm{~cm}$; brown (10YR 4/3)silt loam; few fine and medium faint yellowish brown (10YR 5/4) and grayish brown (10YR 5/2) mottles; weak medium granular structure; friable; common fine roots; strongly acid; clear smooth boundary ( 0 to $15 \mathrm{~cm}$ thick).

Bw 25 to $43 \mathrm{~cm}$; brown (10YR 4/3) silt loam; many medium and coarse faint grayish brown (10YR 5/2) mottles and few medium faint yellowish brown (10YR 5/4) mottles; weak medium platy structure; very friable; common fine roots; strongly acid; clear smooth boundary ( 0 to $25 \mathrm{~cm}$ thick).

$\mathrm{Cg} 143$ to $53 \mathrm{~cm}$; grayish brown (10YR $5 / 2)$ silt loam, common fine and medium faint brown (10YR 4/3) mottles; few fine very dark grayish brown and black specks and stains; weak medium platy structure; massive in places; very friable; common fine roots; strongly acid; gradual wavy boundary (8 to $25 \mathrm{~cm}$ thick).

Cg2 53 to $61 \mathrm{~cm}$; grayish brown (10YR 5/2) silt loam, common fine and medium faint brown (10YR 4/3) mottles; massive; friable; few fine roots; strongly acid; clear smooth boundary ( 0 to $25 \mathrm{~cm}$ thick).

Cg3 61 to $107 \mathrm{~cm}$; light brownish gray (10YR 6/2) silt loam, many fine to coarse distinct brown (10YR 4/3) and a few fine and medium distinct very dark grayish brown (10YR 3/2) mottles; massive; friable; few very fine pores; some evidence of bedding planes; strongly acid; gradual smooth boundary ( 0 to $64 \mathrm{~cm}$ thick).

Egb 107 to $127 \mathrm{~cm}$; light gray (10YR 6/1) silt loam, many fine to coarse distinct mottles of brown (10YR 4/3), dark grayish brown (10YR 4/2), and few of medium yellowish brown (10YR 5/4); weak medium platy parting to weak medium subangular blocky structure; friable; slightly brittle; few black and brown concretions; strongly acid; gradual smooth boundary ( 0 to $64 \mathrm{~cm}$ thick).

Bxb 127 to $165 \mathrm{~cm}$; mottles light gray $10 \mathrm{YR} 6 / 1,7 / 1)$ light brownish gray $(10 \mathrm{YR} 6 / 2)$, dark grayish brown (10YR 4/2) and yellowish brown (10YR 5/6) silt loam, weak coarse platy parting to weak medium subangular blocky structure; moderately brittle; firm; common vesicular pores; common veins of grayish clay and grayish silt; few brown and black concretions; strongly acid. 
RANGE IN CHARACTERISTICS: The depth to the upper boundary of the A or E horizons of any buried soil, if present, typically is between 51 and $114 \mathrm{~cm}$ and ranges from 114 to 152 or more $\mathrm{cm}$. Depth to the upper boundary of argillic or fragipan horizons of a buried soil, if present, ranges from 102 to more than $203 \mathrm{~cm}$. Total sand content in the control section is less than 10 percent. The soil is strongly acid or very strongly acid except the surface layer where limed.

The Ap horizon, and A horizon, where present, has hue of 10YR or 2.5Y, value of 4 or 5 , and chroma of 2 or 3 . Texture is silt or silt loam.

The Bw horizon, where present, has hue of 10YR, value of 4 or 5, and chroma of 3 with mottles in shades of brown and gray, and it is silt or silt loam.

The $\mathrm{Cg}$ and the $\mathrm{Bg}, \mathrm{Egb}, \mathrm{Bxb}$, and Btb horizons, where present, have hue of $10 \mathrm{YR}$ or $2.5 Y$, value of 4 to 7 , and chroma of 1 or 2 . These horizons have few to common mottles in shades of yellow, gray, and brown. Texture is silt or silt loam.

COMPETING SERIES: These are the Gillsburg series in the same family and the Ariel, Arkabutla, Belden, Collins, Commerce, Convent, Gillsburg, Mantachie, Oaklimeter, Rosebloom, and Waverly series. Arkabutla, Belden, Commerce, and Rosebloom soils are finesilty. Ariel, Collins, and Oaklimeter soils are better drained. Convent soils are non-acid. Gillsburg soils have more than 10 percent sand in the control section. Mantachie soils are fine loamy. Rosebloom and Waverly soils are poorly drained.

GEOGRAPHIC SETTING: Falaya soils are on level or nearly level rather wide floodplains. Slopes range from 0 to 2 percent. The soil formed in relatively thin deposits of silty alluvium from loess. Near the type location, mean annual temperature is $16^{\circ} \mathrm{C}$, and mean annual precipitation is $135 \mathrm{~cm}$.

GEOGRAPHICALLY ASSOCIATED SOILS: These are the competing Collins and Waverly series, and the Vicksburg series. Vicksburg soils are well drained.

DRAINAGE AND PERMEABILITY: somewhat poorly drained; slow runoff; moderate permeability. The soil is subject to flooding from flowing of standing water, and the water table is within $51 \mathrm{~cm}$ of the surface during periods of high rainfall.

USE AND VEGETATION: Most of the soil is used for growing corn, cotton, soybeans, and small grains. Some is used for growing pasture and hay. The native vegetation is mixed hardwoods.

DISTRIBUTION AND EXTENT: In the loess belts bordering the Mississippi River in Arkansas, Kentucky, Louisiana, Mississippi, Missouri, and Tennessee, and in Alabama. The series is of large extent.

SERIES ESTABLISHED: Quitman County, Mississippi; 1950.

REMARKS: Diagnostic features recognized in this pedon are:

Ochric epipedon-the zone from the surface of the soil to about $25 \mathrm{~cm}$. 


\section{HENRY SERIES}

The Henry series consists of deep, poorly drained soils that have a slowly permeable fragipan in the subsoil. These soils formed in loess more than $122 \mathrm{~cm}$ in thickness in depressions and nearly level areas on uplands and terraces. Slopes are dominantly less that 1 percent, but range from 0 to 2 percent.

TAXONOMIC CLASS: Coarse-silty, mixed, thermic Typic Fragiaqualfs.

TYPICAL PEDON: Henry silt loam - cultivated.

Ap $\quad 0$ to $23 \mathrm{~cm}$; brown (10YR 5/3) silt loam; weak fine granular structure; very friable; few small concretions; strongly acid; abrupt smooth boundary.

A21g 23 to $51 \mathrm{~cm}$; gray (10YR 5/1) silt loam; common, medium dark grayish brown (10YR 4/2), brown (10YR 4/3), and light brownish gray (10YR 6/2) mottles; weak fine granular structure; very friable; common medium pores; common fine concretions; very strongly acid; gradual smooth boundary (18 to $38 \mathrm{~cm}$ thick).

A22g 51 to $79 \mathrm{~cm}$; gray (10YR 5/1) silt loam; few medium dark brown (10YR 4/3) mottles; weak fine granular structure; friable; somewhat brittle; many small vesicular pores; common dark brown concretions; very strongly acid; clear irregular boundary (15 to $31 \mathrm{~cm}$ thick).

Bx $\quad 79$ to $127 \mathrm{~cm}$; gray (10YR 5/1) light silty clay loam; seams and tubes of gray silt; very coarse prisms about 15 or $20 \mathrm{~cm}$ in diameter breaking to weak coarse prisms and weak medium subangular blocky structure; firm; brittle; many very fine and fine pores; clay films $0.32 \mathrm{~cm}$ in thickness between large prisms in upper part; many thick clay films within prisms in upper $10 \mathrm{~cm}$, thin patchy clay films in lower part, all mostly on vertical faces; many brown concretions; very strongly acid; gradual smooth boundary ( 43 to $76 \mathrm{~cm}$ thick).

B3g 127 to $229 \mathrm{~cm}$; pale brown (10YR 6/3) silt; many medium mottles of light brownish gray (10YR 6/2) and yellowish brown (10YR 5/4); friable; structureless, massive; medium acid.

RANGE IN CHARACTERISTICS: Thickness of solum ranges from 122 to more than 183 $\mathrm{cm}$. Depth to the fragipan ranges from 51 to $91 \mathrm{~cm}$. Reaction is strongly acid or very strongly acid in the upper part of the solum and ranges from strongly acid to mildly alkaline in the lower part of the solum and $C$ horizon. Surface layers are less acid where recently limed. Depth to a horizon with more than 10 percent sand is $102 \mathrm{~cm}$ or more. Clay content between $25 \mathrm{~cm}$ and the top of the fragipan ranges from 10 to 18 percent. Much of the illuvial clay is in vertical streaks and pockets rather than being uniformly distributed throughout the $B$ horizon.

The Ap horizon, or A1 if present, has hue of $10 \mathrm{YR}$, value of 4 to 6 , and chroma of 2 or 3. Mottles range from none to common in shades of brown, yellow, and gray. The $\mathrm{A} 2$ horizon has hue of $10 \mathrm{YR}$, value of 4 to 6 , and chroma of 1 or 2 . Mottles are in shades of brown, yellow, and gray. The A horizon texture is dominantly silt loam, but also includes silt. 
The Bx horizon has hue of $10 \mathrm{YR}$, value of 5 to 7, and chroma of 1 or 2. Mottles are in shades of brown, yellow, and gray and some pedons are mottled without a dominant matrix color. It is silt loam or silty clay loam.

The B3 and C horizons have hue of 10YR, value of 5 to 7 , and chroma of 1 to 3 . In addition to these colors, some pedons have hue of 10YR or 7.5YR, value of 4 or 5 , and chroma of 4. These brown colors are in the Roxana loess formation where it occurs within 91 to $152 \mathrm{~cm}$ of the surface. Mottles are in shades of brown, yellow, and gray. The texture is silt loam or silt.

COMPETING SERIES: Henry is the only series in this family. Soils in similar families are the Almaville, Almo, Amagon, Calhoun, Calloway, Frost, Fountain, Robertsville, and Routon series. All of these soils are fine-silty. In addition, Almaville soils are siliceous, Almo soils have more than 10 percent sand above $102 \mathrm{~cm}$, and Robertsville soils are mesic. Calloway soils have chroma of 3 or higher in the upper part of the B horizon. Amagon, Calhoun, Frost, Fountain, and Routon soils lack fragipans.

GEOGRAPHIC SETTING: Henry soils are in depressions, broad drainageways, or on nearly level areas in the uplands or on terraces of low relief. They formed in silty material (loess) more than $122 \mathrm{~cm}$ in thickness. At the type location average annual temperature is $16^{\circ} \mathrm{C}$, and average annual precipitation is $125 \mathrm{~cm}$.

GEOGRAPHICALLY ASSOCIATED SOILS: These are the competing Calhoun, Calloway, and Routon series and the Bonn and Foley soils which have natric horizons, and the Grenada soils which are moderately well drained.

USE AND VEGETATION: Most areas have been cleared. Pasture, soybeans, and rice are the main crops grown on these soils. Some areas are in corn and cotton. Wooded areas are in oaks, sweetgum, sycamore, hackberry, and elm.

DISTRIBUTION AND EXTENT: Tennessee, Kentucky, Mississippi, Arkansas, and possibly Louisiana and Missouri. The series is of large extent.

SERIES ESTABLISHED: Henry County, Tennessee; 1922.

REMARKS: Henry series was formerly classified in the Planosols great soil group. 


\section{VICKSBURG SERIES}

The Vicksburg series consists of deep, well-drained, moderately permeable soils. These soils formed in thick silty alluvium, mainly derived from loess, on floodplains along streams that drain areas of the Southern Mississippi Valley Silty Uplands. Slopes range from 0 to 3 percent.

TAXONOMIC CLASS: Coarse-silty, mixed, acid, thermic Typic Udifluvents.

TYPICAL PEDON: Vicksburg silt loam - cultivated field.

Ap 0 to $18 \mathrm{~cm}$; dark grayish brown (10YR 4/2) silt loam; weak fine granular structure; very friable; few fine roots; strongly acid; abrupt smooth boundary (15 to $31 \mathrm{~cm}$ thick).

C1 18 to $71 \mathrm{~cm}$; dark brown (10YR 4/3) silt loam; structureless; very friable; few fine roots; many worm casts; has bedding planes; strongly acid; clear smooth boundary.

C2 71 to $112 \mathrm{~cm}$; dark yellowish brown (10YR 4/4) silt loam; few medium distinct gray (10YR 6/1) and pale brown (10YR 6/3) mottles; structureless; very friable; has bedding planes; strongly acid; gradual smooth boundary.

C3 112 to $140 \mathrm{~cm}$; mottled dark yellowish brown (10YR 4/4), gray (10YR 6/1) and light gray (10YR 7/2) silt loam; structureless; very friable; few fine black concretions; strongly acid.

RANGE IN CHARACTERISTICS: The soil is very strongly acid or strongly acid throughout, except the surface layers in areas that have been limed.

The A horizon has hue of 10YR, 7.5YR, or 2.5YR, value of 4 or 5 , and chroma of 2 to 4. It is silt loam, silt, loam, or very fine sandy loam.

The upper part of the $C$ horizon has hue of 7.5YR or 10YR, value of 4 or 5 , and chroma of 3 or 4; mottles with chroma of 2 or less, if present, are below a depth of $51 \mathrm{~cm}$ and commonly are below $76 \mathrm{~cm}$. The lower part of the $\mathrm{C}$ horizon commonly is mottled in shades of brown and gray; or less commonly, it has a matrix with the same color range as the upper part of the $\mathrm{C}$ horizon with common to many mottles in shades of brown and gray. The texture is silt, silt loam, or very fine sandy loam. Bedding planes or these stratifications are evident in most pedons. The $25-$ to $102-\mathrm{cm}$ control section has 5 to 18 percent clay and less than 30 percent sand, which is mainly very fine sand.

COMPETING SERIES: There are no competing series in the same family. Closely related soils include the Adler, Caruthersville, Chaseburg, Clemville, Collins, Haymond, Juneau, Morganfield, Norwood, Ochlockonee, Severn, and Sharon series. Adler and Collins soils have mottles with chroma of 2 or less within a depth of $51 \mathrm{~cm}$; also, Adler soils have a non-acid reaction class. Caruthersville, Clemville, Norwood, and Severn soils are calcareous; also, Clemville and Norwood soils have a fine-silty particle size class. Chaseburg, Haymond, Juneau, and Sharon soils have a mesic temperature regime; also, Chaseburg and Juneau soils have a 
non-acid reaction class; Haymond soils have an umbric epipedon. Morganfield soils have nonacid reaction clays. Ochlockonee soils have a coarse-loamy control section.

GEOGRAPHIC SETTING: Vicksburg soils are on floodplains along streams that drain areas of the Southern Mississippi Valley Silty Uplands Major Land Resource Area. These soils formed in thick silty alluvium, mainly from loess. Slopes mainly are 0 to 2 percent and range to 3 percent. Near the type location, average annual temperature is $17^{\circ} \mathrm{C}$, mean January and July temperatures are $7^{\circ} \mathrm{C}$, and $27^{\circ} \mathrm{C}$, respectively, and average annual precipitation is 127 cm.

GEOGRAPHICALLY ASSOCIATED SOILS: These are the competing Collins soils and the Falaya soils. The moderately well drained Collins soils are in similar positions as the Vicksburg soils, and the somewhat poorly drained Falaya soils are in slightly lower areas on floodplains.

DRAINAGE AND PERMEABILITY: Well drained; slow runoff; moderate permeability. The soil overflows occasionally unless protected.

USE AND VEGETATION: Most areas of the soils are cleared and cropped to cotton, corn, sqybeans, and small grains. Some is used for pasture and hay crops. The native vegetation is bottom land hardwoods. Cherrybark oak, Eastern cottonwood, green ash, loblolly pine, nutall oak, American sycamore, yellow poplar, and sweetgum are common trees.

DISTRIBUTION AND EXTENT: Kentucky, Louisiana, Mississippi, Missouri, and Tennessee. The series is of moderate extent.

SERIES ESTABLISHED: Warren County, Mississippi; 1912.

REMARKS: Diagnostic horizons and features recognized in this pedon are:

Ochric epipedon-the zone from the surface to a depth of about $18 \mathrm{~cm}$ (Ap horizon).

Fluvents features-does not have fragments of diagnostic horizons below the Ap horizon and is structureless ( $\mathrm{C} 1, \mathrm{C} 2$, and $\mathrm{C} 3$ horizons). Has bedding planes from approximately 18 to $112 \mathrm{~cm}$ ( $\mathrm{C} 1$ and $\mathrm{C} 2$ horizons). 


\section{WAVERLY SERIES}

The Waverly series consists of nearly level, deep, poorly drained soils that have moderate permeability. These soils are on floodplains of streams that drain the southern Mississippi Valley Silty Uplands Major Land Resource Area. They formed in silty alluvium derived from loess. Slopes range from 0 to 2 percent.

TAXONOMIC CLASS: Coarse-silty, mixed, acid, thermic Typic Fluvaquents.

TYPICAL PEDON: Waverly silt loam - cultivated. (Colors are for moist soil unless otherwise stated.)

Ap 0 to $13 \mathrm{~cm}$; grayish brown (10YR 5/2) silt loam; weak fine granular structure; friable; common fine roots; few brown concretions; strongly acid; abrupt smooth boundary ( 8 to $25 \mathrm{~cm}$ thick).

Bg1 13 to $36 \mathrm{~cm}$; light gray (10YR 7/1) silt loam; few medium distinct pale brown (10YR 6/3) mottles; weak medium subangular blocky structure; friable; common fine roots; few fine brown concretions; strongly acid; clear wavy boundary.

Bg2 36 to $64 \mathrm{~cm}$; light gray (10YR 7/1) silt loam; common medium distinct yellowish brown (10YR 5/6) mottles; weak medium subangular blocky structure; friable; common reddish brown coatings; common fine black and brown concretions; strongly acid; clear wavy boundary.

Bg3 64 to $102 \mathrm{~cm}$; light gray (10YR 7/1) silt loam; few medium distinct dark yellowish brown (10YR 4/4) mottles, weak medium subangular blocky structure; friable; few black and brown concretions; strongly acid; gradual wavy boundary (combined thickness of the $\mathrm{Bg}$ horizon is 61 to $117 \mathrm{~cm}$ ).

Cg 102 to $152 \mathrm{~cm}$; mottles light gray (10YR 7/1) light brownish gray (10YR 6/2) and dark yellowish brown (10YR 4/4) silt loam; massive; friable; common brown coatings, few fine pieces of charcoal; strongly acid.

RANGE IN CHARACTERISTICS: The solum is 69 to $142 \mathrm{~cm}$ thick. The soil is very strongly acid or strongly acid, except the surface layer in areas that have been limed. Brown and black concretions are few to many.

The Ap or the A horizon has hue of 10YR, value of 4 to 6 , and chroma of 1 to 4 . It is silt, silt loam, or very fine sandy loam.

The Bg horizon has hue of 10YR, 2.5Y, or 5Y, value of 6 to 7, and chroma of 1 or 2 , or value of 4 or 5 , and chroma of 1 ; mottles in shades of yellow or brown are few to common. Texture is silt or silt loam. The $25-$ to $102-\mathrm{cm}$ control section has 5 to 18 percent clay.

The $\mathrm{C}$ horizon has the same range in color and texture as the $\mathrm{Bg}$ horizon. Some pedons have buried $A$ and $B$ horizons below a depth of $51 \mathrm{~cm}$. 
COMPETING SERIES: There are no other series in this family. Closely related series in other families are the Arkabutla, Bibb, Convent, Falaya, Gillsburg, Kingston, Mantachie, Mhoon, and Rosebloom series. Arkabutla, Kingston, and Mantachie soils have a fine-loamy particle size clay; also, Arkabutla soils have higher chroma in the upper part of the $B$ horizon, and Kingston and Mantachie soils have siliceous mineralogy. Bibb soils have a coarse-loamy particle size class and siliceous mineralogy. Convent, Falaya, and Gillsburg soils have a subhorizon with higher chroma in the upper part of the B horizon; also, Convent soils have a non-acid reaction clays. Mhoon and Rosebloom soils have fine-silty particle size class; also, Mhoon soils have a non-acid reaction class.

GEOGRAPHIC SETTING: These soils are on floodplains. Slope gradients mainly are less than 1 percent but range to 2 percent along streams that drain the Southern Mississippi Valley Silty Uplands Major Land Resource Area. Waverly soils formed in silty alluvium derived mainly from loess of low sand content. The climate is warm and humid. Average annual temperature is about $18^{\circ} \mathrm{C}$, and average annual precipitation is about $137 \mathrm{~cm}$ near the type location.

GEOGRAPHICALLY ASSOCIATED SOILS: These are Falaya and Rosebloom soils of the competing series and the Collins soils. The somewhat poorly drained Falaya soils are on slightly higher parts of the floodplain, and the poorly drained Rosebloom soils are in similar positions as the Waverly soils. The moderately well drained Collins soils, which are in slightly higher areas near channels, have bedding planes in the upper $51 \mathrm{~cm}$.

DRAINAGE AND PERMEABILITY: Poorly drained, slow runoff; moderate permeability. Areas in depressions are ponded during wet seasons. The water table is at or within one foot of the surface during the winter and spring months. These soils are subject to occasional or frequent flooding for brief to long durations after heavy rainfall.

USE AND VEGETATION: Most areas of the Waverly soils are in bottomland hardwoods. Principal trees are sweetgum, cherrybark oak, willow oak, water oak, nutall oak, eastern cottonwood, American sycamore, loblolly pine, water tupelo and cypress. Cleared areas are used for growing cotton, corn, soybeans, or hay crops and pasture.

DISTRIBUTION AND EXTENT: Arkansas, Kentucky, Louisiana, Mississippi, Missouri, and Tennessee. The series is of moderate extent.

SERIES ESTABLISHED: Union County, Kentucky; 1902.

REMARKS: Diagnostic horizons and features recognized in this pedon are:

Ochric epipedon-The zone from the surface to a depth of about $13 \mathrm{~cm}$ (Ap horizon).

Fluvaquents features -60 percent of matrix between the Ap and $76 \mathrm{~cm}$ with hue of 10YR, value of 7, and chroma of 1 ( $\mathrm{Ap}, \mathrm{Bg} 1, \mathrm{Bg} 2$, and $\mathrm{Bg} 3$ horizons). 


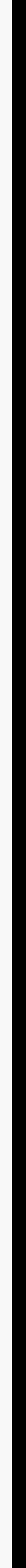


Appendix C

SOIL SURVEY MAP OF BALLARD COUNTY 
Soil Sample Sites In Ballard and McCracken Counties

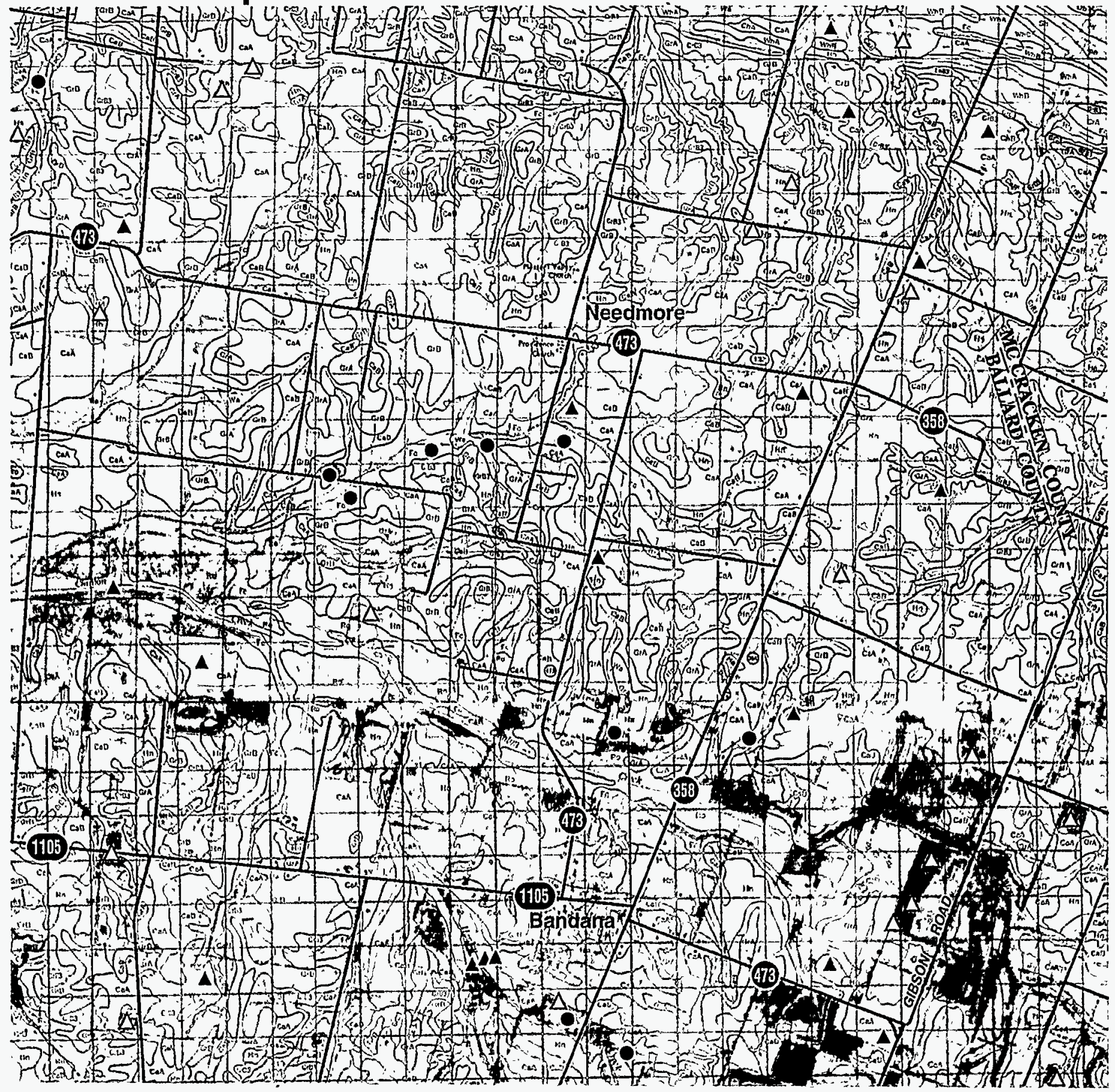




\section{DISTRIBUTION}

1. M. L. Ambrose

2. L. V. Asplund

3. J. R. Blewett

4. R. R. Bonczek

5. J. L. Boulton

6. B. A. Bowers

7. T. L. Brindley

8. J. L. Carpenter

9. D. L. Chumbler

10. L. T. Cusick

11. M. F. P. DeLozier

12. A. F. Diefendorf

13-14. D. B. Ellis

15. T. E. Fitzgerald

16. P. A. Gourieux

17. D.R. Guminski

18. T. L. Hatmaker

19. P. S. Henegar

20. D. A. Hill

21. L. M. Houlberg

22-23. C. A. Hudson

24. B. L. Jackson

25. G. L. Johnson
26. T. M. Koepp

27-28. S. Y. Lee

29-33. C. J. Marshall

34. J. C. Massey

35. S. E. Meiners

36. G. R. Miller

37. B. J. Montgomery

38. J. W. Morgan

39. L. S. Payne

40. W. L. Richards

41. C. T. Rightmire

42. R. L. Schmoyer

43. S. H. Stow

44-45. D. R. Watkins

46. H. K. Young

47. Central Research Library

48. ESD Library

49-51. Central ER Document Management Record Center

52-54. PGDP ER Document Management Record Center

55-56. ORNL Laboratory Records

57-61. T. Able, U.S. EPA-Region IV, 345 Courtland St. NE, Atlanta, GA 30365

62-64. C. R. Alvarado, U.S. Department of Energy, P.O. Box 1410, Paducah, KY 42002-1410

65. A. Barber, KDEP, 14 Reilly Rd., Frankfort, KY 40601

66. D. R. Beall, PGDP, MK-Ferguson, P.O. Box 1410, Paducah, KY 42002-1410

67. D. M. Carden, DOE Oak Ridge Operations Office, P.O. Box 2001, Oak Ridge, TN 37831-8541

68. N. L. Carnes, DOE Oak Ridge Operations Office, P.O. Box 2001, Oak Ridge, TN 37831-8541

69. W. Davis, KDFW, Arnold L. Mitchell Bldg., No. 1 Game Farm Rd., Frankfort, KY 40601

70. L. Fleming/T. Mullins, U.S. Department of Energy, P.O. Box 1410, Paducah, KY 42002-1410

71. C. P. Haight, KDWM, KDEP, Frankfort Office Park, 18 Reilly Rd., Frankfort, KY 40601

72. J. C. Hodges, Paducah Site Manager, U.S. Department of Energy, P.O. Box 1410, Paducah, KY 42002-1410

73. D. F. Hutcheson, PGDP, U.S. Enrichment Corp., P.O. Box 1410, Paducah, KY 42002-1410

74-75. D. L. Jones, Foster Wheeler Environmental Corp., 111 Union Valley Rd., Oak Ridge, TN 37830-8045

76. K. Kates, DOE Oak Ridge Operations Office, P.O. Box 2001, Oak Ridge, TN 37831-8541

77. J. Lee, Office of Environmental Affairs, Richard B. Russell Federal Bldg., 75 Spring St. SW, Suite 345, Atlanta, GA 30303

78. D. A. Lietzke, Lietzke Soil Services, Route No. 3, Box 607, Rutledge, TN 37861

79. C. W. Logson, West Kentucky Wildlife Management Area, 10535 Ogden Landing Rd., Kevil, KY 42053

80. A. Loudermilk, TVA, 400 W. Summit Hill Dr., Knoxville, TN 37902 


\section{DISTRIBUTION (continued)}

81-82. R. L. Nace, U.S. Department of Energy, 19901 Germantown Rd., Germantown, MD 20874-1290

83. A. B. Perkins, U.S. DOE Information Resource Center, 105 Broadway, Oak Ridge, TN 37830

84. A. Robison, U.S. Department of Interior, Fish and Wildlife Service, 446 Neal St., Cookeville, TN 38501

85. M. Rose, U.S. Geological Survey, 2301 Bradley Ave., Louisville, KY 40217

86. A. A. Sims, DOE Oak Ridge Operations Office, P.O. Box 2001, Oak Ridge, TN 37831-8541

87. R. C. Sleeman, DOE Oak Ridge Operations Office, P.O. Box 2001, Oak Ridge, TN 37831-8541

88-91. T. M. Taylor, KDWM, Frankfort Office Park, 18 Reilly Rd., Frankfort, KY 40601

92. J. A. Volpe, Radiation and Toxic Agent Section, Kentucky Department of Human Resources, Centralized Radiation Laboratory, 100 Sower Blvd., Suite 108, Frankfort, KY 40601-8272

93. B. Walton, TVA, Office of General Council WT-10A, 400 W. Summit Hill Dr., Knoxville, TN 37902

94. J. Watts, TVA, 1101 Market St., LP5D-C, Chattanooga, TN 37402-2801

95. T. Whitaker, TVA Shawnee Steam Plant, 7900 Metropolis Lake Rd., West Paducah, KY 42086

96-97. D. J. Wilkes, Jacobs Engineering, 175 Freedom Blvd., Kevil, KY 42053 